Utah State University

DigitalCommons@USU

\title{
Effects of Acceptance and Commitment Therapy on Impulsive Decision Making
}

Kate L. Morrison

Utah State University

Follow this and additional works at: https://digitalcommons.usu.edu/etd

Part of the Psychology Commons

\section{Recommended Citation}

Morrison, Kate L., "Effects of Acceptance and Commitment Therapy on Impulsive Decision Making" (2016). All Graduate Theses and Dissertations. 5069.

https://digitalcommons.usu.edu/etd/5069

This Dissertation is brought to you for free and open access by the Graduate Studies at DigitalCommons@USU. It has been accepted for inclusion in All Graduate Theses and Dissertations by an authorized administrator of DigitalCommons@USU. For more information, please contact digitalcommons@usu.edu.

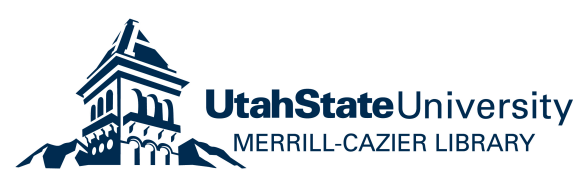




\title{
EFFECTS OF ACCEPTANCE AND COMMITMENT THERAPY ON \\ IMPULSIVE DECISION MAKING
}

\author{
by \\ Kate L. Morrison \\ A dissertation submitted in partial fulfillment \\ of the requirements for the degree \\ of
}

DOCTOR OF PHILOSOPHY

in

Psychology

Approved:

Michael P. Twohig, Ph.D.

Major Professor

Gregory J. Madden, Ph.D.

Committee Member

Timothy A. Slocum, Ph.D.

Committee Member
Michael E. Levin, Ph.D.

Committee Member
Amy L. Odum, Ph.D.

Committee Member

Mark McLellan, Ph.D.

Vice President for Research and

Dean of the School of Graduate Studies

UTAH STATE UNIVERSITY

Logan, Utah 
Copyright $@$ Kate L. Morrison 2016

All Rights Reserved 


\begin{abstract}
Effects of Acceptance and Commitment Therapy on Impulsive Decision Making

by

Kate L. Morrison, Doctor of Philosophy

Utah State University, 2016
\end{abstract}

Major Professor: Michael P. Twohig, Ph.D.

Department: Psychology

Delay discounting is a measure of impulsive decision making that is associated with different forms of problem behavior. This study examined the transdiagnostic effect of Acceptance and Commitment Therapy (ACT) on delay discounting in a community sample. Forty adults were randomized into eight individual sessions of ACT or an inactive control. Participants completed pre-, mid-, and post-assessments for delay discounting, psychological flexibility, distress tolerance, overall psychological symptoms, behavior change, and valued living. Data were analyzed with multilevel modeling of growth curves. Significant interaction effects of time and condition were present for psychological flexibility, distress tolerance, psychological symptoms, and the obstruction subscale of valued living. No significant interaction effect was found for two delay discounting tasks nor the progression subscale of valued living. The ACT condition had a significantly larger reduction of problem behavior at post-, but not mid-assessment. Treatment was provided in a competent and ACT-consistent manner and was rated as highly satisfactory by treatment completers. The results support use of ACT as a 
transdiagnostic treatment. The lack of changes in delay discounting are in contrast to previous research. The clinical implications of delay discounting need to be explored further. 
PUBLIC ABSTRACT

Effects of Acceptance and Commitment Therapy on Impulsive Decision Making

\author{
Kate L. Morrison
}

For some people, decision making is more often influenced by immediate gratification, rather than what is best for them in the long term. This study intended to change how those people made decisions, in order to help them live meaningful lives. This was done through eight sessions of a treatment called Acceptance and Commitment Therapy (ACT; in comparison to no treatment). Forty adults were randomly assigned to either treatment or a no treatment control. The treatment did not change the way people responded on the decision making measures, although the treatment reduced problematic behaviors and obstacles to living a meaningful life. The treatment increased openness and flexibility to emotions, thoughts, and bodily sensations that can influence decision making. Treatment also increased overall well-being. Taken together, the results suggest that $\mathrm{ACT}$ is a useful treatment to help people change behaviors that are a problem for them and can increase their quality of life. However, these changes did not occur in the expected manner. 


\section{ACKNOWLEDGMENTS}

I would like to thank Dr. Michael Twohig not only for his help on this project, but also for years of research and professional guidance. My graduate school experience has been life changing and his role as my mentor is one of the main reasons for that.

I would also like to thank the wonderful team of individuals who made this project possible.

Thanks to my committee members, Gregory Madden, Amy Odum, Timothy Slocum, and Michael Levin for their assistance in designing and refining this study and document. Jodi Siri was in a less glamorous, but essential role of research assistant for this study. Completing the study without her would have been extremely difficult. Jonathan Friedel and Jillian Rung were critical collaborators in collecting, analyzing, and understanding the delay discounting data. Brooke Smith and Clarissa Ong generously provided their time as superb therapists. Eric Lee and Clarissa Ong spent tiresome hours coding for treatment adherence. Thomas Ledermann and Sarah Schwartz provided highly appreciated statistical explanations and support. Thank you to my lab mates who were always willing to brainstorm, problem solve, and share in the joys of doing research.

I would like to thank my patient and caring partner, Mac Gilbert. With his encouragement to eat, sleep, and exercise, I stayed somewhat healthy during this process. I would especially like to thank my family for their endless support in my educational pursuits and for always providing comic relief when needed. We absolutely earned this degree together.

Finally, I would like to thank the people who participated in this study. They 
devoted a portion of their lives to better the field of clinical psychology and, for that, I am forever grateful.

Kate L. Morrison 


\section{CONTENTS}

\section{Page}

ABSTRACT

iii

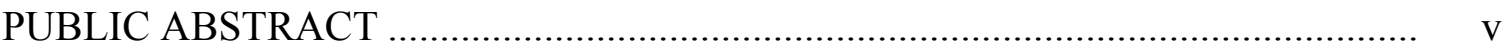

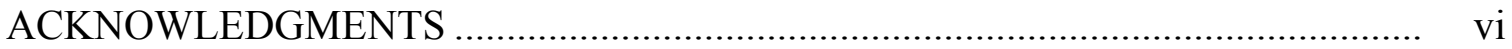

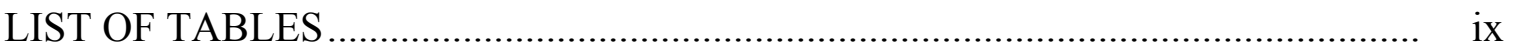

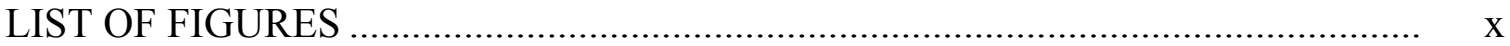

\section{CHAPTER}

1. INTRODUCTION ........................................................................ 1

2. REVIEW OF THE LITERATURE .......................................................... 3

Delay Discounting ............................................................................ 3

Proposed Intervention ............................................................................ 7

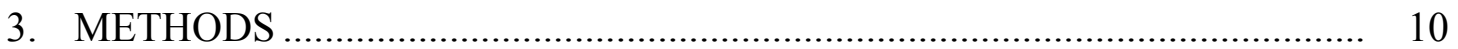

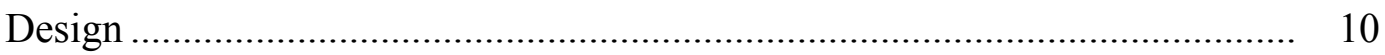

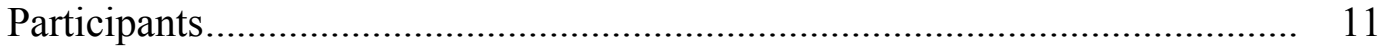

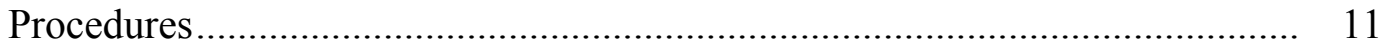

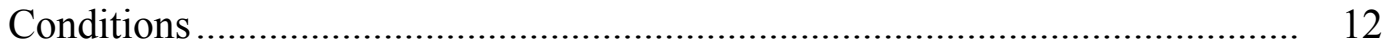

Treatment Adherence........................................................................... 13

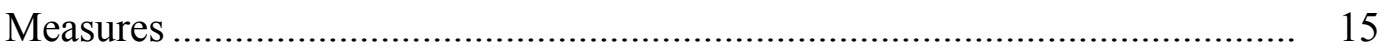

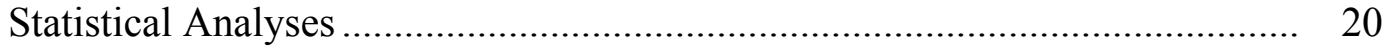

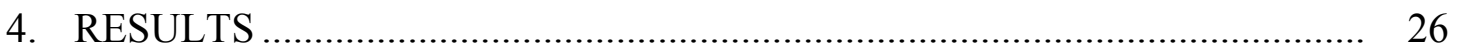

Participant Characteristics .................................................................. 26

Treatment Adherence.............................................................................. $\quad 30$

Problem Behavior Frequency ................................................................ 31

Delay Discounting Outcomes ................................................................ 31

Clinical Outcomes................................................................................... $\quad 35$

Addressing Lack of Power....................................................................... $\quad 39$

Treatment Satisfaction ....................................................................... 40 


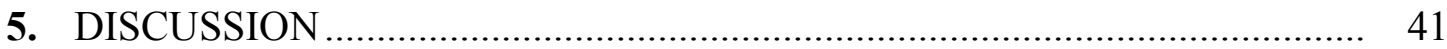

Transdiagnostic Application .................................................................... 41

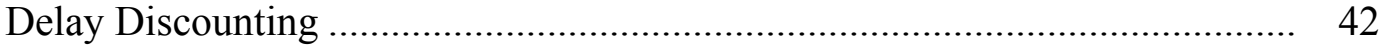

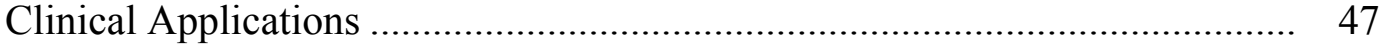

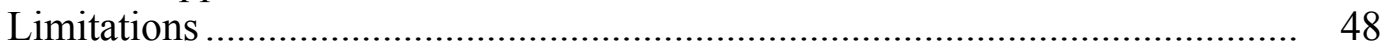

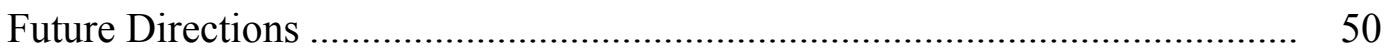

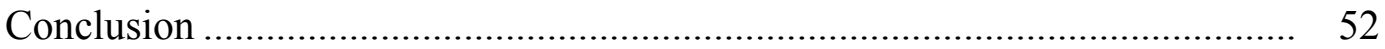

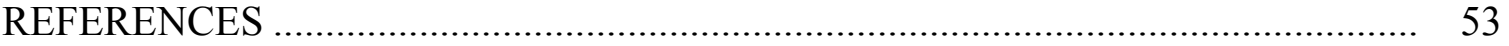

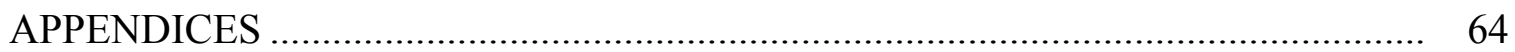

Appendix A: Recruitment Materials......................................................... 65

Appendix B: Measures .......................................................................... 68

Appendix C: ACT Treatment Manual ...................................................... 78

Appendix D: Individual Data........................................................ 108

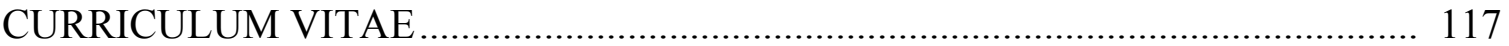




\section{LIST OF TABLES}

Table Page

3.1 ACT Treatment Components ................................................................ 14

4.1 Summary of Participant Characteristics and Outcome Variables by

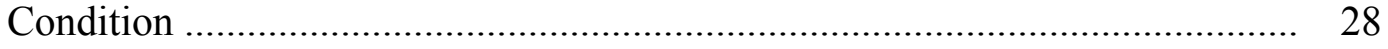

4.2 Summary of Outcome Variables at Time 1 by Completer Status...................... 29

4.3 Summary of Target Behaviors ………………......................................... $\quad 30$

4.4 Delay Discounting Multilevel Model of Growth Curve Estimates .................. 33

4.5 Clinical Multilevel Model of Growth Curve Estimates and Effect Sizes......... 36

4.6 Delay Discounting Multilevel Model Growth Curve Estimates and Effect Sizes of Increased Sample Sizes .................................................................... 40 


\section{LIST OF FIGURES}

Figure $\quad$ Page

4.1 Flow of participants throughout study ................................................. 27

4.2 Median proportion of baseline problem behavior frequency ........................ 32

4.3 Multilevel growth curve results for the Delay Discounting Task (AUC)......... 34

4.4 Multilevel growth curve results from the Delay Discounting Task-Wait

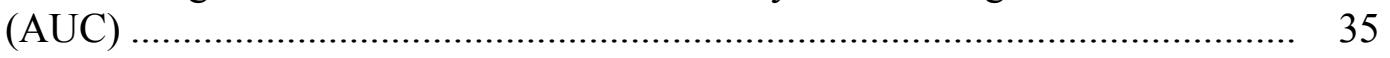

4.5 Multilevel growth curve results from the Acceptance and Action Questionnaire (AAQ-II) ............................................................. 36

4.6 Multilevel growth curve results from the Distress Tolerance Scale (DTS)...... 37

4.7 Multilevel growth curve results from the Outcome Questionnaire (OQ-45.2).. 37

4.8 Multilevel growth curve results from the Valuing Questionnaire-Obstruction

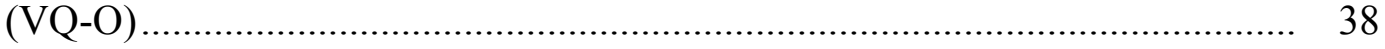

4.9 Multilevel growth curve results from the Valuing Questionnaire-Progression

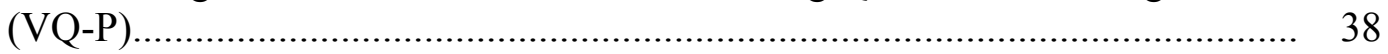

D.1 Delay Discounting Task individual data................................................. 109

D.2 Acceptance and Action Questionnaire individual results ............................ 110

D.3 Distress Tolerance Scale individual results ............................................... 111

D.4 Outcome Questionnaire-45.2 individual results ....................................... 112

D.5 Valuing Questionnaire-Progression individual results ............................. 113

D.6 Valuing Questionnaire-Obstruction individual results .............................. 114

D.7 Delay Discounting Task-Free individual results...................................... 115

D.8 Delay Discounting Task-Wait individual results ................................... 116 


\section{CHAPTER 1 \\ INTRODUCTION}

The Diagnostic and Statistical Manual of Mental Disorders (DSM-5) is the most widely used diagnostic system for mental health disorders in the U.S. (American Psychiatric Association [APA], 2013) and it classifies presenting symptomology into categories. This categorical system has enabled communication between health professionals and facilitated exploration and understanding of symptom clusters. Yet, the recent revisions of the DSM, and subsequent creation of the DSM-5, have increased the dialogue questioning the utility of the categorical approach to mental health.

The high rate of comorbid diagnoses (Kessler, Chiu, Demler, \& Walters, 2005; Kessler, Petukhova, Sampson, Zaslavsky, \& Wittchen, 2012) suggests the existence of underlying "core processes" that are not being captured in the categorical approach (Krueger, 2002). Interventions that target only one disorder often have an effect on cooccurring disorders, indicating that shared underlying processes are being altered (e.g., Borkovec, Abel, \& Newman, 1995; Tsao, Mystkowski, Zucker, \& Craske, 2005). Although the categorical approach specifies boundaries that indicate the level of severity and a need for treatment, subthreshold symptoms can respond equally to treatment as symptoms at or above the threshold (Krug et al., 2008). In light of these issues, a recent shift in mental health research and services has occurred. Treatments that target topographically different, but functionally similar, behaviors have accumulated and the National Institute of Mental Health (NIMH) has put out a call for researchers to investigate new psychopathology classification methods by determining underlying 
processes to facilitate treatment development_-The Research Domain Criteria Project (RDoC; Insel et al., 2010).

A transdiagnostic approach addresses many of the disadvantages of the categorical approach. The transdiagnostic approach to psychopathology seeks to understand multiple disorders and problematic behaviors through shared underlying processes (Nolen-Hoeksema \& Watkins, 2011). Comprehension of the processes that occur across diagnoses may increase efficiency in assessing and treating psychopathology. Treatment packages can be used to target core constructs that lead to dysfunctional behavior, reducing the number of treatments needed. Assessments can be restructured to assess for common core processes that lead to dysfunctional behaviors. This can inform treatment providers of the best course of action. To better understand psychopathology and to facilitate treatment development, it is necessary to identify core constructs, understand their influence on topographically different symptoms, and measure them quickly and accurately. While there are multiple core constructs of dysfunctional behavior that have been identified (e.g., Aldao \& Nolen-Hoeksema, 2010), this paper will focus on the construct of delay discounting (Ainslie, 1975), its transdiagnostic components, and the proposal of altering it through the use of Acceptance and Commitment Therapy (ACT; Hayes, Luoma, Bond, Masuda, \& Lillis, 2006)—a therapy created to address underlying functions of behavior. 


\section{CHAPTER 2}

\section{REVIEW OF THE LITERATURE}

\section{Delay Discounting}

Several fundamental processes underlying disorders have been explored including distress tolerance, rumination, suppression, problem-solving, reappraisal, intolerance of uncertainty, negativity bias, as well as many others (e.g., Aldao \& Nolen-Hoeksema, 2010; Bernstein, Marshall, \& Zvolensky, 2011; Mahoney \& McEvoy, 2012; Rozin \& Royzman, 2001). An example of one that has shown particular promise due to its translational nature is a paradigm that has been examined in neuroscience, behavioral economics, and nonhuman and human psychological research called delay discounting. Delay discounting is the tendency to choose smaller immediate rewards over larger delayed rewards (Ainslie, 1975). It is considered to be one of the many facets of impulsive decision making (Monterosso \& Ainslie, 1999). While the concept of smaller immediate rewards influencing behavior more than larger delayed rewards is well known (Lattal, 2010; Richards, 1981), comprehension of the process has greatly improved as assessment procedures (e.g., Kirby, Petry, \& Bickel, 1999; Rachlin, Raineri, \& Cross, 1991) and quantitative methods (Mazur, 1987; Myerson, Green, \& Warusawitharana, 2001) have been created and refined.

The tendency to choose immediate smaller rewards over delayed larger rewards is a fundamental construct involved in various forms of dysfunctional behavior. In comparison to healthy controls, higher rates of delay discounting is consistently and 
significantly related to addictive behaviors (e.g., alcohol, tobacco, opiates, stimulants, pathological gambling; MacKillop et al., 2011), pathological video gaming (Irvine et al., 2013), obsessive-compulsive personality disorder (Pinto, Steinglass, Greene, Weber, \& Simpson, 2014), antisocial personality disorder (Petry, 2002), obesity (Davis, Patte, Curtis, \& Reid, 2010; Dodd, 2014; Epstein et al., 2014; Rasmussen, Lawyer, \& Reilly, 2010), problematic pornography viewing (Lawyer, 2008), and criminal thinking (Varghese, Charlton, Wood, \& Trower, 2014). It is significantly and positively correlated with co-occurring risky sexual behavior and alcohol use $(r=0.23, p<.01)$, but not risky sexual behavior alone $(r=0.12, p>.05$; MacKillop et al., 2015), suggesting that delay discounting accounts for a variable that is present with co-occurring disorders or problem behaviors.

An earlier onset of substance use, increased severity of use, increased number of substances used (Kollins, 2003), and increased needle sharing in an opioid using population (Odum, Madden, Badger, \& Bickel, 2000) have also been found to be positively and significantly related to delay discounting. Those with high delay discounting rates are at a greater risk for future substance use (Audrain-McGovern et al., 2009; Fernie et al., 2013) and poor treatment outcomes for nicotine (MacKillop \& Kahler, 2009; Sheffer et al., 2012, 2014; Yoon et al., 2007), cocaine (Washio et al., 2011), and marijuana (Stanger et al., 2012) abstinence. Nonhuman research models have also shown that delay discounting predicts higher rates of cocaine self-administration (Anker, Perry, Gliddon, \& Carroll, 2009; Perry, Larson, German, Madden, \& Carroll, 2005). Resistance to extinction and an increased risk for relapse are also predicted by 
preference of smaller sooner rewards in non-human models (Broos, Diergaarde, Schoffelmeer, Pattij, \& De Vries, 2012; Diergaarde et al., 2008). Together this literature suggests that high rates of delay discounting is predictive of future behavior and is present across multiple forms of problematic behavior, furthering its validity as a transdiagnostic process (Bickel, Jarmolowicz, Mueller, Koffarnus, \& Gatchalian, 2012; Bickel, Koffarnus, Moody, \& Wilson, 2014; Story, Vlaev, Seymour, Darzi, \& Dolan, 2014).

Changing delay discounting rates may have an impact on the negative outcomes with which they are associated (Koffarnus, Jarmolowicz, Mueller, \& Bickel, 2013). Rates of delay discounting tend to be stable up to one year (e.g., Kirby, 2009), but some procedures have been successful in changing those rates. While a variety of experimental manipulations to alter delay discounting exist (Koffarnus et al., 2013), only interventions with direct clinical and transdiagnostic relevance are summarized here.

One study saw a decrease in delay discounting (47.1\% less discounting from baseline) after different forms of contingency management, substance abuse counseling, and shaping of positive behaviors for opiate use (Landes, Christensen, \& Bickel, 2012). These reductions in delay discounting, however, did not match the reductions in abstinence. Another study using 5 days of contingency management for cigarette smokers significantly reduced delay discounting (along with lower levels of cigarette use) from pre- to post-treatment compared to the control condition (Yi et al., 2008). The use of a financial management procedure (focused on changing financial behavior to attain future goals), in comparison to an active control, significantly reduced delay discounting (Black 
\& Rosen, 2011). Group sessions of Cognitive Behavior Therapy to reduce nicotine use did not have a significant impact on discounting immediately after treatment for smokers or nonsmokers, but at the 12-month follow-up nonsmokers had significantly lower rates of discounting $\left(\eta_{\mathrm{p}}^{2}=0.07\right.$; Secades-Villa, Weidberg, García-Rodríguez, FernándezHermida, \& Yoon, 2014). Surprisingly, in a sample of undergraduates, neither set of interventions which began with a brief motivational intervention (focused on substance use) followed by either a discussion about (a) their goals and values as they related to their career or (b) substance use education (active control) had an impact on delay discounting (Dennhardt, Yurasek, \& Murphy, 2015). Together, these studies generally suggest that delay discounting can be altered with clinically relevant interventions, typically alongside behavioral changes, but in some studies that change does not occur.

Some contextual variables such as emotions and thoughts can also influence responding on delay discounting tasks. For example, fear (Luo, Ainslie, \& Monterosso, 2014), worry (Worthy, Byrne, \& Fields, 2014), hopelessness (Pulcu et al., 2014), and stress (Fields, Lange, Ramos, Thamotharan, \& Rassu, 2014) all have differing impacts on delay discounting. As an explanation of these correlations, Fields, Ramos, and Reynolds (2015) theorize that in the presence of stress, immediate needs and reduction of stress seem more important. Thus, decisions are based on meeting the needs that appear to be more valuable while in distress. Based on the interactions between emotions and delay discounting, addressing these and other internal experiences during decision making may influence rates of discounting and the related behaviors. 


\section{Proposed Intervention}

A psychotherapeutic intervention that targets a process similar to delay discounting is called Acceptance and Commitment Therapy (ACT; Hayes et al., 2006). ACT has traditionally been a transdiagnostic treatment because the primary focus is on the function rather than the content or topography of behaviors. The goal of ACT is to increase situationally appropriate decision making through a decreased impact of internal events and an increased impact of external future rewards. Successful implementation of ACT results in a shift from engaging in behaviors for immediate gratification (e.g., emotion regulation) to behaviors that serve the purpose of maintaining meaningful longterm outcomes.

The process that is believed to underlie this shift is referred to as psychological flexibility (Hayes et al., 2006). The opposing process, psychological inflexibility, is characterized by excessive attention to the future and/or past, beliefs that internal experiences are accurate and meaningful indicators of behavior, being highly attached to beliefs about the self, and persistent attempts to avoid or alter unwanted internal experiences (i.e., thoughts, emotions, sensations) which result in behaviors that are incongruent with a meaningful life (Hayes et al., 2006). Psychological inflexibility occurs across problematic behaviors and is proposed to be present, at varying degrees, in all verbal humans (Hayes et al., 2004). One of the products of having verbal abilities is that behavior can be shaped by indirect, or verbal, contingencies or rules (Blackledge, 2003; Hayes, 1989). While this allows for problem solving and rapid learning, it can also be problematic because the rule may not define an accurate or optimal contingency. 
Following verbal rules of this nature could have a negative long-term impact on overall quality of life; yet, is functional in the moment because it removes unwanted and uncomfortable stimuli.

In order to contact direct contingencies, it is necessary to confront or withstand unwanted internal experiences that were previously avoided by rigidly following verbal rules. The inability to stay in contact with distressing stimuli is referred to as distress intolerance (Simons \& Gaher, 2005) and/or experiential avoidance (Boulanger, Hayes, \& Pistorello, 2010). These constructs may be present in those with higher delay discounting rates and there is some empirical support for this thesis. Undergraduates with higher levels of experiential avoidance more often chose to receive three electric shocks after a delay than one shock immediately (Salters-Pedneault \& Diller, 2013). Also, higher rates of distress tolerance were significantly related to lower levels of delay discounting in African American and European American alcohol using undergraduates (Dennhardt \& Murphy, 2011).

Although little research has been conducted on the relationship of psychological flexibility, distress tolerance/experiential avoidance, and delay discounting, ACT has been successful at reducing dysfunctional behaviors that are related to delay discounting (e.g., Crosby \& Twohig, 2016; Hernández-López, Luciano, Bricker, Roales-Nieto, \& Montesinos, 2009; Nastally \& Dixon, 2012; Niemeier, Leahey, Reed, Brown, \& Wing, 2012). It is theorized that an open, welcoming, nonattached stance toward internal experiences frees decision making that matches with the overall highest reward value (larger delayed rewards). Consistent decision making and action toward delayed, albeit 
larger rewards are likely to increase quality of life and decreases in psychological disturbances. This theory was tested in a pilot study where delay discounting rates were reduced $(d=0.57)$ by a brief training based on ACT principles in a college sample with mild pathology (Morrison, Madden, Odum, Friedel, \& Twohig, 2014). The current study expanded on these findings by using a full course of ACT in an attempt to change delay discounting of treatment seeking individuals with more severe pathology (which is more representative of treatment seeking and receiving populations). It was anticipated that ACT would (a) decrease delay discounting, (b) increase psychological flexibility, distress tolerance, overall well-being, and valued-living, and (c) reduce problematic target behaviors in comparison to the inactive control condition. 


\section{CHAPTER 3}

\section{METHODS}

\section{Design}

This study was approved by the Utah State University Institutional Review Board. Funding for this study was provided by the Center for Clinical Research (the research group of the primary researcher). The treatment effect was determined through a randomized controlled trial with an inactive control comparison condition. At the conclusion of the data collection phase of the study, those in the control condition were offered the same treatment by the research team or were referred to appropriate services, but their treatment was not monitored as part of this study. Participants were initially screened over the phone to determine preliminary eligibility (e.g., age, treatment seeking, at least one target behavior). If preliminary eligibility was met, the participants completed an in-person pre-assessment (Time 1). Those that met eligibility criteria were randomly assigned to the ACT or the control condition using block randomization (in blocks of 10). Those in the ACT condition began treatment involving eight 50-minute weekly individual sessions, as soon as possible after Time 1. They completed a mid-treatment assessment (Time 2) between sessions four and five and a post-treatment assessment (Time 3) one week after the final session. Those in the control condition completed the same assessments on the same time schedule during the inactive period (Time $2=$ between weeks four and five; Time 3 = during week nine). 


\section{Participants}

The first 40 participants who met the following criteria were randomized into a condition: (a) 18 years of age or older, (b) ability to read and communicate in English, (c) interested in treatment to modify a specific behavior, (d) area under the curve (AUC) value of 0.5 or less on the delay discounting task (with systematic responding specified by M. W. Johnson and Bickel [2008]), (e) Outcome Questionnaire—45.2 total score of 54 or higher, (f) be stable on any psychotropic medications for 30 days or more, and (g) not actively receiving psychotherapy or received psychotherapy within the past 30 days (excluding support groups). Participants were excluded if they: (a) self-reported an inability to participate due to physical/medical complications or (b) self-reported a diagnosed mental health concern that restricted his/her ability to understand instructions or participate fully.

\section{Procedures}

Participants were recruited through fliers, newspaper advertisements, community and university announcements, student mental and physical health services, and local internet postings (see Appendix A). The lead researcher screened participants by phone using an eligibility criteria questionnaire (see Appendix B). If participants appeared to meet the requirements, they were scheduled for the Time 1 assessment as soon as possible. Time 1 included the informed consent and the following assessments: Delay Discounting Task (DDT), Background Information Questionnaire, Problem Behavior Severity Questionnaire, Outcome Questionnaire-45.2 (OQ-45.2), Delay Discounting 
Task-Free (DDT-Free), Delay Discounting Task-Wait (DDT-Wait), Acceptance and Action Questionnaire (AAQ-II), Distress Tolerance Scale (DTS), and Valuing Questionnaire (VQ; in that order). Completing the assessments took 30-60 minutes. Assessments were conducted by the lead researcher and an undergraduate research assistant. If eligible, participants were randomly assigned to a condition.

Treatment was scheduled promptly after the Time 1 assessment for those in the ACT condition. At the Time 2 assessment, all participants completed the DDT, Problem Behavior Severity Questionnaire, OQ-45.2, DDT-Free, DDT-Wait, AAQ-II, DTS, and VQ. All participant completed the same measures at Time 3, with the exception of the Client Satisfaction Questionnaire (CSQ-8) added to the ACT condition assessments. Course credit was given for university students based on the course in which they were enrolled and all participants received $\$ 10$ per assessment completed (up to $\$ 30$ per participant).

\section{Conditions}

Those in the inactive control did not receive an intervention and were instructed to "go about life as usual," to not begin or change psychotropic medications nor doses, and to not begin psychotherapy. The treatment condition consisted of exercises and discussions to (a) assist in noticing the detrimental effects of attempts to control thoughts, emotions, and urges, (b) aid in noticing that controlling thoughts, emotions, and urges only work in the short term, (c) teach willingness to experience distress, (d) increase the distinction between internal experiences and behaviors, (e) increase awareness of values, 
and (f) increase engagement in values consistent behavior. A summary of the treatment protocol is shown in Table 3.1 and the full manual is provided in Appendix C. The manual provided a guide to the therapists of the general order of ACT processes. As with all psychological treatment manuals, individualization was necessary. Some processes were covered more or less depending on the need of the participant. Two advanced graduate student therapists provided the ACT intervention. Both therapist had substantial experience in applied behavior analysis and ACT prior to the study.

\section{Treatment Adherence}

Each session was video and audio recorded. Twenty percent of the total sessions (randomly selected) were rated for therapist competence and adherence to the treatment model. Ratings were conducted by two trained graduate research assistants. The rating system was initially described in Plumb and Vilardaga (2010) and has been used in other published works (Armstrong, Morrison, \& Twohig, 2013; Dehlin, Morrison, \& Twohig, 2013; Twohig et al., 2010). Raters coded each minute of the coding sessions for ACT processes (i.e., acceptance, defusion, self-as-context, present moment, values clarification, and committed action), ACT-inconsistent processes (i.e., cognitive challenging, experiential avoidant change strategies, thoughts and feelings cause action), and general assessment/comments. To represent the overall frequency and depth of the processes covered in the session, the ACT and ACT-inconsistent processes were rated on a scale of 1 (the variable was never explicitly covered) to 5 (the variable occurred with high frequency and was covered in a very in-depth manner). In order to capture therapist 
Table 3.1

ACT Treatment Components

\begin{tabular}{|c|c|c|}
\hline Session & Process & Items within each process \\
\hline \multirow[t]{4}{*}{1} & Informed consent & Warning that therapy may result in emotional discomfort \\
\hline & $\begin{array}{l}\text { Limits to } \\
\text { confidentiality }\end{array}$ & Suicide, homicide, and abuse of children or disabled adults \\
\hline & Gather information & $\begin{array}{l}\text { Gain information about the client, history of presenting problem, and } \\
\text { contextual variables }\end{array}$ \\
\hline & $\begin{array}{l}\text { Contact with } \\
\text { present moment }\end{array}$ & $\begin{array}{l}\text { Help the client be aware and present with their inner experiences using } \\
\text { exercises like Leaves on a Stream and body scans }\end{array}$ \\
\hline \multirow[t]{7}{*}{2} & Acceptance & $\begin{array}{l}\text { Identify the distinction between behavior and urges to engage in } \\
\text { behavior }\end{array}$ \\
\hline & & Short-term vs. long-term effectiveness of attempts to control urges \\
\hline & & Identify the negative impact of attempts to control urges \\
\hline & & $\begin{array}{l}\text { Highlight paradoxical nature of attempts to control urges using the Man } \\
\text { in the Hole metaphor }\end{array}$ \\
\hline & & $\begin{array}{l}\text { Identify attempts to control urges as part of the problem using the } \\
\text { Polygraph, Chocolate Cake, and What are the Numbers? Exercises }\end{array}$ \\
\hline & & $\begin{array}{l}\text { Introduce acceptance as an alternative to control using the Two Scales } \\
\text { metaphor }\end{array}$ \\
\hline & & Encourage acceptance of any problematic inner experiences \\
\hline \multirow[t]{3}{*}{3} & Values & Discuss what could be gained by letting go of the control agenda \\
\hline & & Define the concept of values \\
\hline & & $\begin{array}{l}\text { Clarify the client's values and assess the consistency of the his/her } \\
\text { behavior with those values }\end{array}$ \\
\hline \multirow[t]{2}{*}{4} & Self as context & Increase distinction between the self and thoughts/emotions \\
\hline & & Chessboard metaphor \\
\hline 5 & Defusion & Undermine cognitive fusion using the Passengers on the Bus metaphor \\
\hline 6 & Committed action & $\begin{array}{l}\text { Increased behavioral commitments to engage in valued living based on } \\
\text { recent values work }\end{array}$ \\
\hline \multirow[t]{2}{*}{$7 \& 8$} & Review & Review any processes that still need attention \\
\hline & & Discuss future behavior and addressing relapse \\
\hline
\end{tabular}

Note. Exercises/content (modified from Twohig \& Hayes, 2008). 
competency and consistency with the ACT therapeutic stance, the therapist for each session was rated from 1 (not at all competent/adherent) to 5 (extremely competent/ adherent).

\section{Measures}

\section{Background Information Questionnaire}

This measure assessed sex, marital status, age, ethnicity/race, employment status, education, religious affiliation, income, physical ability to participate, previous psychological diagnoses, current medication information, and length of time behavior has been problematic.

\section{Problem Behavior Severity Questionnaire}

This brief self-report questionnaire was designed by the researchers to assess the frequency, duration, and perceived impact of the target behavior(s).

\section{Delay Discounting Task}

Delay Discounting Task (DDT; Rachlin et al., 1991; Yi et al., 2008) measures the rate at which the value of a perceived reward decreases as the delay to receive the reward increases. This task was completed via E-Prime software with set hypothetical choices of smaller amounts of money available immediately and larger amounts of money available after a specified delay. While the larger, later reward stayed at $\$ 1,000$, the monetary value of the smaller outcome gradually declined for each delay. The specified delays were 1 week, 2 weeks, 1 month, 6 months, 1 year, 5 years, and 25 years. The specified 
monetary amounts were $\$ 1,000, \$ 990, \$ 960, \$ 920, \$ 850, \$ 800, \$ 750, \$ 700, \$ 650, \$ 600$, $\$ 550, \$ 500, \$ 450, \$ 400, \$ 350, \$ 300, \$ 250, \$ 200, \$ 150, \$ 100, \$ 80, \$ 60, \$ 40, \$ 20, \$ 10$, $\$ 5$, and $\$ 1$. Participants were instructed to make decisions as if they were actually receiving the money. Using hypothetical monetary values in delay discounting tasks produces results similar to real monetary rewards and test-retest reliability is strong across various time points (Matusiewicz, Carter, Landes, \& Yi, 2013; Weafer, Baggott, \& de Wit, 2013).

\section{Opportunity Cost Delay Discounting Tasks}

In the aforementioned delay discounting task, the conditions during the delay are not specified. Depending on the perception of what occurs during that delay (e.g., earn large sums of money, start a new job), responses may differ. To control for this potential variation, two tasks were given that were explicit about the context of the delay (P. S. Johnson, Herrmann, \& Johnson, 2015). Participants completed the Delay Discounting Task-Free condition (DDT-Free) followed by the Delay Discounting Task-Wait condition (DDT-Wait). Both conditions described hypothetical contexts for which the participant would consider when choosing monetary values at each delay. Each condition included three questions about the instructions that had to be answered correctly before proceeding to the tasks. After the instruction clarification and before the task, a practice question was given and participants could only proceed after the format of the question was marked as understood (see Appendix B for full instructions and questions). The specified delays were 5 minutes, 10 minutes, 30 minutes, 1 hour, 3 hours, 6 hours, 12 hours, and 24 hours. Using a slider bar $(\$ 0-\$ 100)$, participants selected an immediate monetary value that felt 
"just as good" as receiving $\$ 100$ at each delay.

The DDT-Free hypothetical context allowed the participant to "leave the room and go about life as normal" while waiting for the delayed reward. The DDT-Wait hypothetical context required the participant to stay in the assessment room alone without access to the computer, could not sleep, and only allowed to leave to use the bathroom and mealtimes while waiting for the delayed reward. The instructions were modified based on the initial tasks researched by P. S. Johnson et al. (2015) where the effect of reward availability during the delay was shown.

\section{Outcome Questionnaire-45.2}

The Outcome Questionniare-45.2 (OQ-45.2; Lambert et al., 1996) is a 45-item self-report measure is used to assess levels of common psychological symptoms (overall well-being) and to determine a change in symptoms during treatment. Each item is ranked on a Likert scale from 0 (never) to 4 (almost always). Scores are divided into three domains, but, given recent concerns regarding the factor structure of this measure (Rice, Suh, \& Ege, 2014), only the total score was computed and interpreted. The cutoff for clinically significant levels of symptoms is 63 and a change of 14 points or more indicate clinically significant change in symptoms (Kim, Beretvas, \& Sherry, 2010). Higher scores indicate a higher frequency of psychological symptoms and lower wellbeing. The OQ-45.2 total score has good internal consistency and test-retest reliability: 0.93/0.84 (Lambert et al., 1996). Total score distinguishes between patient and nonpatient samples and is highly correlated with measures of depression $(r=0.62-0.88)$, anxiety $(r$ $=0.64-0.86)$, and general distress $(r=0.72-0.78$; Lambert et al., 1996). 


\section{Acceptance and Action Questionnaire-II}

The Acceptance and Action Questionnaire-II (AAQ-II; Bond et al., 2011) is a 7item self-report measure of psychological inflexibility and experiential avoidance. The choices for each item ranges from 1 (never true) to 7 (always). Higher scores indicate greater psychological inflexibility. While there is no established cutoff for the AAQ-II, scores that fall above a range of 24-28 are associated with higher levels of psychological distress (Bond et al., 2011). Across seven samples totaling 3,280 participants, it has good test-retest reliability ( $r=0.81$ at 3 months, $r=0.79$ at 1 year; Bond et al., 2011) and correlation with the original AAQ-I is strong $(r=0.97$; Bond et al., 2011).

\section{Distress Tolerance Scale}

The Distress Tolerance Scale (DTS; Simons \& Gaher, 2005) is a 15-item selfreport measure captures beliefs about feeling distressed or upset. These beliefs are rated from 1 (strongly agree) to 5 (strongly disagree). There are four different types of questions: perceived ability to tolerate emotional distress, subjective appraisal of distress, attention being absorbed by negative emotions, and regulation efforts to alleviate distress (Simons \& Gaher, 2005). Test-retest reliability is good at 6 months ( $r=$ 0.61; Simons \& Gaher, 2005). Higher scores indicate higher distress tolerance.

\section{Client Satisfaction Questionnaire}

The Client Satisfaction Questionnaire (CSQ-8; Attkisson \& Zwick, 1982; Larsen, Attkisson, Hargreaves, \& Nguyen, 1979) is an 8-item self-report measure of satisfaction with the treatment provided (e.g., "How would you rate the quality of service you have 
received?"). Each item is rated on a Likert scale from one to four. Total scores range from 8-32. Higher scores indicate higher satisfaction with treatment. It has been used across populations, settings, and types of treatment to evaluate the level of satisfaction as an additional outcome of interest. It has strong internal consistency $(\alpha=0.93$; Attkisson \& Zwick, 1982) and is related to session attendance ( $r=0.56$; Attkisson \& Zwick, 1982). The CSQ-8 is also highly correlated with lengthier versions of the CSQ $(r=0.93$; Attkisson \& Zwick, 1982).

\section{Valuing Questionnaire}

The Valuing Questionnaire (VQ; Smout, Davies, Burns, \& Christie, 2014) is a 10item self-report questionnaire assesses engagement in values during the previous week. There are two factors within the measure that are reported separately: progression and obstruction. The progression subscale (VQ-P; 5-items) measures awareness of and action toward values (higher scores indicate living a more valued life). The obstruction subscale (VQ-O; 5-items) measures the obstacles that interfere with valued living (lower scores indicate living a more valued life). The VQ-O has a strong correlation with the AAQ-II ( $r$ $=0.65)$, while the VQ-P has a more moderate correlation $(r=-0.4$; Smout et al., 2014). This suggests that the VQ-P measures valued living that may not be related to psychological distress and may better represent overall quality of life (Smout et al., 2014). An error occurred when entering the VQ into the survey software and the range of potential responses was limited from 1 (not at all true) to 6 (completely true), when in actuality, the measure offers the range of 0 to 6 . The restricted values need to be taken into consideration if comparing this VQ data to other samples. 


\section{Statistical Analyses}

DDT data was collected through E-Prime computer software (Psychology Software Tools, 2012) and all other data were collected online using Qualtrics survey software (Qualtrics, 2005). Data were downloaded periodically from both programs during data collection to ensure data safety. If participants were randomized into a group, their data was used for analyses (i.e., intent-to-treat). Data were analyzed using SPSS statistical software (version 21; IBM Corp., 2012). Descriptive statistics were calculated for both conditions at Time 1 and the outcome variables were compared to determine any prerandomization differences (from the MLM analysis described below; see Figures 4.24.8 in Chapter 4). Descriptive statistics were calculated for the CSQ-8 to determine the acceptability of treatment for the ACT condition.

\section{Delay Discounting Tasks}

The delay discounting data were assessed for systematic responding using the criteria set forth by M. W. Johnson and Bickel (2008). Data are considered to be systematic if neither of the following criteria are met: (JB1) "if any indifference point (starting with the second delay) was greater than the preceding indifference point by a magnitude greater than $20 \%$ of the larger later reward" (M. W. Johnson \& Bickel, 2008, p. 268), or (JB2) "if the last indifference point was not less than the first indifference point by at least a magnitude equal to $10 \%$ of the larger later reward" (M. W. Johnson \& Bickel, 2008; p. 268). A computing error occurred when calculating the JB1 criterion for eligibility status (Time 1) for the DDT. The criterion was set at a less stringent $21 \%(\geq$ 
\$210), rather than $20 \%(\geq \$ 200)$. This error was detected during data analysis. The $21 \%$ criterion was used throughout the other time points for the DDT for consistency (the $20 \%$ criterion was maintained for the DDT-Free and DDT-Wait). If either criteria were met in the delay discounting data, the data at that time point was removed from analyses. Additional data were removed that displayed an inverse discounting function (opposite of the expected trend), which suggested confusion with the task.

Both AUC and $k$ values were calculated from the systematic data. The discounting tasks produce a series of indifference points. An indifference point is the value at which the participant is indifferent about the choice for larger later rewards and smaller sooner rewards (Myerson et al., 2001). This was defined as the last immediate option chosen at each delay. AUC values represent the area under the curve that is formed from each indifference point. It represents the steepness of the discounting curve. The area of each trapezoid (formed between subjective amounts and the specified delays) were calculated and summed for a total AUC value (Myerson et al., 2001). The range of potential values is $0-1$, with 0 being extreme discounting and 1 being no discounting. A $k$ value is an alternative representation of the discounting curve. It represents the discounting rate of each participant and was calculated using the following formula:

$$
V=\frac{A}{1+k D}
$$

$\mathrm{V}$ is the discounted value of the future reward, $\mathrm{A}$ is the amount of the reward, and D is the delay to receipt (Mazur, 1987). Larger $k$ values represent more delay discounting (steeper curve). Values range from 0 and above. The decision to use AUC or $k$ values to represent delay discounting was based on which statistic provided normally distributed 
data. AUC was chosen if the statistics provided similar results because AUC is the simpler model.

\section{Treatment Adherence Coding}

Two coders were trained using the coding system. The interrater agreement between each of the two coders and the base coder (KLM) on two randomly assigned sessions (one for each therapist) was calculated using an intraclass correlation coefficient (ICC) using the absolute agreement model (Hallgren, 2012; Shrout \& Fleiss, 1979). The results of the coding were summarized using descriptive statistics and results were compared between therapists using independent samples $t$-tests.

\section{Missing Data}

Per the scoring protocol for the OQ-45.2, missing data were addressed by imputing the individual mean of the subscale into the missing item (Time $1=0 \%$, Time 2 $=0 \%$, Time $3=11 \%$ for one participant; $0.3 \%$ of all OQ-45.2 data). For the remaining amount of missing data (6 items; each from a different participant and item), individual mean imputation was used because of the extremely small percentage of missing data $(<$ $12 \%$ per participant per measure; $0.07 \%$ of all data). Mean imputation is generally not recommended because it can underestimate variance. However, when missingness is less than $5 \%$ (in a sample of 50 or less) mean imputation produces similar results as other imputation methods (Cheema, 2014). The $0.07 \%$ missingness in this study fell far below the $5 \%$ cutoff and was, thus, deemed appropriate. Participants who did not complete all time points were not addressed as this is accounted for with the primary analyses. To 
determine any potential differences between those that completed the study and those that did not, independent samples $t$ tests were conducted for the outcome variables.

\section{Primary Analyses}

The treatment effect on the primary variables of interest (AAQ-II, problem behavior frequency, DDT, DDT-Free, DDT-Wait, DTS, OQ-45.2, and VQ) were determined through restricted maximum likelihood multilevel modeling (MLM) of the growth curves (Singer \& Willett, 2003). Multilevel growth curve modeling accounts for within and between individual changes while accounting for the hierarchical nature of the data. Both fixed (accounted for) and random (unknown) effects can be included in the model. This study had both random intercepts and random slopes. This means that each individual was allowed to begin at different values (intercepts) and were allowed to vary in their trajectory over time (due to treatment and/or time). MLM of growth curves was selected because it allows for heteroscedasticity and accommodates participants with missing values, which both are problems using repeated measures analysis of variance. Moreover, MLM allows for different intervals between measurement points, allows binary and continuous variables as predictors, and analyzes partial completers.

There are two levels of data in this study. Level 1 contains the measurement observations of the outcome variables and is nested within the level 2 data, which contains the individuals (grouped by experimental condition). Each outcome variable was analyzed individually. The condition, time, and the interaction of condition and time were set as fixed variables. The slope of time and the intercepts were set as random (allowed to vary based on participant) in each of the models. The most appropriate models were 
chosen based on the theoretical expectations of the covariance structure and the Bayesian Information Criteria (BIC) model fit indices. An unstructured covariance structure (no expectation of consistency in the covariance structure) was selected for each of the variables. MLM of growth curves is robust against violations of normality (Hox, 2010). Thus, only extreme deviations from normality were addressed. The data were visually examined for normality using scatterplots of the overall residuals by predicted values.

Within group effect size values were calculated for both conditions. Cohen's $d$ was calculated to specify the magnitude of the effect of those variables from Time 1 to Time 3. Dependent samples $t$ tests were conducted to obtain the values necessary for the effect size calculations. In order to account for the correlation between repeated measurements, the following formula was used (Dunlap, Cortina, Vaslow, \& Burke, 1996):

$$
d=t\left[\frac{2(1-r)}{n}\right]^{\frac{1}{2}}
$$

Between group effect size values were calculated for each variable. Cohen's $d$ was used to specify the magnitude of the difference between conditions, using the following formulas:

$$
\begin{gathered}
S D_{\text {pooled }}=\sqrt{\left(\frac{\left(n_{A C T}-1\right) S D_{A C T}^{2}+\left(n_{\text {control }}-1\right) S D_{\text {control }}^{2}}{n_{A C T}+n_{\text {control }}-2}\right)} \\
d=\frac{M_{A C T}-M_{\text {control }}}{S D_{\text {pooled }}}
\end{gathered}
$$

To compare rates of behavior change, a proportion of baseline was calculated 
using the following formula:

$$
\frac{\text { Later Behavior }}{\text { Baseline Behavior }} \text { x } 100
$$

The proportion of baseline behavior for each condition at Time 2 and Time 3 were compared using nonparametric Mann-Whitney $U$ tests after removing outliers for normality.

The a priori power analysis, using G*Power software (Faul, Erdfelder, Lang, \& Buchner, 2007), used an alpha level of 0.05 , power of 0.95 , and a large effect size (Cohen's $d$ ) of 0.65 . The effect size was based on data from the pilot study of an acceptance based intervention for high delay discounting of 0.57 (Morrison et al., 2014) and was increased because the magnitude of the intervention was increased. This power analysis specified 40 participants were necessary to detect a large effect in a mixed between-within participants repeated measures MANOVA. As mentioned above, MLM of growth curves was used instead to test the hypotheses. A sample of approximately 100 participants (level 2) would have been necessary to obtain power of 0.80 (Raudenbush et al., 2011). Thus, any rejection of the null hypotheses can be observed with reasonable certainty. Yet, failing to reject the null hypotheses could indicate either a true lack of differences or a lack of power to detect differences that truly exist. Attempts to address the issues of power are reported in the Results section. 


\section{CHAPTER 4}

\section{RESULTS}

\section{Participant Characteristics}

Ninety individuals were screened by phone for participation. Seventy-two met the preliminary eligibility criteria to complete the Time 1 assessment, with 40 eligible to participate in the study. Twenty participants were randomly assigned into each condition. Sixteen from the ACT condition and 17 from the control condition completed all three time points (see Figure 4.1 for more detail). Of the 20 ACT participants, 15 were seen by one therapist and 5 were seen by the other. Table 4.1 summarizes participant characteristics at Time 1 . There were no differences between conditions at Time 1 on the outcome variables (as shown in Figures 4.3-4.9, discussed and shown later in this chapter), suggesting randomization was effective. At Time 3, all participants denied beginning (or changing) any psychotropic medication(s) or participating in therapy during the study.

The comparison of completer status (Table 4.2) showed a significant difference at Time 1 on the DDT-Wait $(\mathrm{AUC})(t(38)=2.32, p=0.01)$, VQ-P $(t(20.97)=-2.65, p=$ $0.02)$, and VQ-O $(t(38)=2.26, p=0.03)$. These values suggest that those that did not complete the study had lower delay discounting on the DDT-Wait and were less likely to live a valued life at Time 1 . While differences in valued living (both progression and obstruction) would be expected for noncompleters, lower delay discounting is the opposite of what would be expected. These variables were not included into the MLM 


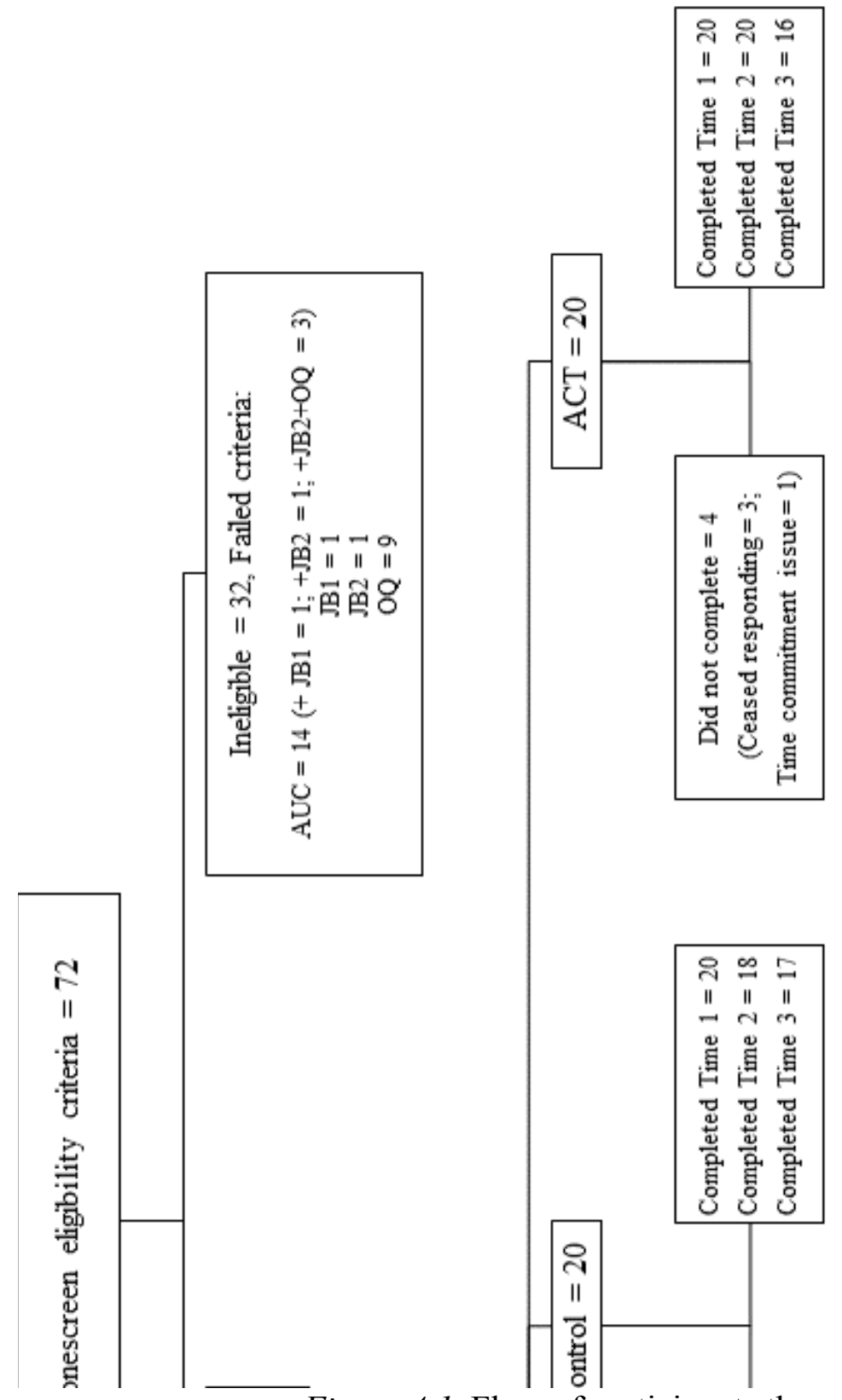

Figure 4.1. Flow of participants throughout study. 
Table 4.1

Summary of Participant Characteristics and Outcome Variables by Condition

\begin{tabular}{|c|c|c|c|c|}
\hline \multirow[b]{2}{*}{ Variables } & \multicolumn{2}{|c|}{ Control $(n=20)$} & \multicolumn{2}{|c|}{$\operatorname{ACT}(n=20)$} \\
\hline & $n$ & $\%$ & $n$ & $\%$ \\
\hline Age $(M \pm S D)$ & $28.35 \pm 9.81$ & & $25.40 \pm 6.75$ & \\
\hline Attempted previous treatment & 9 & 45 & 9 & 45 \\
\hline \multicolumn{5}{|l|}{ Education (highest level completed) ${ }^{\mathrm{a}}$} \\
\hline High school diploma or equivalent & 5 & 25 & 3 & 15 \\
\hline Some college & 3 & 15 & 8 & 40 \\
\hline Associates degree or equivalent & 4 & 20 & 4 & 20 \\
\hline B.A./B.S. or equivalent & 0 & 0 & 2 & 10 \\
\hline Some graduate school & 1 & 5 & 0 & 0 \\
\hline M.A./M.S. or equivalent & 1 & 5 & 3 & 15 \\
\hline \multicolumn{5}{|l|}{ Employment $^{\mathrm{a}}$} \\
\hline Unemployed/not working & 7 & 35 & 1 & 5 \\
\hline Working part-time & 2 & 10 & 8 & 40 \\
\hline Working full-time & 4 & 20 & 4 & 20 \\
\hline Full-time student (work and not working) & 7 & 35 & 7 & 35 \\
\hline Impact of target behavior $(M \pm S D)$ & $6.05 \pm 0.89$ & & $6.30 \pm 0.57$ & \\
\hline \multicolumn{5}{|l|}{ Income } \\
\hline$\$ 50,001+$ & 3 & 15 & 4 & 20 \\
\hline$\$ 20,001-\$ 50,000$ & 6 & 30 & 5 & 25 \\
\hline$\$ 20,000$ or less & 11 & 55 & 11 & 55 \\
\hline \multicolumn{5}{|l|}{ Length of target behavior } \\
\hline Less than 12 months & 2 & 10 & 0 & 0 \\
\hline 13 months - 5 years & 4 & 20 & 5 & 25 \\
\hline $6-10$ years & 5 & 25 & 6 & 30 \\
\hline Over 10 years & 9 & 45 & 9 & 45 \\
\hline \multicolumn{5}{|l|}{ Marital status $^{\text {a }}$} \\
\hline Divorced/separated & 2 & 10 & 0 & 0 \\
\hline Married & 6 & 30 & 5 & 25 \\
\hline Partnered & 1 & 5 & 2 & 10 \\
\hline Single & 11 & 55 & 13 & 65 \\
\hline \multicolumn{5}{|l|}{ Race $^{\text {a }}$} \\
\hline Caucasian/White & 16 & 80 & 16 & 80 \\
\hline Latino/a & 1 & 5 & 2 & 10 \\
\hline Asian/Asian American & 1 & 5 & 1 & 5 \\
\hline 2 or More Races & 1 & 5 & 1 & 5 \\
\hline Other & 1 & 5 & 0 & 0 \\
\hline
\end{tabular}




\begin{tabular}{|c|c|c|c|c|}
\hline \multirow[b]{2}{*}{ Variables } & \multicolumn{2}{|c|}{ Control $(n=20)$} & \multicolumn{2}{|c|}{$\operatorname{ACT}(n=20)$} \\
\hline & $n$ & $\%$ & $n$ & $\%$ \\
\hline \multicolumn{5}{|l|}{ Religion $^{a}$} \\
\hline LDS & 12 & 60 & 16 & 80 \\
\hline Christian & 2 & 10 & 0 & 0 \\
\hline Muslim & 1 & 5 & 0 & 0 \\
\hline Presbyterian & 0 & 0 & 1 & 5 \\
\hline $\begin{array}{l}\text { Unaffiliated (Atheist, Agnostic, or No } \\
\text { Affiliation) }\end{array}$ & 5 & 25 & 3 & 15 \\
\hline $\operatorname{Sex}(\text { male })^{\mathrm{a}}$ & 12 & 60 & 15 & 75.0 \\
\hline Taking psychotropic medication & 2 & 10 & 6 & 30 \\
\hline
\end{tabular}

Table 4.2

Summary of Outcome Variables at Time 1 by Completer Status

\begin{tabular}{|c|c|c|c|c|c|}
\hline \multirow[b]{2}{*}{ Variable } & \multicolumn{2}{|c|}{ Completer $(n=33)$} & \multicolumn{2}{|c|}{ Noncompleter $(n=7)$} & \multirow[b]{2}{*}{$p$} \\
\hline & $M$ & $S D$ & $M$ & $S D$ & \\
\hline Acceptance and Action Questionnaire-II & 29.91 & 7.43 & 32.71 & 5.09 & 0.35 \\
\hline Distress Tolerance Scale & 2.68 & 0.81 & 2.43 & 0.52 & 0.44 \\
\hline Delay Discounting Task (AUC) & 0.23 & 0.15 & 0.23 & 0.16 & 0.99 \\
\hline Delay Discounting Task $(k)$ & 0.10 & 0.25 & 0.08 & 0.09 & 0.90 \\
\hline Delay Discounting Task -Wait (AUC) & 0.41 & 0.24 & 0.68 & 0.25 & $0.01 * *$ \\
\hline Outcome Questionnaire-45.2 & 80.42 & 15.27 & 85.43 & 24.21 & 0.48 \\
\hline Valuing Questionnaire-Progress & 11.97 & 5.29 & 8.57 & 2.37 & $0.02 *$ \\
\hline Valuing Questionnaire-Obstruction & 14.67 & 3.51 & 17.86 & 2.73 & $0.03 *$ \\
\hline
\end{tabular}

$* p<.05$.

$* * p<.01$.

analyses to account for these differences because including additional parameters would have exhausted the model with the small sample.

Table 4.3 summarizes the types of problem behavior participants requested to target at Time 1 . The primary target behaviors were procrastination/time management, problematic pornography use, and eating habits. Twenty-two participants (55\%) requested help for only one behavior $($ control $=8, \mathrm{ACT}=14), 14(35 \%)$ for two 
Table 4.3

Summary of Target Behaviors

\begin{tabular}{lc}
\hline Type of target behavior & Percent of total sample $^{a}$ \\
\hline Procrastination/time-management & 40 \\
Problematic pornography use & 30 \\
Eating habits & 25 \\
Overall self-control & 10 \\
Interaction style (e.g., yelling, over-dependency) & 10 \\
Risky sexual behavior & 8 \\
Sleeping habits & 8 \\
Substance use & 8 \\
Financial management & 5 \\
Media use & 5 \\
Self-harm & 5 \\
Being active & 3 \\
\hline${ }^{a}$ Total does not equal 100\% because of multiple behaviors for some participants.
\end{tabular}

behaviors $($ control $=11, \mathrm{ACT}=3)$, and $4(10 \%)$ for three or more behaviors $($ control $=1$, $\mathrm{ACT}=3)$.

\section{Treatment Adherence}

The average measure ICC for coder 1 and coder 2 in comparison to the base coder were strong at .98 and .99 , respectively, for the first session and .97 and .92 for the second session. After completing the interrater agreement ratings, each coder coded 15 randomly selected sessions (balanced for session, participant, and therapist), totaling $20 \%$ of all sessions. Coding results indicate an average session time of 49.76 minutes $(S D=$ 11.86). Across all coded sessions, the ACT processes were covered with moderate frequency and depth: acceptance $(M=2.7, S D=1.29)$, defusion $(M=2.5, S D=1.2)$, selfas-context $(M=1.33, S D=0.79)$, present moment $(M=1.93, S D=1.2)$, values $(M=$ 
$2.43, S D=0.85)$, and committed action $(M=2.77, S D=0.77)$. The processes that received the most focus in the coded sessions were committed action, acceptance, defusion, and values. The ACT-inconsistent processes did not occur in any of the coded sessions. Across both therapists, competency $(M=4.67, S D=0.48)$ and adherence to the ACT therapeutic stance $(M=4.67, S D=.48)$ were high. In comparing therapist $1(n=$ $24)$ and therapist $2(n=6)$, there were no statistically significant differences on any of the observed variables (all $p>0.05$ ). These results suggest that the therapists provided competent and ACT consistent treatment.

\section{Problem Behavior Frequency}

Four outliers were removed from the proportion of baseline data (Time $2[\mathrm{ACT}]=$ 1; Time $3[\mathrm{ACT}]=3$ ). At Time 2 , there was no significant difference between the control $(M d n=0.71, I Q R=0.36-1.36)$ and $\mathrm{ACT}(M d n=1.00, \mathrm{IQR}=0.25-1.75)$ conditions on reported occurrences of problem behavior $\left(U=145, n_{\text {control }}=18, n_{A C T}=17, p=0.81\right)$. At Time 3, the ACT condition $(M d n=0.10, I Q R=-0.15-0.35)$ had significantly lower proportions of their baseline behavior $\left(U=48.5, n_{\text {control }}=17, n_{A C T}=12, p=0.02\right)$ in comparison to the control condition $(M d n=0.71, I Q R=0.24-0.57)$. See Figure 4.2 for a visual depiction of the results.

\section{Delay Discounting Outcomes}

\section{Delay Discounting Task}

Two measurement incidents were removed from analyses, one for meeting the 


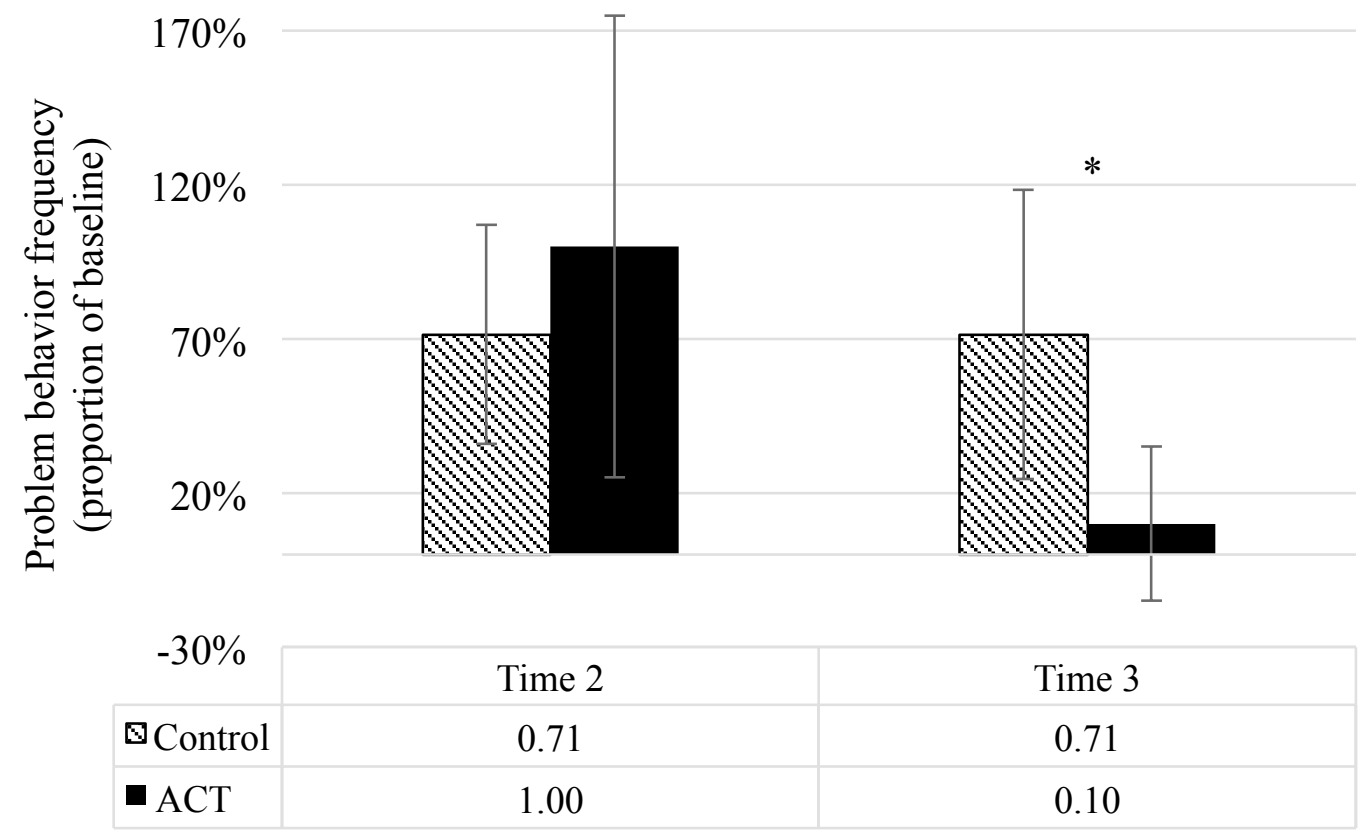

Note. Lower values indicate less problem behavior from baseline values. Error bars represent the interquartile range.

$* p<.05$.

Figure 4.2. Median proportion of baseline problem behavior frequency.

JB1 criterion at Time 2 (ACT) and one for meeting the JB2 criterion at Time 3 (control). Both AUC and $k$ values were calculated for the DDT. The $k$ values were not normally distributed and a logarithm (base 10) transformation was conducted. While this somewhat corrected the distribution violations, the AUC values were more normally distributed. Thus, the AUC values were analyzed and presented here. AUC values of the DDT decreased significantly over time in both conditions. Yet, the difference between the control and ACT conditions was not statistically significant alone or with the interaction of time. Delay discounting MLM results are displayed in Table 4.4. Results suggest that both conditions showed significant reductions in delay discounting over time and there 
Table 4.4

Delay Discounting Multilevel Model of Growth Curve Estimates

\begin{tabular}{lcccc}
\hline \multicolumn{1}{c}{ Parameter } & $\begin{array}{c}\text { Delay Discounting Task } \\
\text { (AUC) }\end{array}$ & $S E$ & $\begin{array}{c}\text { Delay Discounting Task-Wait } \\
\text { (AUC) }\end{array}$ & $S E$ \\
\hline Intercept & 0.191 & 0.03 & 0.48 & 0.08 \\
Condition & 0.019 & 0.05 & -0.10 & 0.12 \\
Time & $0.058^{* *}$ & 0.02 & 0.03 & 0.03 \\
Condition $x$ Time & -0.034 & 0.03 & -0.01 & 0.04 \\
\hline$* * p<.01$. & & & &
\end{tabular}

was no statistically significant difference between the conditions. Thus, participating in ACT did not impact delay discounting beyond an inactive control. Figure 4.3 shows a visual depiction of the results.

\section{Opportunity Cost Delay Discounting Tasks}

Only the DDT-Wait was analyzed due to extreme deviations from normality in the DDT-Free. Nondiscounting (JB2) occurred across most of the sample in the DDTFree $($ control $=68.3 \%, \mathrm{ACT}=55 \%)$ which interfered with normal distributions of both AUC and $k$ values. Removal of the nondiscounters would have drastically reduced the data to be analyzed and data transformation techniques (e.g., logarithm, square root) were not effective due to the large number of nondiscounters. It was expected that little to no discounting would occur in this condition because of the short maximum delay (24 hours) and the ability to move about freely during the hypothetical delay. Unfortunately, this left the data unanalyzable.

Only the JB1 criterion was used to determine systematic data in the DDT-Wait, 


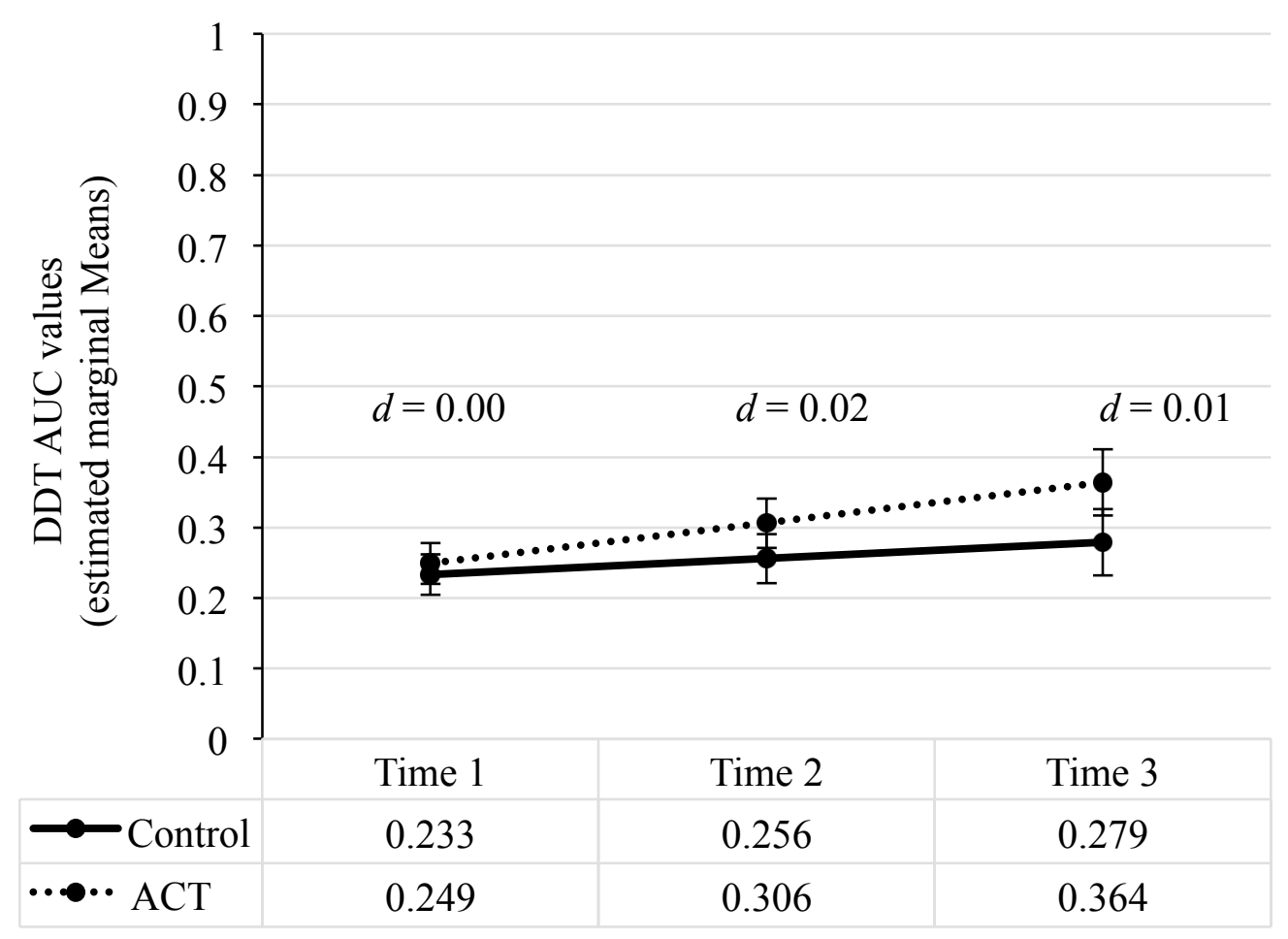

Note. Higher values represent less delay discounting. Range of potential values are 0-1. Error bars represent standard error.

Figure 4.3. Multilevel growth curve results for the Delay Discounting Task (AUC).

because removal of nondiscounting data would have noticeably reduced the sample size (control $=9.4 \%, \mathrm{ACT}=12.5 \%)$. For the DDT-Wait, one measurement incident was removed for meeting both the JB1 criterion and for having an inverse curve and one measurement incident was removed for having an inverse curve alone. Each of those measurements were at Time 1 in the control condition. Both $k$ and AUC were calculated for the DDT-Wait. AUC values better met the normality assumptions for the analyses. Data transformation attempts did not correct violations of normality; thus, analysis of $k$ values was not conducted. No statistically significant effects were found for condition, 
time, or the interaction of condition and time for the DDT-Wait (AUC). Results are summarized in Table 4.4. Results suggest that the intervention did not have a statistically significant effect on delay discounting. DDT-Wait outcomes are shown graphically in Figure 4.4.

\section{Clinical Outcomes}

The MLM growth curve results for the clinical outcomes are listed in Table 4.5. There was a significant interaction effect of time and condition on AAQ-II, DTS, OQ45.2, and VQ-O. Figures 4.5 through 4.9 show that those that participated in ACT had significantly lower psychological inflexibility (AAQ-II), higher distress tolerance (DTS),

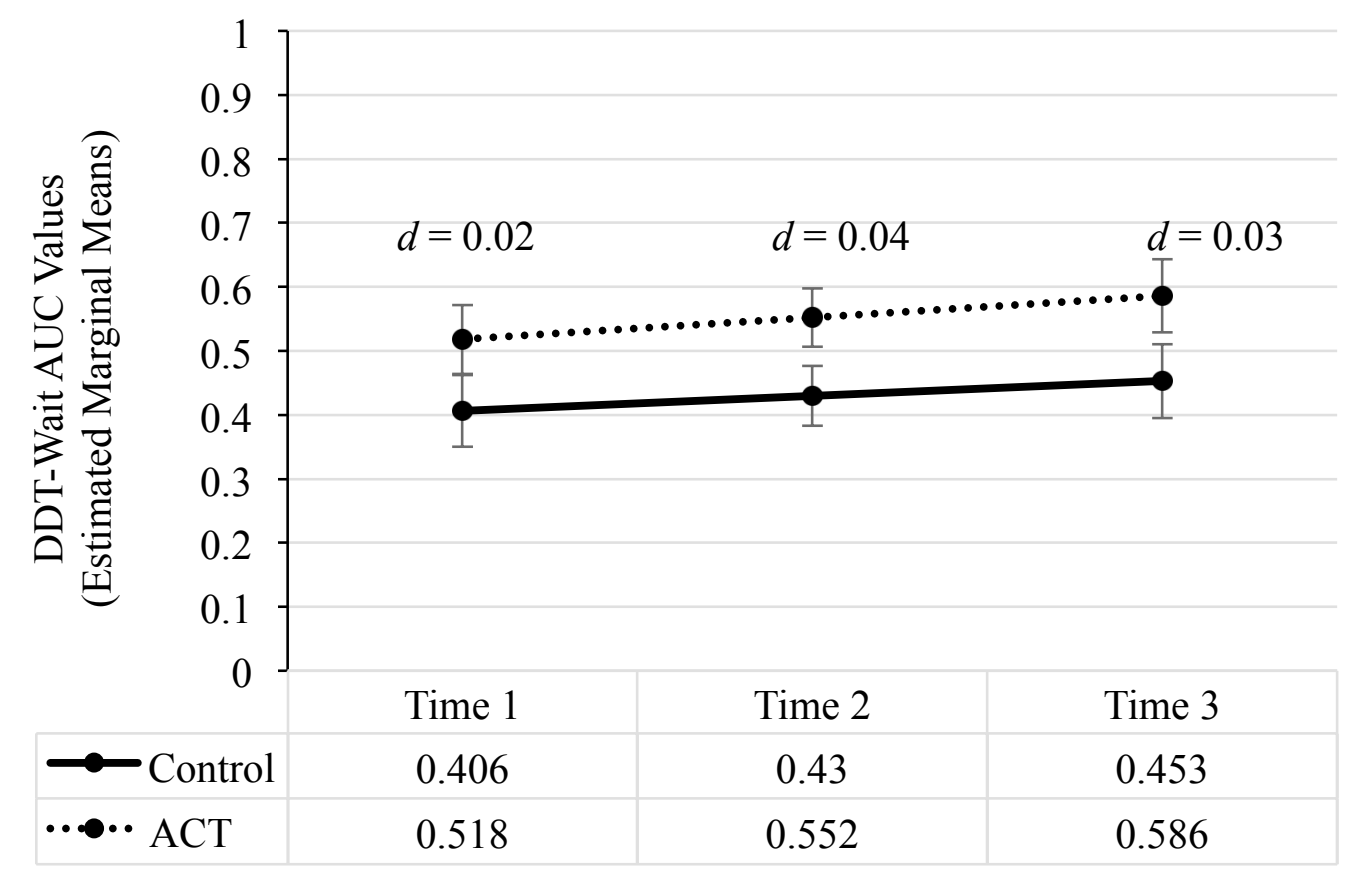

Note. Higher values represent lower delay discounting. Error bars represent standard error.

Figure 4.4. Multilevel growth curve results from the Delay Discounting Task-Wait (AUC). 
Table 4.5

Clinical Multilevel Model of Growth Curve Estimates and Effect Sizes

\begin{tabular}{|c|c|c|c|c|c|c|c|c|c|c|}
\hline \multirow[b]{2}{*}{ Parameter } & \multicolumn{2}{|c|}{$\begin{array}{l}\text { Acceptance and } \\
\text { Action } \\
\text { Questionnaire-II }\end{array}$} & \multicolumn{2}{|c|}{$\begin{array}{c}\text { Distress } \\
\text { Tolerance Scale }\end{array}$} & \multicolumn{2}{|c|}{$\begin{array}{c}\text { Outcome } \\
\text { Questionnaire- } \\
45.2\end{array}$} & \multicolumn{2}{|c|}{$\begin{array}{c}\text { Valuing } \\
\text { Questionnaire- } \\
\text { Progress }\end{array}$} & \multicolumn{2}{|c|}{$\begin{array}{c}\text { Valuing } \\
\text { Questionnaire- } \\
\text { Obstruction }\end{array}$} \\
\hline & Value & $S E$ & Value & $S E$ & Value & $S E$ & Value & $S E$ & Value & $S E$ \\
\hline Intercept & 32.35 & 2.24 & 2.18 & 0.23 & 86.82 & 5.00 & 10.76 & 1.62 & 17.97 & 1.26 \\
\hline Condition & -0.83 & 3.16 & 0.42 & 0.32 & -1.67 & 7.06 & -2.24 & 2.28 & -2.30 & 1.78 \\
\hline Time & $-3.23 * * *$ & 0.92 & $0.42 * * *$ & 0.08 & $-7.64 * * *$ & 1.94 & $1.61^{*}$ & 0.69 & $-2.85 * * *$ & 0.59 \\
\hline Condition $\mathrm{x}$ Time & $2.81 * *$ & 1.29 & $-0.37 * *$ & 0.11 & $6.05^{*}$ & 2.74 & 0.34 & 0.98 & $1.99 *$ & 0.83 \\
\hline $\mathrm{ACT} d$ & 1.09 & 1.09 & -1.26 & & 1.35 & & N/A & & 1.42 & \\
\hline Control $d$ & 0.07 & 0.07 & -0.04 & & 0.09 & & N/A & & 0.32 & \\
\hline
\end{tabular}

* $p<.05$.

$* * p<.01$.

$* * * p<.001$.

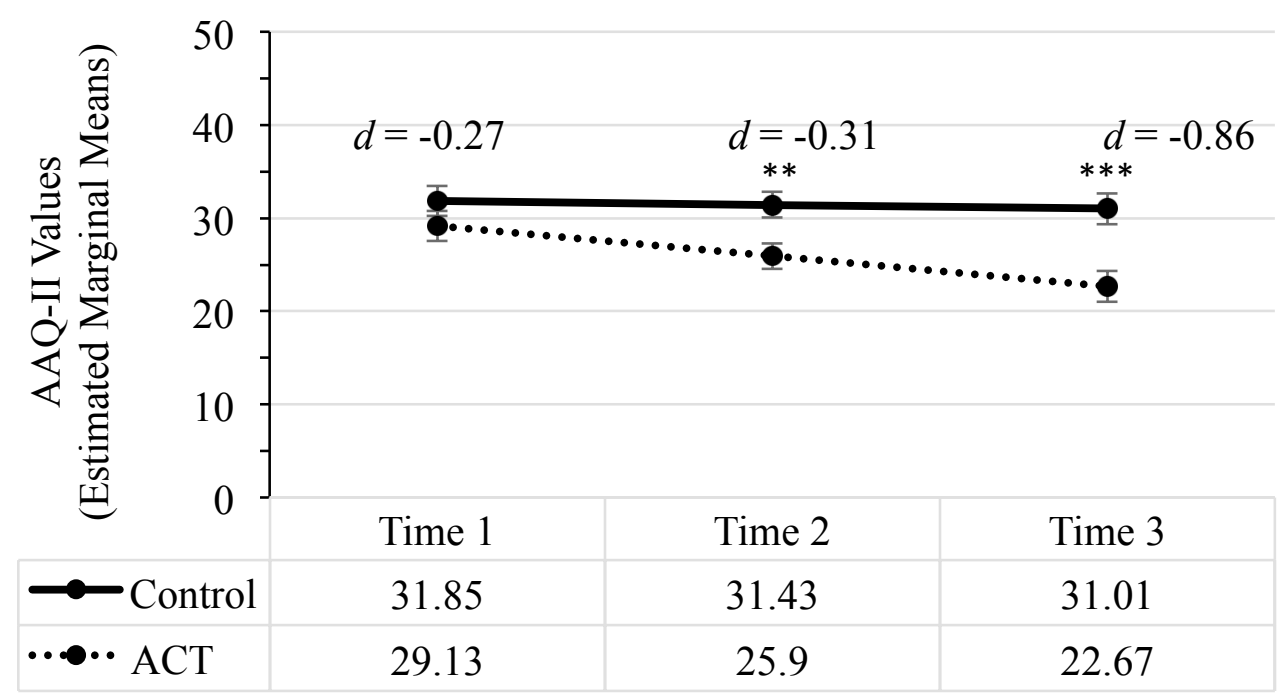

Note. Lower values represent more psychological flexibility. Values above 24-28 indicate higher psychological distress. Range of potential values are 7-49. Error bars represent standard error.

$$
\begin{aligned}
& * * \quad p<0.01 . \\
& * * * \quad p<0.001 .
\end{aligned}
$$

Figure 4.5. Multilevel growth curve results from the Acceptance and Action Questionnaire (AAQ-II). 


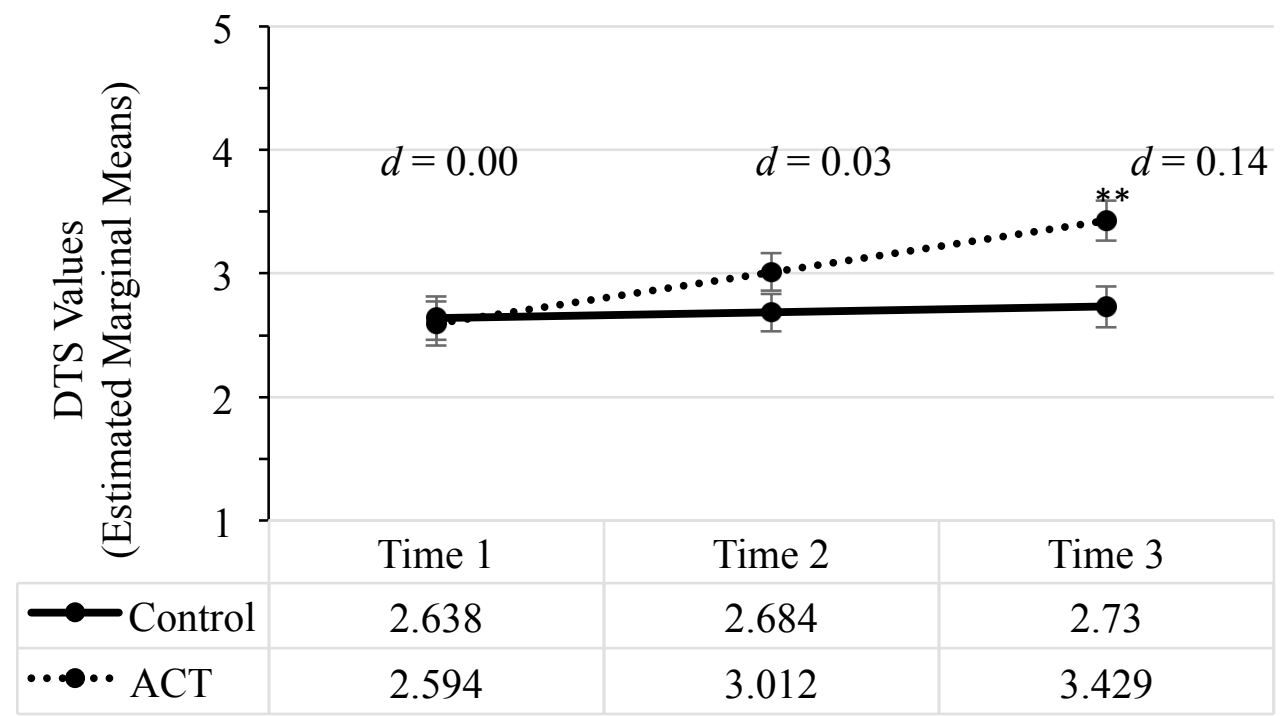

Note. Higher values represent higher distress tolerance. Range of potential values are 1-5. Error bars represent standard error.

** $p<0.01$.

Figure 4.6. Multilevel growth curve results from the Distress Tolerance Scale (DTS).

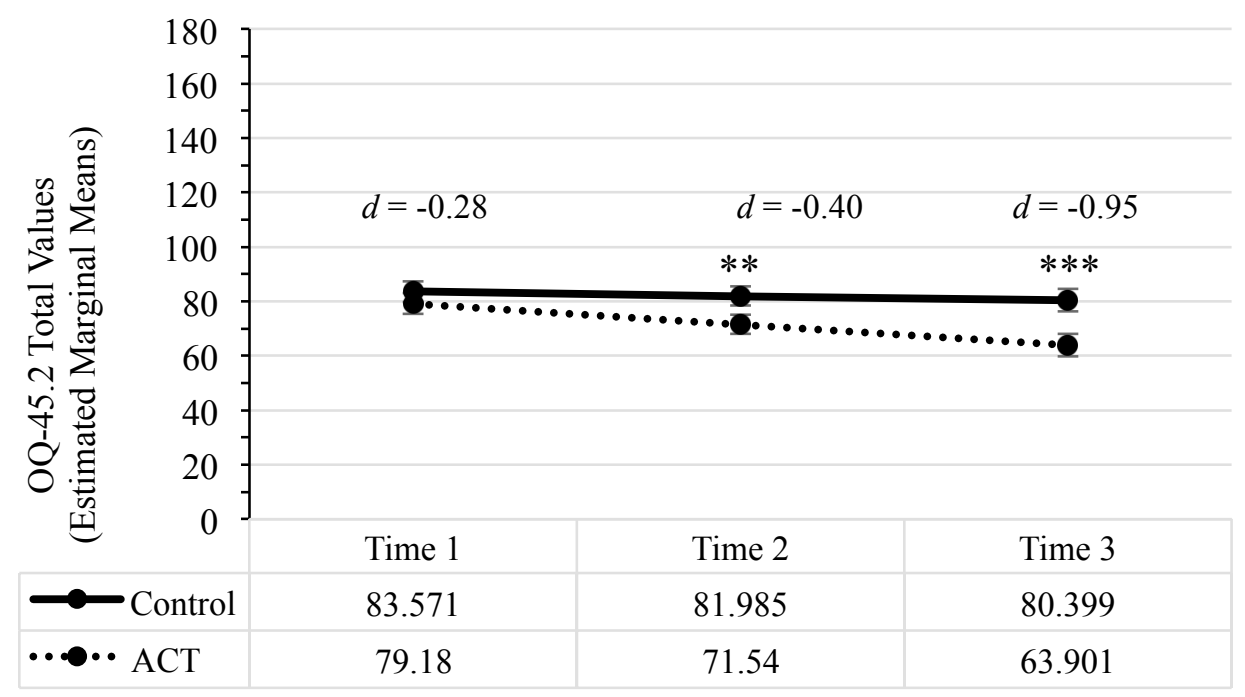

Note. Lower values represent higher well-being and fewer psychological symptoms. Range of potential values are 0-180. Values above 63 suggest clinical levels of psychological symptoms. A change of 14 points or more are indicative of clinically relevant change (control T3 - T1 = -3.17; ACT T3 - T1 = -15.28). Error bars represent standard error.

$* * \quad p<.01$.

$* * * p<.001$.

Figure 4.7. Multilevel growth curve results from the Outcome Questionnaire (OQ-45.2). 


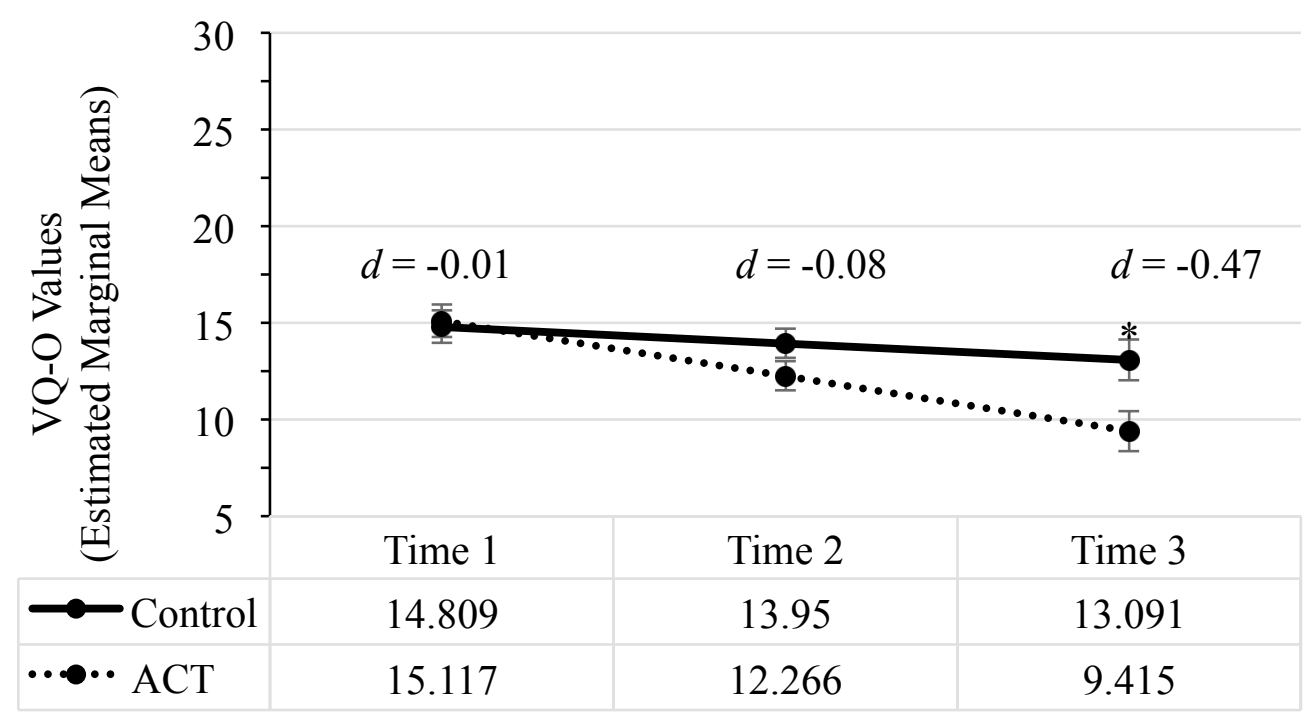

Note. Lower values represent more valued living (reduced impact of obstacles). Range of potential values are 5-30 (based on questionnaire entry error; actual range 0-30). Error bars represent standard error.

$* p<.05$.

Figure 4.8. Multilevel growth curve results from the Valuing Questionnaire-Obstruction (VQ-O).

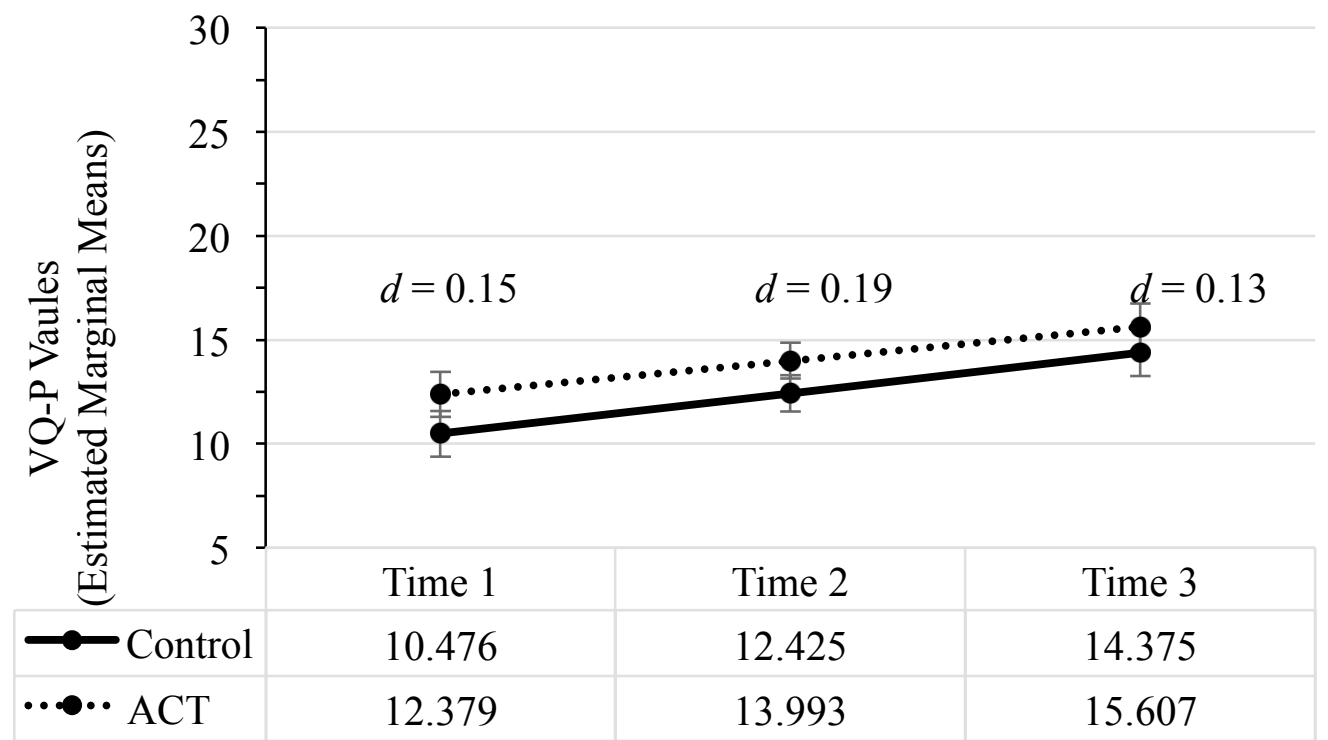

Note. Higher values represent more valued living (clarification and action toward values). Range of potential values are 5-30 (based on questionnaire entry error; actual range 0-30). Error bars represent standard error.

Figure 4.9. Multilevel growth curve results from the Valuing Questionnaire-Progression (VQ-P). 
lower psychological symptoms (higher well-being; OQ-45.2), and were impacted less by obstacles to valued living (VQ-O; shown by an increased score). The magnitude of these effects were all large (Table 4.5). There was no significant interaction effect on the progress subscale of valued living (VQ-P), but there was a significant effect of time, suggesting both conditions increased progress toward valued living.

\section{Addressing Lack of Power}

As stated previously, this study was underpowered. Although statistically significant effects were found for most variables, the hypothesized changes in delay discounting were not confirmed. In order to determine if these results were due to the lack of power or to a true lack of differences, the data were doubled and tripled to mimic samples of 80 and 120 participants. These results should be viewed for illustration purposes only because they assume the additional 40-80 participants would have behaved identically to the original 40 participants. The analyses for the DDT and DDT-Wait were repeated with these larger samples. Results (Table 4.6) show that the interaction of time and condition of the AUC values for the DDT approached significance with 80 participants $(p=0.06)$ and reached significance with 120 participants $(p=0.02)$. This suggests that a lack of power may account for the nonsignificant interaction in the original data, but only with a much larger sample. The time and condition interaction effect for the DDT-Wait (AUC) did not reach significance with $80(p=0.74)$ nor 120 ( $p$ $=0.68$ ) participants. These results suggest that there is a true lack of differences between the growth curves of participants across time and condition in the DDT-Wait. 
Table 4.6

Delay Discounting Multilevel Model Growth Curve Estimates and Effect Sizes of Increased Sample Sizes

\begin{tabular}{|c|c|c|c|c|c|c|c|c|}
\hline \multirow[b]{3}{*}{ Parameter } & \multicolumn{4}{|c|}{ Area under the curve $(n=80)$} & \multicolumn{4}{|c|}{ Area under the curve $(n=120)$} \\
\hline & \multicolumn{2}{|c|}{$\begin{array}{c}\text { Delay } \\
\text { Discounting Task }\end{array}$} & \multicolumn{2}{|c|}{$\begin{array}{c}\text { Delay Discounting } \\
\text { Task-Wait }\end{array}$} & \multicolumn{2}{|c|}{$\begin{array}{c}\text { Delay } \\
\text { Discounting Task }\end{array}$} & \multicolumn{2}{|c|}{$\begin{array}{l}\text { Delay Discounting } \\
\text { Task-Wait }\end{array}$} \\
\hline & Value & $S E$ & Value & $S E$ & Value & $S E$ & Value & $S E$ \\
\hline Intercept & 0.191 & 0.03 & 0.483 & 0.05 & 0.19 & 0.02 & 0.48 & 0.04 \\
\hline Condition & 0.019 & 0.03 & -0.101 & 0.08 & 0.02 & 0.03 & -0.1 & 0.06 \\
\hline Time & $0.058 * * *$ & 0.01 & 0.034 & 0.02 & $0.06 * * *$ & 0.01 & $0.03 *$ & 0.02 \\
\hline Condition $\mathrm{x}$ Time & -0.035 & 0.02 & -0.01 & 0.03 & $-0.03 *$ & 0.01 & -0.1 & 0.03 \\
\hline Effect size $(d)$ & N/A & & N/A & & -0.6 & & N/A & \\
\hline
\end{tabular}

Treatment Satisfaction

Those in the ACT condition that completed Time $3(n=16)$ reported levels of treatment satisfaction. The data were negatively skewed and peaked due to two outliers. The median $(M d n=30.5, I Q R=28-31)$ of the data with the outliers is reported, as it is not influenced by outliers. In comparison, removing the outliers $(n=14)$, resulted in a normal distribution, but did not result in a meaningful change from the previous analysis $(M=30.14, S D=1.46 ; M d n=31, I Q R=30-31)$. Both sets of results suggest a high level of satisfaction with treatment. 


\section{CHAPTER 5}

\section{DISCUSSION}

This study examined the effects of eight individual sessions of ACT, compared to an inactive control, on the rate of delay discounting, psychological flexibility, distress tolerance, psychological symptoms/well-being, valued living, and problem behavior frequency in a sample of adults with high delay discounting and low well-being. The sample self-referred to the study to change at least one behavior related to "self-control." It was hypothesized that the intervention would decrease delay discounting and problematic behaviors as well as increase psychological flexibility, distress tolerance, well-being, and valued living more so than the inactive control. All of those hypothesized changes were seen except for delay discounting and the progression subscale of valued living. The magnitude of the treatment effect on psychological flexibility, distress tolerance, well-being, and obstacles to valued living were large.

\section{Transdiagnostic Application}

While finding that ACT changed psychological flexibility, distress tolerance, well-being, and obstacles to valued living is not surprising, changing these constructs across multiple forms of behavior is. Although ACT arose from a behavior analytic tradition and is a functional treatment, much of the applied ACT research has focused on categorical diagnoses. This study was an attempt to apply ACT in a transdiagnostic, functional form across broad symptomology. The results indicate that different forms of behavior can be changed with ACT by focusing on the underlying function of the 
behavior. While this was primarily an efficacy trial, the results found here may be more generalizable to an actual treatment setting because of the expansive eligibility criteria. Interventions that can be applied across diagnoses or behaviors will likely reduce the burden on clients. Further, providers can focus training on addressing underlying concerns rather than learning multiple interventions for topographical differences. Of the approximately 130 ACT randomized controlled trials (Association for Contextual Behavioral Science, 2016), only a small portion include broad symptom presentations (Bethay, Wilson, Schnetzer, Nassar, \& Bordieri, 2013; Clarke, Kingston, James, Bolderston, \& Remington, 2014; Fledderus, Bohlmeijer, Smit, \& Westerhof, 2010; Lappalainen et al., 2007; Muto, Hayes, \& Jeffcoat, 2011; Räsänen, Lappalainen, Muotka, Tolvanen, \& Lappalainen, 2016). To the author's knowledge, there is only one study that has fully assessed the effectiveness of ACT in a true clinical setting (Strosahl, Hayes, Bergan, \& Romano, 1998). Thus, testing ACT in a transdiagnostic manner adds considerable information to the body of ACT treatment outcome research and provides evidence for appropriate broad application of ACT (when the symptoms are a functional match).

\section{Delay Discounting}

The underlying construct that was expected to change (delay discounting), did not. Both the DDT and DDT-Wait showed no significant effect of treatment over the three time points. The addition of the DDT-Free and DDT-Wait were used to measure delay discounting to capture different aspects of the decision making process when delay 
conditions vary. Not surprisingly, there was little discounting that occurred during the free condition, suggesting that the ability to continue with normal activities decreases the influence of the delay (when the maximum delay is brief). This lack of discounting restricted the possible analyses, however, and could not be compared to the task with a hypothetical wait during the delay. While not explicit, it is likely that participants believe they are free to move about during the delays of the DDT and may be a useful parallel to the DDT-Free. Staying in the assessment room during the delay (as was specified in the DDT-Wait) would likely create more unwanted distress than a free condition. Given that addressing the impact of this distress on behavior is a primary component of ACT, it was particularly expected to see a change in the DDT-Wait. However, no significant changes were seen in either of the tasks.

The lack of significance in either of the analyzed delay discounting tasks was not hypothesized and is surprising based on a much shorter intervention (one 90-minute session) significantly decreasing delay discounting (Morrison et al., 2014). There are several reasons this may have occurred. First, the current study included additional criteria that increased the clinical severity of the sample. Although, the amount of time individuals struggled with the target behavior was not assessed in the Morrison et al. study, target behaviors discussed during the intervention appeared to be less entrenched than the behaviors in the current study. The majority of the sample in the current study had struggled with the target behavior(s) for 6 or more years $(73 \%)$ and almost half of the sample struggled with them for more than 10 years $(45 \%)$. While the intervention changed most of the clinically relevant outcomes, delay discounting may be more 
resistant to change when clinical severity is higher. It has been suggested that more severe populations may struggle to use acceptance and mindfulness techniques when urges are especially intense and may be better suited to use distraction techniques, or potentially a combination of the two (Ashe, Newman, \& Wilson, 2015). Interventions that combine mindfulness and distraction techniques, like Dialectical Behavior Therapy (Linehan, 1993), may be worthy of investigation in changing delay discounting especially in more severe populations.

Second, the participant commitment of this study was drastically more than the pilot study, especially for those receiving treatment. While most of the participants completed the study, scheduling and attendance was a persistent issue for the intervention and data collection. It would be expected that those that contacted the researchers and completed this study are more self-controlled than those that did not (in the population), suggesting that they may be more amendable to behavior change. Those in the pilot study likely included a wider range in levels of self-control because they did not self-refer to change behavior, but were selected based on AUC values. This may have influenced the flexibility of delay discounting rates.

Third, the brief, targeted intervention in the pilot study may have led to changes in responding because of demand characteristics rather than true intervention effects. Participants self-referred to this study to change problematic behaviors in their lives. Thus, it is likely that from the participants' perspectives, that was the goal of treatment. If demand characteristics were expected to occur, it would have likely been in behavior tracking or measures that appeared more clearly applicable. Some participants made 
comments after data collection that suggested they were unaware of the purpose of the delay discounting measures (e.g., "Why are you asking about money?" "Those are odd questions."). This study was designed to reduce potential demand characteristics on the delay discounting task (e.g., focused recruitment on behavior change and issues of "selfcontrol," treatment focused on behavior change and valued living). While we do not have information to show that demand characteristics influenced responding in either of these studies, it is a factor to consider when understanding the differences. Using a direct, brief intervention may be more likely to elude to the hypothesized results.

More generally, using delay discounting as a clinical target and outcome has its limitations. While theoretically, the concepts of delay discounting, ACT, and ACT related processes match closely, the measures may not be accounting for the similarities. One of the primary issues in connecting delay discounting and problem behaviors due to psychological inflexibility, is the lack of internal experiences that can guide decision making when completing the delay discounting tasks. The task may not be measuring delay discounting while under the same internal contextual control as in the real world.

If there is internal distress during the monetary delay discounting tasks, that internal distress may be perceived as less threatening or influential in comparison to distress tied to the problem behavior(s). Delay discounting is higher when nonmonetary tasks are used, but responding across commodities tends to be related (Odum, 2011). This suggests that while delay discounting is consistent across individuals, they discount commodities related to their struggles more than money. The perception of the commodity, and possibly the cognitions, emotions, and urges associated with those 
commodities, may impact decision making and sensitivity to change. If this is the case, it is reasonable to expect $\mathrm{ACT}$ to alter decisions that are related to commodities of particular interest, but not money. One of the main targets of ACT is to equalize the perceptions of cognitions, emotions, and urges in order to change behavior. If an individual in this study did not struggle with money, but did struggle with compulsive lying, ACT would have equalized the perceptions of urges related to lying with those of money and the perceptions of money would stay the same. By only measuring delay discounting of money, no change would appear. Consequently, monetary tasks may not be as amendable from therapeutic interventions, especially for individuals with specific commodity struggles (e.g., pornography, food, homework). An example of this may be shown by the results Hendrickson and Rasmussen (2013) found. Using a mindful eating intervention, delay discounting of food was reduced $\left(\eta^{2} \mathrm{p}=0.06\right)$, but not money in an obese sample.

Where the current study saw changes in behavior and constructs that are tied to behavior change, it suggests that the intervention was effective in changing delay discounting in a real-world context (choosing behaviors with larger delayed rewards more often than those with smaller immediate rewards). However, this is only a theoretical assumption. Unfortunately, there is not currently a way to measure delay discounting that maps exactly onto real-world decision making. The tasks that are available, and that were used in this study, are certainly valuable at identifying individuals that are more likely to have problem behaviors. Yet, they may be capturing a construct that does not move with behavior change or treatment. 
The information here adds to the literature of unsuccessful attempts to alter delay discounting. Given that interventions have had mixed outcomes, delay discounting has not been determined as a static or malleable construct. The fact that it has changed with some interventions suggests that it is malleable, but only in the appropriate context. Thus, the most efficient intervention to alter delay discounting may be the best area to focus future research.

\section{Clinical Applications}

In comparing the clinical constructs of the pilot study and the current study, both studies increased distress tolerance with the current study having a larger effect $(d$ $=-1.26)$ than the pilot study $(d=0.49)$. The pilot data did not see a significant interaction

effect for psychological flexibility, but there was both a significant interaction effect of condition and time and a large effect of treatment in the current study. Brief ACT interventions may result in a change of distress tolerance because the lack of time decreases the experiential nature of ACT and rule-governed behavior may be more likely. Thus, it would be expected for a longer intervention to also change psychological flexibility and to maintain the changes in distress tolerance. Where behavior change may occur quickly during a brief intervention, it may occur as a product of "pushing-through" uncomfortable distress. This would be expected to only have a temporary effect on behavior. The decrease in problem behavior and psychological flexibility in this study suggests that not only can ACT change problem behavior, but it can also change the way in which people view their internal experiences. That shift in perspective and new 
decision making skills are expected to influence behavior long after the intervention is complete. Supporting this idea that ACT positively impacted quality of life, two of the three measures of valued living and well-being showed a significant change over time in the ACT condition. This suggests that ACT was also successful at increasing well-being and reducing obstacles to valued living.

\section{Limitations}

The small sample size in this study is an obvious limitation with regard to inferences about the absence of delay discounting changes. The differences between conditions (for delay discounting) may have been undetectable with the study design and number of participants. Additionally, conducting analyses to understand variables that influenced change would have exhausted the models being used (e.g., mediation, moderation).

Given that measures of delay discounting are not traditionally used in a clinical context, difficulties with appropriately identifying the desired sample were anticipated. Thus, the addition of the OQ-45.2 cutoff and a specific target behavior were used to identify a sample that more closely matched a clinical population. The culmination of these three criteria may have removed individuals that fit the target population, but were not captured by the measures used.

The intervention was provided by two advanced ACT therapists that both have training in behavior analysis. Identifying the function of behavior is likely easier for them in comparison to a provider without a behavioral background. Obtaining that knowledge 
may involve moderate amounts of training. It requires being able to identify what is driving the behavior, determining the most appropriate ACT response, and providing the intervention in a compassionate, competent manner all in a short period of time. Many advanced ACT providers have these skills after years of training. Yet, specialized psychologists with years of training in one type of therapy are unlikely to be front-line providers. It is more likely that experts in their own fields (e.g., dieticians, parole officers, substance use counselors, religious officials) will be using this intervention across multiple behaviors they see in their settings (e.g., communities, schools, public health policies, medical office). While transdiagnostic therapies have many pros, the ability to disseminate them is a potential con.

The treatment manual was designed for this study and was not tested previously. The main distinctions between this manual and other ACT manuals were the early focus on values (session 3), no session devoted to present moment (dispersed throughout), and no specific population was addressed. The use of values early on seemed appropriate for this population in order to gain buy-in for the remaining activities and is recommended to keep. Adding a session devoted to present moment would have allowed for more depth in this process and could be considered for future manuals. Based on the outcomes of this study, it seems worthwhile to continue to determine if one manual can be used for a diverse set of behaviors.

Eight sessions of therapy may not be sufficient for this population. Highly entrenched decision making processes and valued living may take longer than eight weeks to alter. The lasting impact of the changes is also unknown without follow-up 
assessments. The outcomes may have looked different during a follow-up period, as was the case in the Secades-Villa et al. (2014) trial. Follow-up data were not collected because requesting an additional 1, 6, or 12 months without treatment for the treatment seeking, inactive control participants was ethically questionable. Following only the ACT condition through follow-up would have provided information about the persistence of the effects, but the interpretation of any findings would have been limited by the lack of a comparison condition.

\section{Future Directions}

Given the reported changes in clinical outcomes that are indicative of strong mental health from a transdiagnostic intervention, it would be beneficial to continue researching functional interventions in this way. ACT outcome research has tended to target DSM diagnoses although it was not intended to be a diagnosis specific treatment. As more issues with a categorical system come to light, a shift in treatment research has as well (e.g., Barlow, Allen, \& Choate, 2004). Although the design and recruitment for this study were slightly more difficult than a traditional DSM diagnosis treatment study, mapping research designs to the theoretical stance of the intervention will likely be worth the minimal increase in effort. This effort is expected to be in the form of identifying the appropriate measures that apply across diagnoses, creating a treatment manual that describes how to functionally address the target, determining eligibility status (when the needed assessment may not exist), and finding the most appropriate terminology for recruitment. 
As for delay discounting in treatment research, it may be useful to, first, take a step back to the level of assessment. The commodity of the tasks may be relevant for more severe populations. To examine this hypothesis, to determine measure sensitivity, and to determine applicability to clinical populations, one could use commodity specific tasks for those with specific struggles (e.g., pornography, food, homework) and use more general tasks for those with general struggles (e.g., overall lack of self-control). Unfortunately, changing the commodity for each person reduces the transdiagnostic application of this measure.

If matching commodities to the individual would not be realistic, finding a way to measure delay discounting while it is being influenced by real-world contingencies would make it more applicable to clinical settings and interventions. Involving technology and situationally appropriate prompts may allow for assessment in the actual decision making context. Ideally, measures would combine the aspects of psychological flexibility, distress tolerance measures (self-report or behavioral), values identification, valued living, quality of life/well-being, and delay discounting in order to account for all of the proposed aspects of decision making.

To address the issue of dissemination mentioned previously, brief, nonclinical interventions may be worth investigating within a clinical context. For example, interventions targeting working memory reduced $\left(\eta_{\mathrm{G}}{ }^{2}=0.07\right.$; neurocognitive memory training; Bickel, Yi, Landes, Hill, \& Baxter, 2011) and increased $(d=0.40$; increased working memory load; Finn, Gunn, \& Gerst, 2014) delay discounting. An intervention as simple as brief exposure to nature images reduced delay discounting, in comparison to 
human-made (Cliff's Delta $=0.24)$ and geometric images $($ Cliff's Delta $=0.22$; Berry, Sweeney, Morath, Odum, \& Jordan, 2014). Writing a paragraph about oneself including future and self-control oriented words (e.g., save, willpower) resulted in lower delay discounting in comparison to neutral and past focused words (Sheffer et al., 2016). There was no baseline delay discounting data to know if priming with future oriented words altered discounting, but it is a novel intervention to shape decision making. While these interventions are simpler to implement than a therapy package, the question remains if these changes in delay discounting are lasting and if changes in problem behavior and quality of life are impacted by decreases in delay discounting.

With the inconsistent delay discounting outcomes from the ACT trials (Morrison et al., 2014 and the current study), replication of either study would be worthwhile (e.g., larger samples, an altered protocol, specific treatment groups). Study materials are available by request in order to conduct these replications.

\section{Conclusion}

As the data currently stand, the effect of ACT on delay discounting is unknown. At one end of the gap in knowledge is a clear connection between delay discounting and problem behavior. At the other end, there is a clear connection between clinical interventions and reduction of problem behavior and increased well-being. While closing that gap continues to be a worthwhile endeavor, this study left a few more unanswered questions about the contents of the gap. 


\section{REFERENCES}

Ainslie, G. (1975). Specious reward: A behavioral theory of impulsiveness and impulse control. Psychological Bulletin, 82(4), 463-496. doi:10.1037/h0076860

Aldao, A., \& Nolen-Hoeksema, S. (2010). Specificity of cognitive emotion regulation strategies: A transdiagnostic examination. Behaviour Research and Therapy, 48(10), 974-983. doi:10.1016/j.brat.2010.06.002

American Psychiatric Association. (2013). Diagnostic and statistical manual of mental disorders: $D S M-5^{\mathrm{TM}}\left(5^{\text {th }}\right.$ ed. $)$. Arlington, VA: Author.

Anker, J. J., Perry, J. L., Gliddon, L. A., \& Carroll, M. E. (2009). Impulsivity predicts the escalation of cocaine self-administration in rats. Pharmacology Biochemistry and Behavior, 93(3), 343-348. doi:http://dx.doi.org/10.1016/j.pbb.2009.05.013

Armstrong, A. B., Morrison, K. L., \& Twohig, M. P. (2013). A preliminary investigation of acceptance and commitment therapy for adolescent obsessive-compulsive disorder. Journal of Cognitive Psychotherapy, 27(2), 175-190.

Ashe, M. L., Newman, M. G., \& Wilson, S. J. (2015). Delay discounting and the use of mindful attention versus distraction in the treatment of drug addiction: A conceptual review. Journal of the Experimental Analysis of Behavior, 103(1), 234-248. doi:10.1002/jeab.122

Association for Contextual Behavioral Science. (2016). ACT randomized controlled trials since 1986. Retrieved from https://contextualscience.org/ACT_Randomized_ Controlled_Trials

Attkisson, C. C., \& Zwick, R. (1982). The Client Satisfaction Questionnaire: Psychometric properties and correlations with service utilization and psychotherapy outcome. Evaluation and Program Planning, 5(3), 233-237.

Audrain-McGovern, J., Rodriguez, D., Epstein, L. H., Cuevas, J., Rodgers, K., \& Wileyto, E. P. (2009). Does delay discounting play an etiological role in smoking or is it a consequence of smoking? Drug and Alcohol Dependence, 103(3), 99106.

Barlow, D. H., Allen, L. B., \& Choate, M. L. (2004). Toward a unified treatment for emotional disorders. Behavior Therapy, 35(2), 205-230.

Bernstein, A., Marshall, E. C., \& Zvolensky, M. J. (2011). Multi-method evaluation of distress tolerance measures and construct(s): Concurrent relations to mood and anxiety psychopathology and quality of life. Journal of Experimental Psychopathology, 2(3), 386-399. 
Berry, M. S., Sweeney, M. M., Morath, J., Odum, A. L., \& Jordan, K. E. (2014). The nature of impulsivity: Visual exposure to natural environments decreases impulsive decision-making in a delay discounting task. PLoS ONE, 9(5). Retrieved from http://dx.doi.org/10.1371/journal.pone.0097915

Bethay, J. S., Wilson, K. G., Schnetzer, L. W., Nassar, S. L., \& Bordieri, M. J. (2013). A controlled pilot evaluation of acceptance and commitment training for intellectual disability staff. Mindfulness, 4(2), 113-121. doi:10.1007/s12671-012-0103-8

Bickel, W. K., Jarmolowicz, D. P., Mueller, E. T., Koffarnus, M. N., \& Gatchalian, K. M. (2012). Excessive discounting of delayed reinforcers as a trans-disease process contributing to addiction and other disease-related vulnerabilities: Emerging evidence. Pharmacology \& Therapeutics, 134(3), 287-297.

doi:10.1016/j.pharmthera.2012. 02.004

Bickel, W. K., Koffarnus, M. N., Moody, L., \& Wilson, A. G. (2014). The behavioraland neuro-economic process of temporal discounting: A candidate behavioral marker of addiction. Neuropharmacology, 76, Part B, 518-527. doi:10.1016/j.neuropharm.2013.06.013

Bickel, W. K., Yi, R., Landes, R. D., Hill, P. F., \& Baxter, C. (2011). Remember the future: Working memory training decreases delay discounting among stimulant addicts. Biological Psychiatry, 69(3), 260-265. doi:10.1016/j.biopsych.2010. 08.017

Black, A. C., \& Rosen, M. I. (2011). A money management-based substance use treatment increases valuation of future rewards. Addictive Behaviors, 36(1-2), 125-128. doi:10.1016/j.addbeh.2010.08.014

Blackledge, J. T. (2003). An introduction to relational frame theory: Basics and applications. The Behavior Analyst Today, 3(4), 421-433. doi:10.1037/h0099997

Bond, F. W., Hayes, S. C., Baer, R. A., Carpenter, K. M., Guenole, N., Orcutt, H. K., ... Zettle, R. D. (2011). Preliminary psychometric properties of the Acceptance and Action Questionnaire-II: A revised measure of psychological inflexibility and experiential avoidance. Behavior Therapy, 42(4), 676-688. doi:10.1016/j.beth.2011.03.007

Borkovec, T. D., Abel, J. L., \& Newman, H. (1995). Effects of psychotherapy on comorbid conditions in generalized anxiety disorder. Journal of Consulting and Clinical Psychology, 63(3), 479-483. doi:http://dx.doi.org/10.1037/0022006X.63.3.479 
Boulanger, J. L., Hayes, S. C., \& Pistorello, J. (2010). Experiential avoidance as a functional contextual concept. In A. M. Kring \& D. M. Sloan (Eds.), Emotion regulation and psychopathology: A transdiagnostic approach to etiology and treatment. (pp. 107-136). New York, NY: Guilford.

Broos, N., Diergaarde, L., Schoffelmeer, A. N. M., Pattij, T., \& De Vries, T. J. (2012). Trait impulsive choice predicts resistance to extinction and propensity to relapse to cocaine seeking: A bidirectional investigation. Neuropsychopharmacology, 37(6), 1377-1386. doi: http://www.nature.com/npp/journal/v37/n6/suppinfo/ npp2011323s1.html

Cheema, J. R. (2014). Some general guidelines for choosing missing data handling methods in educational research. Journal of Modern Applied Statistical Methods, 13(2), 53-75.

Clarke, S., Kingston, J., James, K., Bolderston, H., \& Remington, B. (2014). Acceptance and commitment therapy group for treatment-resistant participants: A randomized controlled trial. Journal of Contextual Behavioral Science, 3(3), 179-188. doi:http://dx.doi.org/10.1016/j.jcbs.2014.04.005

Crosby, J. M., \& Twohig, M. P. (2016). Acceptance and commitment therapy for problematic internet pornography use: A randomized trial. Behavior Therapy, 47(3), 355-366. doi:10.1016/j.beth.2016.02.001

Davis, C., Patte, K., Curtis, C., \& Reid, C. (2010). Immediate pleasures and future consequences. A neuropsychological study of binge eating and obesity. Appetite, 54(1), 208-213. doi:10.1016/j.appet.2009.11.002

Dehlin, J. P., Morrison, K. L., \& Twohig, M. P. (2013). Acceptance and commitment therapy as a treatment for scrupulosity in obsessive compulsive disorder. Behavior Modification, 37(3), 409-430.

Dennhardt, A. A., \& Murphy, J. G. (2011). Associations between depression, distress tolerance, delay discounting, and alcohol-related problems in European American and African American college students. Psychology of Addictive Behaviors, 25(4), 595-604. doi:http://dx.doi.org/10.1037/a0025807

Dennhardt, A. A., Yurasek, A. M., \& Murphy, J. G. (2015). Change in delay discounting and substance reward value following a brief alcohol and drug use intervention. Journal of the Experimental Analysis of Behavior, 103(1), 125-140. doi:10.1002/jeab.121

Diergaarde, L., Pattij, T., Poortvliet, I., Hogenboom, F., de Vries, W., Schoffelmeer, A. N., \& De Vries, T. J. (2008). Impulsive choice and impulsive action predict vulnerability to distinct stages of nicotine seeking in rats. Biol Psychiatry, 63(3), 301-308. doi:10.1016/j.biopsych.2007.07.011 
Dodd, M. C. (2014). Intertemporal discounting as a risk factor for high BMI: Evidence from Australia, 2008. Economics \& Human Biology, 12, 83-97. doi:10.1016/j.ehb.2013.05.005

Dunlap, W. P., Cortina, J. M., Vaslow, J. B., \& Burke, M. J. (1996). Meta-analysis of experiments with matched groups or repeated measures designs. Psychological Methods, 1(2), 170-177. doi:10.1037/1082-989X.1.2.170

Epstein, L. H., Jankowiak, N., Fletcher, K. D., Carr, K. A., Nederkoorn, C., Raynor, H. A., \& Finkelstein, E. (2014). Women who are motivated to eat and discount the future are more obese. Obesity, 22(6), 1394-1399. doi:10.1002/oby.20661

Faul, F., Erdfelder, E., Lang, A.-G., \& Buchner, A. (2007). GPower 3: A flexible statistical power analysis program for the social, behavioral, and biomedical sciences. Behavior Research Methods, 39(2), 175-191. doi:10.3758/BF03193146

Fernie, G., Peeters, M., Gullo, M. J., Christiansen, P., Cole, J. C., Sumnall, H., \& Field, M. (2013). Multiple behavioural impulsivity tasks predict prospective alcohol involvement in adolescents. Addiction, 108(11), 1916-1923. doi:10.1111/add.12283

Fields, S. A., Lange, K., Ramos, A., Thamotharan, S., \& Rassu, F. (2014). The relationship between stress and delay discounting: a meta-analytic review. Behav Pharmacol, 25(5-6), 434-444. doi:10.1097/fbp.0000000000000044

Fields, S. A., Ramos, A., \& Reynolds, B. A. (2015). Delay discounting and health risk behaviors: the potential role of stress. Current Opinion in Psychology, 5, 101-105. doi:http://dx.doi.org/10.1016/j.copsyc.2015.07.003

Finn, P. R., Gunn, R. L., \& Gerst, K. R. (2014). The effects of a working memory load on delay discounting in those with externalizing psychopathology. Clinical Psychological Science, 3(2), 202-214. doi:10.1177/2167702614542279

Fledderus, M., Bohlmeijer, E. T., Smit, F., \& Westerhof, G. J. (2010). Mental health promotion as a new goal in public mental health care: A randomized controlled trial of an intervention enhancing psychological flexibility. American Journal of Public Health, 100(12), 2372-2378. doi:10.2105/AJPH.2010.196196

Hallgren, K. A. (2012). Computing inter-rater reliability for observational data: An overview and tutorial. Tutor Quant Methods Psychol, 8(1), 23-34.

Hayes, S. C. (1989). Rule-governed behavior: Cognition, contingencies, and instructional control. New York, NY: Plenum. 
Hayes, S. C., Luoma, J. B., Bond, F. W., Masuda, A., \& Lillis, J. (2006). Acceptance and Commitment Therapy: Model, processes and outcomes. Behaviour Research and Therapy, 44(1), 1-25. doi:10.1016/j.brat.2005.06.006

Hayes, S. C., Strosahl, K., Wilson, K. G., Bissett, R. T., Pistorello, J., Toarmino, D., ... McCurry, S. M. (2004). Measuring experiential avoidance: A preliminary test of a working model. The Psychological Record, 54(4), 553-578.

Hendrickson, K. L., \& Rasmussen, E. B. (2013). Effects of mindful eating training on delay and probability discounting for food and money in obese and healthyweight individuals. Behaviour Research and Therapy, 51(7), 399-409. doi:10.1016/j.brat.2013.04.002

Hernández-López, M., Luciano, M. C., Bricker, J. B., Roales-Nieto, J. G., \& Montesinos, F. (2009). Acceptance and commitment therapy for smoking cessation: A preliminary study of its effectiveness in comparison with cognitive behavioral therapy. Psychology of Addictive Behaviors, 23(4), 723-730. doi:10.1037/a0017632

Hox, J. J. (2010). Multilevel analysis: Techniques and applications. Mahwah, NJ: Erlbaum.

IBM Corp. (2012). IBM SPSS Statistics for Macintosh (Version 21.0). Armonk, NY: Author.

Insel, T., Cuthbert, B., Garvey, M., Heinssen, R., Pine, D. S., Quinn, K., ... Wang, P. (2010). Research domain criteria (RDoC): Toward a new classification framework for research on mental disorders. The American Journal of Psychiatry, 167(7), 748-751. doi:10.1176/appi.ajp.2010.09091379

Irvine, M. A., Worbe, Y., Bolton, S., Harrison, N. A., Bullmore, E. T., \& Voon, V. (2013). Impaired decisional impulsivity in pathological videogamers. PLOS ONE, 8(10). Retrieved from http://dx.doi.org/10.1371/journal.pone.0075914

Johnson, M. W., \& Bickel, W. K. (2008). An algorithm for identifying nonsystematic delay-discounting data. Experimental and Clinical Psychopharmacology, 16(3), 264-274. doi:http://dx.doi.org/10.1037/1064-1297.16.3.264

Johnson, P. S., Herrmann, E. S., \& Johnson, M. W. (2015). Opportunity costs of reward delays and the discounting of hypothetical money and cigarettes. Journal of the Experimental Analysis of Behavior, 103(1), 87-107. doi:10.1002/jeab.110

Kessler, R. C., Chiu, W. T., Demler, O., \& Walters, E. E. (2005). Prevalence, severity, and comorbidity of 12-month DSM-IV disorders in the national comorbidity survey replication. Archives of General Psychiatry, 62(6), 617-627. 
Kessler, R. C., Petukhova, M., Sampson, N. A., Zaslavsky, A. M., \& Wittchen, H.-U. (2012). Twelve-month and lifetime prevalence and lifetime morbid risk of anxiety and mood disorders in the United States. International Journal of Methods in Psychiatric Research, 21(3), 169-184. doi:10.1002/mpr.1359

Kim, S.-H., Beretvas, S. N., \& Sherry, A. R. (2010). A validation of the factor structure of OQ-45 scores using factor mixture modeling. Measurement and Evaluation in Counseling and Development, 42(4), 275-295. doi:10.1177/0748175609354616

Kirby, K. N. (2009). One-year temporal stability of delay-discount rates. Psychonomic Bulletin \& Review, 16(3), 457-462. doi:10.3758/PBR.16.3.457

Kirby, K. N., Petry, N. M., \& Bickel, W. K. (1999). Heroin addicts have higher discount rates for delayed rewards than non-drug-using controls. Journal of Experimental Psychology: General, 128(1), 78-87. doi:10.1037/0096-3445.128.1.78

Koffarnus, M. N., Jarmolowicz, D. P., Mueller, E. T., \& Bickel, W. K. (2013). Changing delay discounting in the light of the competing neurobehavioral decision systems theory: A review. Journal of the Experimental Analysis of Behavior, 99(1), 32-57. doi:10.1002/jeab.2

Kollins, S. H. (2003). Delay discounting is associated with substance use in college students. Addictive Behaviors, 28(6), 1167-1173.

Krueger, R. F. (2002). Psychometric perspectives on comorbidity. In J. E. Helzer \& J. J. Hudziak (Eds.), Defining psychopathology in the 21st century: DSM-V and beyond. (pp. 41-54). Arlington, VA: American Psychiatric Publishing.

Krug, I., Casasnovas, C., Granero, R., Martinez, C., Jiménez-Murcia, S., Bulik, C., \& Fernández-Aranda, F. (2008). Comparison study of full and subthreshold bulimia nervosa: Personality, clinical characteristics, and short-term response to therapy. Psychotherapy Research, 18(1), 37-47. doi:10.1080/10503300701320652

Lambert, M. J., Burlingame, G. M., Umphress, V., Hansen, N. B., Vermeersch, D. A., Clouse, G. C., \& Yanchar, S. C. (1996). The reliability and validity of the outcome questionnaire. Clinical Psychology \& Psychotherapy, 3(4), 249-258. doi:10.1002/(SICI)1099-0879(199612)3:4<249::AID-CPP106>3.0.CO;2-S

Landes, R. D., Christensen, D. R., \& Bickel, W. K. (2012). Delay discounting decreases in those completing treatment for opioid dependence. Experimental and Clinical Psychopharmacology, 20(4), 302-309. doi:http://dx.doi.org/10.1037/a0027391

Lappalainen, R., Lehtonen, T., Skarp, E., Taubert, E., Ojanen, M., \& Hayes, S. C. (2007). The impact of CBT and ACT models using psychology trainee therapists: A preliminary controlled effectiveness trial. Behavior Modification, 31(4), 488-511. 
Larsen, D. L., Attkisson, C. C., Hargreaves, W. A., \& Nguyen, T. D. (1979). Assessment of client/patient satisfaction: development of a general scale. Evaluation and Program Planning, 2(3), 197-207.

Lattal, K. A. (2010). Delayed reinforcement of operant behavior. Journal of the Experimental Analysis of Behavior, 93(1), 129-139. doi:10.1901/jeab.2010.93129

Lawyer, S. R. (2008). Probability and delay discounting of erotic stimuli. Behavioural Processes, 79(1), 36-42. doi:10.1016/j.beproc.2008.04.009

Linehan, M. (1993). Cognitive-behavioral treatment of borderline personality disorder. New York, NY: Guilford.

Luo, S., Ainslie, G., \& Monterosso, J. (2014). The behavioral and neural effect of emotional primes on intertemporal decisions. Social Cognitive and Affective Neuroscience, 9(3), 283-291. doi:10.1093/scan/nss132

MacKillop, J., Amlung, M. T., Few, L. R., Ray, L. A., Sweet, L. H., \& Munafò, M. R. (2011). Delayed reward discounting and addictive behavior: A meta-analysis. Psychopharmacology, 216(3), 305-321. doi:10.1007/s00213-011-2229-0

MacKillop, J., Celio, M. A., Mastroleo, N. R., Kahler, C. W., Operario, D., Colby, S. M., ... Monti, P. M. (2015). Behavioral economic decision making and alcohol-related sexual risk behavior. AIDS and Behavior, 19(3), 450-458. doi:10.1007/s10461014-0909-6

MacKillop, J., \& Kahler, C. W. (2009). Delayed reward discounting predicts treatment response for heavy drinkers receiving smoking cessation treatment. Drug and Alcohol Dependence, 104(3), 197-203. doi:10.1016/j.drugalcdep.2009.04.020

Mahoney, A. E. J., \& McEvoy, P. M. (2012). A transdiagnostic examination of intolerance of uncertainty across anxiety and depressive disorders. Cognitive Behaviour Therapy, 41(3), 212-222. doi:10.1080/16506073.2011.622130

Matusiewicz, A. K., Carter, A. E., Landes, R. D., \& Yi, R. (2013). Statistical equivalence and test-retest reliability of delay and probability discounting using real and hypothetical rewards. Behavioural Processes, 100, 116-122. doi:10.1016/j.beproc.2013.07.019

Mazur, J. E. (1987). An adjusting procedure for studying delayed reinforcement. In M. L. Commons, J. E. Mazur, J. A. Nevin, \& H. Rachlin (Eds.), The effect of delay and of intervening events on reinforcement value. (pp. 55-73). Hillsdale, NJ: Erlbaum.

Monterosso, J. R., \& Ainslie, G. (1999). Beyond discounting: Possible experimental models of impulse control. Psychopharmacology, 146(4), 339-347. 
Morrison, K. L., Madden, G. J., Odum, A. L., Friedel, J. E., \& Twohig, M. P. (2014). Altering impulsive decision making with an acceptance-based procedure. Behavior Therapy, 45(5), 630-639.

Muto, T., Hayes, S. C., \& Jeffcoat, T. (2011). The effectiveness of acceptance and commitment therapy bibliotherapy for enhancing the psychological health of Japanese college students living abroad. Behavior Therapy, 42(2), 323-335. doi:10.1016/j.beth.2010.08.009

Myerson, J., Green, L., \& Warusawitharana, M. (2001). Area under the curve as a measure of discounting. Journal of the Experimental Analysis of Behavior, 76(2), 235-243. doi:10.1901/jeab.2001.76-235

Nastally, B. L., \& Dixon, M. R. (2012). The effect of a brief acceptance and commitment therapy intervention on the near-miss effect in problem gamblers. The Psychological Record, 62(4), 677-690.

Niemeier, H. M., Leahey, T., Reed, K. P., Brown, R. A., \& Wing, R. R. (2012). An acceptance-based behavioral intervention for weight loss: A pilot study. Behavior Therapy, 43(2), 427-435. doi:10.1016/j.beth.2011.10.005

Nolen-Hoeksema, S., \& Watkins, E. R. (2011). A heuristic for developing transdiagnostic models of psychopathology explaining multifinality and divergent trajectories. Perspectives on Psychological Science, 6(6), 589-609. doi:10.1177/1745691611419672

Odum, A. L. (2011). Delay discounting: Trait variable? Behavioural Processes, 87(1), 19. doi:10.1016/j.beproc.2011.02.007

Odum, A. L., Madden, G. J., Badger, G. J., \& Bickel, W. K. (2000). Needle sharing in opioid-dependent outpatients: Psychological processes underlying risk. Drug and Alcohol Dependence, 60(3), 259-266. doi:10.1016/S0376-8716(00)00111-3

Perry, J. L., Larson, E. B., German, J. P., Madden, G. J., \& Carroll, M. E. (2005). Impulsivity (delay discounting) as a predictor of acquisition of IV cocaine selfadministration in female rats. Psychopharmacology, 178(2-3), 193-201. doi:10.1007/s00213-004-1994-4

Petry, N. M. (2002). Discounting of delayed rewards in substance abusers: Relationship to antisocial personality disorder. Psychopharmacology, 162(4), 425-432. doi:10.1007/s00213-002-1115-1

Pinto, A., Steinglass, J. E., Greene, A. L., Weber, E. U., \& Simpson, H. B. (2014). Capacity to delay reward differentiates obsessive-compulsive disorder and obsessive-compulsive personality disorder. Biological Psychiatry, 75(8), 653-659. doi:10.1016/j.biopsych.2013.09.007 
Plumb, J. C., \& Vilardaga, R. (2010). Assessing treatment integrity in acceptance and commitment therapy: Strategies and suggestions. International Journal of Behavioral Consultation and Therapy, 6(3), 263-295.

Psychology Software Tools, I. (2012). E-Prime 2.0. Retrieved from http://www.pstnet.com/

Pulcu, E., Trotter, P. D., Thomas, E. J., McFarquhar, M., Juhasz, G., Sahakian, B. J., ... Elliott, R. (2014). Temporal discounting in major depressive disorder. Psychological Medicine, 44(9), 1825-1834. doi:10.1017/S0033291713002584

Qualtrics. (2005). Qualtrics. Retrieved from http://www.qualtrics.com/

Rachlin, H., Raineri, A., \& Cross, D. (1991). Subjective probability and delay. Journal of the Experimental Analysis of Behavior, 55(2), 233-244.

doi:10.1901/jeab.1991.55-233

Räsänen, P., Lappalainen, P., Muotka, J., Tolvanen, A., \& Lappalainen, R. (2016). An online guided ACT intervention for enhancing the psychological wellbeing of university students: A randomized controlled clinical trial. Behaviour Research and Therapy, 78, 30-42. doi:http://dx.doi.org/10.1016/j.brat.2016.01.001

Rasmussen, E. B., Lawyer, S. R., \& Reilly, W. (2010). Percent body fat is related to delay and probability discounting for food in humans. Behavioural Processes, 83(1), 23-30. doi:10.1016/j.beproc.2009.09.001

Raudenbush, S. W., et al. (2011). Optimal design software for multi-level and longitudinal research (Version 3.01). Retrieved from http://www.wtgrantfoundation.org/

Rice, K. G., Suh, H., \& Ege, E. (2014). Further evaluation of the Outcome Questionnaire-45.2. Measurement and Evaluation in Counseling and Development, 47(2), 102-117. doi:10.1177/0748175614522268

Richards, R. W. (1981). A comparison of signaled and unsignaled delay of reinforcement. Journal of the Experimental Analysis of Behavior, 35(2), 145-152. doi:10.1901/jeab.1981.35-145

Rozin, P., \& Royzman, E. B. (2001). Negativity bias, negativity dominance, and contagion. Personality and Social Psychology Review, 5(4), 296-320. doi:10.1207/S15327957PSPR0504_2

Salters-Pedneault, K., \& Diller, J. W. (2013). A preliminary study of anxiety, negative affect, experiential avoidance, and delaying of aversive events. Behaviour Change, 30(04), 241-248. 
Secades-Villa, R., Weidberg, S., García-Rodríguez, O., Fernández-Hermida, J. R., \& Yoon, J. H. (2014). Decreased delay discounting in former cigarette smokers at one year after treatment. Addictive Behaviors, 39(6), 1087-1093. doi:10.1016/j.addbeh.2014.03.015

Sheffer, C. E., Christensen, D. R., Landes, R., Carter, L. P., Jackson, L., \& Bickel, W. K. (2014). Delay discounting rates: A strong prognostic indicator of smoking relapse. Addictive Behaviors, 39(11), 1682-1689. doi:http://dx.doi.org/10.1016/ j.addbeh.2014.04.019

Sheffer, C. E., Mackillop, J., Fernandez, A., Christensen, D., Bickel, W. K., Johnson, M. W., ... Mathew, M. (2016). Initial examination of priming tasks to decrease delay discounting. Behavior Processes, 128, 144-152. doi:10.1016/j.beproc.2016.05.002

Sheffer, C. E., MacKillop, J., McGeary, J., Landes, R., Carter, L., Yi, R., ... Bickel, W. (2012). Delay discounting, locus of control, and cognitive impulsiveness independently predict tobacco dependence treatment outcomes in a highly dependent, lower socioeconomic group of smokers. The American Journal on Addictions, 21(3), 221-232. doi:10.1111/j.1521-0391.2012.00224.x

Shrout, P. E., \& Fleiss, J. L. (1979). Intraclass correlations: Uses in assessing rater reliability. Psychological Bulletin, 86(2), 420-428. doi:10.1037/00332909.86.2.420

Simons, J. S., \& Gaher, R. M. (2005). The Distress Tolerance Scale: Development and validation of a self-report measure. Motivation and Emotion, 29(2), 83-102. doi:10.1007/s11031-005-7955-3

Singer, J. D., \& Willett, J. B. (2003). Applied longitudinal data analysis: Modeling change and event occurrence. New York, NY: Oxford University Press.

Smout, M., Davies, M., Burns, N., \& Christie, A. (2014). Development of the Valuing Questionnaire (VQ). Journal of Contextual Behavioral Science, 3(3), 164-172.

Stanger, C., Ryan, S. R., Fu, H., Landes, R. D., Jones, B. A., Bickel, W. K., \& Budney, A. J. (2012). Delay discounting predicts adolescent substance abuse treatment outcome. Experimental and Clinical Psychopharmacology, 20(3), 205-212. doi:http://dx.doi.org/10.1037/a0026543

Story, G. W., Vlaev, I., Seymour, B., Darzi, A., \& Dolan, R. J. (2014). Does temporal discounting explain unhealthy behavior? A systematic review and reinforcement learning perspective. Frontiers in Behavioral Neuroscience, 8 (76), 1-20. doi:10.3389/fnbeh.2014.00076 
Strosahl, K. D., Hayes, S. C., Bergan, J., \& Romano, P. (1998). Assessing the field effectiveness of Acceptance and Commitment Therapy: An example of the manipulated training research method. Behavior Therapy, 29(1), 35-64.

Tsao, J. C. I., Mystkowski, J. L., Zucker, B. G., \& Craske, M. G. (2005). Impact of cognitive-behavioral therapy for panic disorder on comorbidity: A controlled investigation. Behaviour Research and Therapy, 43(7), 959-970. doi:10.1016/j.brat.2004.11.013

Twohig, M. P., Hayes, S. C., Plumb, J. C., Pruitt, L. D., Collins, A. B., Hazlett-Stevens, H., \& Woidneck, M. R. (2010). A randomized clinical trial of acceptance and commitment therapy versus progressive relaxation training for obsessivecompulsive disorder. Journal of Consulting and Clinical Psychology, 78(5), 705716. doi:10.1037/a0020508

Varghese, F. P., Charlton, S. R., Wood, M., \& Trower, E. (2014). Temporal discounting and criminal thinking: Understanding cognitive processes to align services. Psychological Services, 11(2), 171-178. doi: http://dx.doi.org/10.1037/a0035004

Washio, Y., Higgins, S. T., Heil, S. H., McKerchar, T. L., Badger, G. J., Skelly, J. M., \& Dantona, R. L. (2011). Delay discounting is associated with treatment response among cocaine-dependent outpatients. Experimental and Clinical Psychopharmacology, 19(3), 243-248. doi:10.1037/a0023617

Weafer, J., Baggott, M. J., \& de Wit, H. (2013). Test-retest reliability of behavioral measures of impulsive choice, impulsive action, and inattention. Experimental and Clinical Psychopharmacology, 21(6), 475-481. doi:10.1037/a0033659

Worthy, D. A., Byrne, K. A., \& Fields, S. (2014). Effects of emotion on prospection during decision-making. Frontiers in Psychology, 5.

doi:10.3389/fpsyg.2014.00591

Yi, R., Johnson, M. W., Giordano, L. A., Landes, R. D., Badger, G. J., \& Bickel, W. K. (2008). The effects of reduced cigarette smoking on discounting future rewards: An initial evaluation. Psychological Record, 58(2), 163-174.

Yoon, J. H., Higgins, S. T., Heil, S. H., Sugarbaker, R. J., Thomas, C. S., \& Badger, G. J. (2007). Delay discounting predicts postpartum relapse to cigarette smoking among pregnant women. Experimental and Clinical Psychopharmacology, 15(2), 176-186. doi:10.1037/1064-1297.15.2.186 
APPENDICES 
Appendix A

Recruitment Materials 


\section{Oral Announcement}

My name is . I am a graduate student in the Psychology Doctoral

Program under the supervision of Dr. Michael Twohig. I am here to invite you to participate in research study that is determining useful psychological treatments for changing unwanted behaviors. We are seeking adults who engage in behaviors that are unwanted and would like to change them. Some examples include cigarette smoking, pornography use, overeating, procrastination, substance use, gambling, risky sexual behavior, self-injury, and any other behavior you might do regularly that is causing problems for you in your life. You must be 18 years of age or older to participate. You will complete an initial interview to determine eligibility. If eligible, you will take part in treatment which involves weekly 1 hour sessions for 8 weeks or will be on a waitlist to begin treatment at a later date. You will receive extra credit indicated by your instructor for your participation (Note: This last statement will be added as appropriate in classes in which instructors have agreed to give class credit for participation and removed for any community announcements.). There is no charge to participate in this treatment study. If you are interested, please contact Kate Morrison at (435) 797-8303 or kate.morrison@aggiemail.usu.edu. 


\section{Flier for Posting on Campus, Community Locations, and On-line}

Free psychological treatment offered through the Psychology Department at Utah State University to determine treatments for unwanted behaviors such as: cigarette smoking, pornography use, overeating, procrastination, substance use, gambling, risky sexual behavior, self-injury, and any other behavior you might do regularly that is causing problems for you in your life. You must be 18 years of age or older to participate. We are seeking individuals interested in changing unwanted behaviors by participating in 1-hour weekly sessions for 8 weeks. If you are a student, you will receive course credit for your participation indicated by your instructor. There is no cost or compensation for your participation. If you are interested or have questions, please contact Kate Morrison at(435) 797-8303 or kate.morrison@aggiemail.usu.edu.

\section{Newspaper Advertisement}

Free psychological treatment offered through the Psychology Department at Utah State University to determine treatments for unwanted behaviors such as: cigarette smoking, pornography use, overeating, procrastination, substance use, gambling, risky sexual behavior, self-injury, and any other behavior you might do regularly that is causing problems for you in your life. You must be 18 years of age or older to participate. For more information, please contact Kate Morrison at (435) 797-8303 or kate.morrison@aggiemail.usu.edu. 
Appendix B

Measures 


\section{Phone Screen}

Phone Screen ID:

Date of Contact:

Person completing phone screen:

Name:

Primary Phone:

(ok to LVM? No/Yes)

Alternative Phone:

(ok to LVM? No/Yes)

Email:

(ok to email? No/Yes)

Contact Tracking:

\begin{tabular}{|l|l|l|l|}
\hline Date & Contact & LVM? & Initials \\
\hline & & & \\
\hline & & & \\
\hline & & & \\
\hline & & & \\
\hline & & & \\
\hline & & & \\
\hline
\end{tabular}

1. Age (must be over 18):

2. Where do you live?

3. What problematic, reoccurring behavior(s) do you engage in?

4. Are you seeking treatment to change this behavior? $\quad 1=$ No $2=$ Yes

5. Does it have an impact on your life currently? $1=$ No $2=$ Yes

6. Are you currently on any psychotropic medication? $\quad 1=$ No $2=$ Yes

a. Name of medication(s):

b. When did you start taking this medication (need to be stable for at least 30 days)? 
c. Do you plan on changing dosage or medication? $1=$ No $\quad 2=$ Yes

3=Other:

7. Are you currently receiving therapeutic or counseling services? $\quad 1=$ No $2=$ Yes

a. Type of services:

b. When did you begin and/or end treatment (need to have stopped for at least 30 days)?

c. Do you plan on beginning therapy (outside of this study)? $1=\mathrm{No} \quad 2=\mathrm{Yes}$ 3=Other:

8. Fluent in English? $\quad 1=$ No $\quad 2=$ Yes

\section{If eligible:}

Thank you for your time. It seems like this study is a good fit for you. I would like to schedule you to come in for your first 1 hour initial intake.

Date \& Time:

Assessor:

Reminder contact desired?:

What format?: $\quad$ Email Primary Phone Alt. Phone

\section{If ineligible:}

Unfortunately you are not eligible to participate in this study. Would you like any referrals at this time? Thank you for your time.

Reason for ineligibility: 


\section{Background Information}

I would like to ask you a few questions about yourself. This information will assist with this study. Please answer all the questions as completely as possible.

1. What is your sex?

2. What is your marital status?

3. What is your age?

4. What is your ethnicity/race?

1=Female
1=Single
2=Married/Civil Union
$3=$ Divorced
4=Separated

1=African American

$2=$ Asian American

$3=$ Caucasian

4=Latino/a

$5=$ Native American

$6=$ other
$2=$ Male

$5=$ Remarried

$6=$ Widowed

$7=$ Other:

5. What is your current employment status?

$1=$ Unemployed/not working

$2=$ Working part-time

$3=$ Working full-time (more than $30 \mathrm{hrs} / \mathrm{wk}$ )

$4=$ On disability

$5=$ Full-time student (working and not working)

$6=$ Retired

6. What was the last level of school you completed?

$$
\begin{aligned}
& \text { 1=Ph.D., M.D. (doctoral) } \\
& 2=\text { M.A./M.S. or equivalent } \\
& 3=\text { Some graduate school } \\
& \text { 4=B.A./B.S. or equivalent } \\
& \text { 5=Associates Degree or equivalent } \\
& 6=\text { Some college } \\
& 7=\text { High school diploma or equivalent } \\
& 8=\text { Some high school }
\end{aligned}
$$

7. What is your current religious identification?

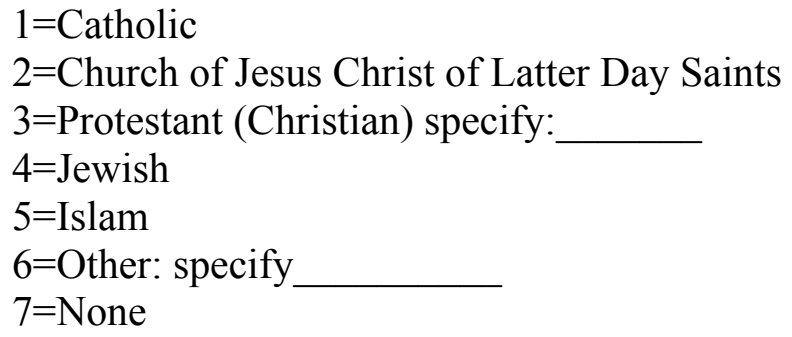


8. Current household income? $\quad 1=\$ 50,000$ or higher

$$
\begin{aligned}
& 2=\$ 40,001-50,000 \\
& 3=\$ 30,001-40,000 \\
& 4=\$ 20,001-30,000 \\
& 5=\$ 15,001-20,000 \\
& 6=\$ 10,001-15,000 \\
& 7=\$ 5,001-10,000 \\
& 8=\$ 5,000 \text { or less }
\end{aligned}
$$

9. Do you have any physical/medical complications that will interfere with your participation in 50 minute, weekly individual therapy sessions?

10. Have you ever received a mental health diagnosis? If yes, please list and note if this will interfere with your participation in 50 minute, weekly individual therapy sessions.

11. What behavior are you seeking treatment to change?

12. How long has this behavior been a problem for you?

13. Have you ever sought treatment or tried other procedures to reduce this behavior before?

$\begin{array}{ll} & 1=\text { No } \quad 2=\text { Yes } \\ \text { If yes, what did you try? } \quad 1=\text { Medication What kind? } \\ \quad \text { SSRI: } 1=\overline{\text { No } 2=\text { Yes }} \\ 3=\text { Talk therapy } \\ 4=\text { Other: }\end{array}$

14. Are you currently taking any psychotropic medications or have you been taking any in the past 30 days? If yes, please list with the date you started the most recent dosage. 


\section{Problem Behavior Severity Questionnaire}

I would like to ask you a few questions about the behavior for which you are seeking treatment.

1. What the current behavior (or group of behaviors) for which you are seeking treatment?

2. On average, how often does this behavior occur (please provide a number of times per hour, day, week, or month)?

3. On average, how much time do you spend on this behavior (please provide a number of minutes/hours per day, week, or month)?

4. Please circle, on average, how you rate the impact of this behavior on your life?

Not a

problem

at all

1

Neutral

Extreme

problem

4

5

6 


\section{Delay Discounting Task: Free Condition}

Participants will complete the following measure through an online questionnaire using a sliding bar to indicate their responses.

Instructions: Now you will tell us about your money preferences again. This time, I want you to imagine that if you chose the delayed money, you would be free to leave this room and go about your life as normal while waiting for the money to be automatically deposited into your bank account. If you chose the immediate money, it would be deposited in your bank account immediately after you made the choice. Your job is to use the slider tool to tell us how much money given to you right now would make you feel just as good as you would feel if you were to receive money after the waiting period. Although the scenarios are pretend, we ask that you consider each scenario as if it was real and as if it was the only scenario you would face today. You will now take a short quiz about these instructions.

1. If you decide to wait for the delayed money, what happens during the delay? (Select one)

a. I am free to leave the experiment, and can do whatever I want.

b. I must stay in this room, I have no access to any forms of entertainment, and cannot sleep while I wait.

2. If you decide to wait for the delayed money, how do you collect it when the delay is over? (Select one)

a. It is automatically deposited into my bank account, regardless of what I am doing.

b. It is automatically deposited into my bank account, provided I have stayed in this room for the entire delay.

3. If you decide to take the money now, what happens? (Check all that apply)

a. The money is deposited into my bank account 1 hour after I leave.

b. The money is immediately deposited to my bank account and is immediately available to spend.

c. I can leave and do whatever I want.

These three questions are repeated until answered correctly. 
Practice Question:

This question is an example of what you will be asked:

a. Receiving \$100 after 2 hours makes me feel JUST AS GOOD as receiving now:

b. You said that receiving now is just as good as having to wait 2 hours for $\$ 100$. Is this correct?

Actual Questionnaire:

1. Receiving $\$ 100$ after 5 minutes makes me feel JUST AS GOOD as receiving now:

2. Receiving $\$ 100$ after 10 minutes makes me feel JUST AS GOOD as receiving now:

3. Receiving $\$ 100$ after 30 minutes makes me feel JUST AS GOOD as receiving now:

4. Receiving $\$ 100$ after 1 hour makes me feel JUST AS GOOD as receiving now:

5. Receiving $\$ 100$ after 3 hours makes me feel JUST AS GOOD as receiving now:

6. Receiving $\$ 100$ after 6 hours makes me feel JUST AS GOOD as receiving now:

7. Receiving $\$ 100$ after 12 hours makes me feel JUST AS GOOD as receiving now:

8. Receiving $\$ 100$ after 24 hours makes me feel JUST AS GOOD as receiving now:

After questions a and 4-11 a slider bar ranging from $\$ 0$ to $\$ 100$ is available. The slider is located in the middle to begin the task. The approximate value of the location of the slider is displayed in the blank space in the question. 


\section{Delay Discounting Task: Wait Condition}

Participants completed the following measure through an online questionnaire using a sliding bar to indicate their responses.

Instructions: Now you will tell us about your money preferences again. This time, I want you to imagine that if you chose the delayed money, 1) you would have to wait in this room for the entire time specified in the question; 2) while you waited, except for trips to the bathroom, you would have to sit in this room, alone, without using the computer, 3) you would not be allowed to sleep; and 4) you could leave for 30 minutes at mealtimes. After the waiting period is over, the money would be automatically deposited into your bank account and you would be free to go. If you chose the immediate money, it would be deposited in your bank account immediately after you made the choice. Your job is to use the slider tool to tell us how much money given to you right now would make you feel just as good as you would feel if you were to receive money after the waiting period. Although the scenarios are pretend, we ask that you consider each scenario as if it was real and as if it was the only scenario you would face today. You will now take a short quiz about these instructions.

9. If you decide to wait for the delayed money, what happens during the delay? (Select one)

a. I am free to leave the experiment, and can do whatever I want.

b. I must stay in this room, I have no access to any forms of entertainment, and cannot sleep while I wait.

10. If you decide to wait for the delayed money, how do you collect it when the delay is over? (Select one)

a. It is automatically deposited into my bank account, regardless of what I am doing.

b. It is automatically deposited into my bank account, provided I have stayed in this room for the entire delay.

11. If you decide to take the money now, what happens? (Check all that apply) 
a. The money is deposited into my bank account 1 hour after I leave.

b. The money is immediately deposited to my bank account and is immediately available to spend.

c. I can leave and do whatever I want.

These three questions are repeated until answered correctly.

Practice Question:

This question is an example of what you will be asked:

a. Receiving \$100 after 2 hours makes me feel JUST AS GOOD as receiving now:

b. You said that receiving now is just as good as having to wait 2 hours for $\$ 100$. Is this correct?

Actual Questionnaire:

12. Receiving $\$ 100$ after 5 minutes makes me feel JUST AS GOOD as receiving now:

13. Receiving \$100 after 10 minutes makes me feel JUST AS GOOD as receiving now:

14. Receiving \$100 after 30 minutes makes me feel JUST AS GOOD as receiving now:

15. Receiving \$100 after 1 hour makes me feel JUST AS GOOD as receiving now:

16. Receiving \$100 after 3 hours makes me feel JUST AS GOOD as receiving now:

17. Receiving $\$ 100$ after 6 hours makes me feel JUST AS GOOD as receiving now:

18. Receiving \$100 after 12 hours makes me feel JUST AS GOOD as receiving now:

19. Receiving \$100 after 24 hours makes me feel JUST AS GOOD as receiving now:

After questions $a$ and $4-11$ a slider bar ranging from $\$ 0$ to $\$ 100$ is available. The slider is located in the middle to begin the task. The approximate value of the location of the slider is displayed in the blank space in the question. 
Appendix C

ACT Treatment Manual 
One Approach for Multiple Behaviors: Acceptance and Commitment Therapy

Kate L. Morrison

Utah State University

Adapted from:

Hayes, S. C., Strosahl, K. D., \& Wilson, K. G. (1999). Acceptance and Commitment Therapy: An Experiential Approach to Behavior Change ( $1^{\text {st }} \mathrm{ed}$.). The Guilford Press.

Hayes, S. C., Strosahl, K. D., \& Wilson, K. G. (2011). Acceptance and Commitment Therapy: The Process and Practice of Mindful Change (2 ${ }^{\text {nd }}$ ed.). Guilford Press.

Twohig, M. P. (2004). ACT for OCD: Abbreviated Treatment Manual

This manual is for 8 individual sessions of Acceptance and Commitment Therapy (ACT) for adults with an intolerance of delays that lead to problem behaviors (e.g., substance use, procrastination, overeating, problematic pornography use, problematic gambling). Prior to treatment, clients were assessed on their level of delay discounting (a measure of impulsivity and tendency to choose smaller, immediate rewards over larger, delayed rewards) and overall well-being. Those that were more impulsive, had lower levels of well-being, had a specific behavior s/he desired to change through treatment, and were self-referred were chosen to begin therapy.

\section{Therapist Training:}

At a minimum level the therapist should have read a comprehensive book on ACT (e.g., Hayes, Strosahl, \& Wilson, 2011) and be familiar with the particular philosophy underlying ACT - functional contextualism. It would be in the therapist's best interest to attend an experiential ACT workshop. These are offered many times per year.

Information on these workshops is available at contextualscience.org. Given that this manual is designed to be applied across a variety of behaviors, it is recommended even more than usual to have a strong understanding of the philosophy and theories underlying ACT. The therapist needs to be able to apply techniques in an accurate way based on what the client shares in session.

\section{The Basics of ACT:}

ACT is a form of therapy that strives to help individuals engage in behaviors that fit with how they want to be as a person. Often people have behaviors that they want to change, but thoughts, emotions, and bodily sensations can persuade them to behave differently. ACT works to reduce the impact of these internal experiences (thoughts, emotions, and bodily sensations) in order to help people behave differently. Put simply, ACT helps people make decisions based on what is important to them (their values) 
rather than what feels better in that moment.

\section{The Basics of an ACT Therapist:} 2011)

Recommended Readings: Chapters 1, 2, 3, \& 5 (Hayes, Strosahl, \& Wilson,

When implementing ACT, it is important to allow individuals to be a neutral figure and to guide the decision making process of the individual based on what works best for that person. ACT is an experiential treatment. Thus, the use of exercises, metaphors, and examples are often used to help the client arrive at his/her own decisions. Explaining, telling, and giving rules does not meet the goals of ACT. ACT providers understand that all humans can get trapped into following their own internal experiences. The providers take an equal stance with the people receiving services. The client is not broken and does not need to be fixed.

Attending an experiential workshop, viewing ACT sessions, and/or receiving supervision from an ACT therapist are recommended in order to see the way ACT is implemented. One can deliver all the exercises and metaphors as written in the book, but not be doing ACT. The behavioral theories (Relational Frame Theory and rule-governed behavior) that underlie ACT techniques recommend against rote, "one size fits all" exercises, metaphors, and techniques.

At the core of an ACT therapeutic strategy is the assumption that that there is nothing wrong with the client. The client is not broken and coming into the therapist to be fixed. The therapist must remember that the client is part of the same verbal community as the therapist and struggles with the same attempts to control emotions. If the therapist can feel that the client is struggling, and share in that struggle, then the therapist will be more effective. The therapist can understand wanting to change a behavior, but struggling to do so because of a variety of emotions, thoughts, and urges that get in the way.

Bringing this awareness and empathy into the room is in the service of helping the client and will increase your effectiveness as an ACT therapist.

As with all manualized treatments, there is a need for flexibility when following the guidelines set below. What you will find below is a summary of the order in which processes were addressed and examples of how they were addressed. Ultimately, a thorough assessment of where your client falls on each of the six ACT processes will determine the focus of treatment. It is recommended to stay with the general pattern of this manual as that was how it was tested, but the amount of time covering each process and how it is done will depend on the client and his/her needs. Assessment tools like the ACT ADVISOR (found at contextualscience.org) can help determine the needs of the client. 


\section{Session 1:}

Outline:

\begin{tabular}{|l|l|}
\hline Introduction & $\begin{array}{l}\text { Explanation of the course of treatment/study and } \\
\text { assessments }\end{array}$ \\
\hline Limits to Confidentiality & $\begin{array}{l}\text { Suicide, homicide, and abuse of children or disabled } \\
\text { adults (based on ethical guidelines for your } \\
\text { profession/region) }\end{array}$ \\
\hline Informed Consent & $\begin{array}{l}\text { Warning that therapy may result in emotional } \\
\text { discomfort }\end{array}$ \\
\hline Gather Information & $\begin{array}{l}\text { Gain information about the client, history of presenting } \\
\text { problem, and contextual variables }\end{array}$ \\
\hline $\begin{array}{l}\text { Contact with Present } \\
\text { Moment }\end{array}$ & $\begin{array}{l}\text { Help the client be aware and present with their inner } \\
\text { experiences using exercises like Leaves on a Stream and } \\
\text { body scans }\end{array}$ \\
\hline
\end{tabular}

Recommended Readings: Chapters 4 and 7 (Hayes, Strosahl, \& Wilson, 2011)

\section{Introduction}

Make sure the client understands what he or she has agreed to participate in. The participant will be attending eight sessions of therapy. The sessions will occur every week, generally at the same time on the same day. The client is expected to attend all sessions and to contact the therapist if he or she cannot attend. Make sure that you have the client's phone number(s) and email so you can reschedule in case the client does not attend the session. At the end of these eight sessions the client will be expected to attend a posttreatment assessment. Allow the participant to ask you questions concerning the study.

\section{Discuss limits to confidentiality}

Explain that everything that occurs in session will remain confidential. The only exceptions to this are that selected individuals will watch a selected number of the videotapes and score them for treatment integrity. In addition, confidentiality must be broken according to the ethical codes of the American Psychological Association (or the relevant ethical code for your region). This includes: if the client reports plans of harming themselves or others, or reports harming a child or the elderly.

\section{Getting participant on board}

Informed Consent. Any attempt to change behavior is going to be psychologically difficult. The client likely has fears, dread, or concerns about contacting his/her internal experiences and may have some reservations about beginning treatment. To keep from scaring the client away from the treatment and to help the therapeutic relationship, the client should be made aware of what treatment involves. This can be 
difficult because ACT is an experiential therapy. Therefore the following description might be useful.

Therapist: I believe in letting clients know what will happen in therapy. I see two ways to go. The approach we are going to use can be demanding and confusing. I can't fully describe this approach to you because to some degree explaining the therapy happens in the course of this therapy. It is focused on changing things that are changeable and to learn how to experience the things you can't change in a different way. It is not an approach to be entered into lightly, but it has been helpful for some people with problems like yours. My experience with this approach is that it can put you on a bit of a roller coaster. All kinds of different emotions might emerge: interest, boredom, anxiety, sadness, anger, clarity, confusion, and so on. It is like cleaning out a dirty glass with sludge in the bottom: the only way to do it is to stir up the dirt. So some stuff might get stirred up, and for a while, things may look worse before they look better. It is not that it is overwhelming - it is just that you should be prepared to let show up whatever comes up.

Commitment to a Course. Changing behavior, for some, can be difficult and frightening. Also, in some cases, the outcomes of ACT are not seen until later in the treatment. Therefore, the client should be warned of this and agree to participate in the entire treatment and not to judge the treatment impulsively.

Therapist: I do want to warn you that there will likely be times in therapy where it feels like things are getting worse rather than better. This is a very normal process. All I ask, is that when that time arrives, when you don't feel like coming to session, just tell me. We will work through it. Sometimes you might feel like quitting therapy all together. This will likely happen in the times where it feels like we are working backwards more than forwards. I don't recommend judging how well this is going on a week to week basis though. If we could make changes that fast, we wouldn't be meeting for 8 sessions. This is a long process, so allow yourself time to change. One of the reasons that I find this important, is that if you do not really engage in these 8 sessions you will not really know whether this treatment is useful or not. So I would like for us to try our hardest for these 8 sessions and really see if this treatment works for you, but let's not decide that until we are all done.

Alliance Building. In addition to providing and gathering the necessary information during these sessions, the therapist should also work to be warm, empathetic, and accepting. It is important that the client and therapist have a sense of mutual trust and respect before beginning work from an acceptance and commitment perspective.

Therapist: Of course, I haven't had the same exact experiences as you, but to the extent possible, it will help me in providing your treatment if I can get a sense of your struggle from the inside - to get a sense of how the world is from inside your skin. 
Now, I'm not going to pretend that I know all of the ins and outs of the specific things you struggle with; we don't share that experience. What we do share, though, is more fundamental. We're both humans, and as humans, we have access to the human struggle. My expertise is in helping people to move forward who have gotten stuck, and who have tried a lot of things to get unstuck. Your job will be to be the expert on your difficulties. My job will be to see how our approach applies to the particulars of your difficulties.

\section{Two Mountains Metaphor}

It's like you're in the process of climbing up a big mountain that has lots of dangerous places on it. My job is to watch out for you and shout out directions if I can see places you might slip or hurt yourself. But I'm not able to do this because I'm standing at the top of your mountain, looking down at you. If I'm able to help you climb your mountain, it's because I'm on my own mountain, just across a valley. I don't have to know anything about exactly what it feels like to climb your mountain to see where you are about to step, and what might be a better path for you to take.

\section{Assessment of Target Behavior and Its Context}

The function of the general assessment is to get a sense of what the client's behavior and struggle with the behavior is like. The manual will fit no matter what the client's particular internal experiences and behaviors are, but this part of therapy is crucial to be able to apply ACT techniques in a flexible manner. An understanding of the function of the behaviors is needed before moving forward. The main pieces of information you want to know after this assessment are: an operational definition of the target behavior, the contexts that tend to precede the behavior (internal or external), and the effect of the behavior (the ABCs). The purpose of this session is for you and the client to both have a clear understanding of the treatment target and the barriers to change that are present.

- $\quad$ Ask the client to describe their target behavior(s).

- Ask how long this behavior has been a problem?

- What other strategies has the client tried?

- What are the situations when they do the behavior the most often?

- Are there thoughts, feelings, or urges that tend to come up before doing the behavior?

- What happens to those internal experiences after doing the behavior?

- Any relevant history information can also be gathered at this time. 
Clients may struggle to explain their target behavior and the surrounding context in the detail that is necessary for a complete understanding for treatment. Thus, this session includes aspects of mindfulness or present moment exercises. These can be done explicitly or can be used mixed in with the description of the presenting concerns.

Awareness of bodily sensations: The therapist guides an eyes closed body scan exercise, where the client brings awareness to his/her body and the sensations that are present in it (starting at the toes and slowly bringing attention to the remainder of the body up to the top of the skull). This can be used to directly describe the urges that precede the target behavior in session or simply be used as practice for out of session awareness.

Awareness of thoughts and emotions: The therapist can guide an eyes closed exercise where the client watches his/her thoughts or emotions as objects passing by (without attaching meaning or values to them). Examples of the objects could be members of a parade holding signs that state the emotion or thought, clouds that contain the same content (especially useful to indicate a lack of control of the flow of the thoughts/emotions), leaves on a stream, words on a TV/computer screen, or some other item that is relevant to the client.

The amount of time spent increasing the client's awareness to internal and external cues to the behavior is dependent upon the amount of awareness the client brings to the session. If the client is fully present and can clearly articulate the antecedents and consequences to the behavior, then less time is needed for mindfulness skills.

Homework: The client will practice bringing awareness to specific aspects of his/her target behavior that was deemed to need more practice from in session exercises.

\section{Session 2:}

\begin{tabular}{|l|l|}
\hline $\begin{array}{l}\text { Acceptance } \\
\text { (Willingness) }\end{array}$ & $\begin{array}{l}\text { Identify the distinction between behavior and urges to engage in } \\
\text { behavior }\end{array}$ \\
\cline { 2 - 3 } & Short-term vs. long-term effectiveness of attempts to control urges \\
\cline { 2 - 3 } & Identify the negative impact of attempts to control urges \\
\cline { 2 - 2 } & $\begin{array}{l}\text { Highlight paradoxical nature of attempts to control urges using the } \\
\text { Man in the Hole metaphor }\end{array}$ \\
\cline { 2 - 2 } & $\begin{array}{l}\text { Identify attempts to control urges as part of the problem using the } \\
\text { Polygraph, Chocolate Cake, and What are the Numbers? Exercises }\end{array}$ \\
\cline { 2 - 2 } & $\begin{array}{l}\text { Introduce acceptance as an alternative to control using the Two } \\
\text { Scales metaphor }\end{array}$ \\
\hline & Encourage acceptance of any problematic inner experiences \\
\hline
\end{tabular}

Recommended Readings: Chapters 6 and 10 (Hayes, Strosahl, \& Wilson, 2011)

Review Homework: Check on the client's awareness of the internal and external 
experiences specific to the target behavior and address any issues the client had with increasing awareness.

\section{Session Review}

This session covers several aspects of ACT. This is a crucial session to allow the client to come to his/her own conclusions and to not provide rules to follow. This session sets the tone for the remainder of therapy. Therapists often struggle with this session because it feels uncomfortable to allow the client to be confused and struggling. This needs to happen for the client to form a direct relationship with his/her experiences.

The session begins with a discussion (or recap) of the internal stimuli that influence the target behavior. This recap can reinforce the idea that internal stimuli and external behaviors are distinct. An example of this:

Therapist: Last week, we talked about two separate pieces of your experience when it comes to smoking. The one piece is what happens inside your skin: the thoughts about going crazy if you don't have a cigarette, the way your body feels when urges to smoke are there, and how you feel irritable if you haven't smoked. Then there is the second piece of what you do with your body, the stuff outside your skin. What we talked about before was that sometimes you choose to smoke a cigarette, sometimes you go for a walk, avoid friends that smoke, sometimes you use a nicotine patch/gum, sometimes you snap at your kids, and sometimes you drink. We're going to dig a little deeper into understanding these two separate pieces and how well they work together.

\section{Effectiveness of Control Strategies}

Therapist: I'm interested in knowing what happens to all of that stuff inside your skin when you do these behaviors.

At this point, the therapist and client can make a list (or do it mentally if the list is short enough) of all of the behaviors the client does when faced with internal experiences to do the target behavior. After an extensive list is created (it is recommended to be prepared with behaviors discussed in the previous session to help this task go faster and to avoid repetition), talk about and write down the short term and long term effectiveness of each behavior. What we mean by effectiveness is "did the behavior stop the unwanted feeling, thought, or sensation?" Make sure the client understands this before starting the task. What will likely result is a list of behaviors that reduce or remove the unwanted internal experience in the short-term, but then the experiences return or become worse in the long-term. There will sometimes be strategies that are more effective than the others and have longer impacts. It is important to not judge or push the client to certain beliefs, but to take an exploratory stance with the client to determine the most effective way for them to move through their lives. The main question you and client are looking to answer with this activity is "Are the behaviors the client is doing making their internal 
experiences better, the same, or worse?" Ultimately you are looking for methods that work long-term. Most methods clients attempt help them feel better in the moment, but impact them poorly in the long run, and is generally the reason they are seeking treatment.

The therapist needs to be careful in this phase not to make the client feel as though the therapist is blaming him or her for what he or she has been doing. The therapist should help the client see that this is what most humans do with private events that are uncomfortable.

Make sure not to blame the client. You are on the client's side and trying to figure out what works to decrease the internal experiences. Do not try and talk the client into this, let the client's experience tell him or her that these methods are or are not effective.

\section{Effects of Control Agenda}

The main goal of this section of treatment is to help the client become aware that the control strategies/behaviors are not working in the long run (usually), that there is significant effort put toward changing an unchangeable object, and that attempts to change the unchangeable objects is actually making the internal experiences worse and having a negative impact on quality of life. This can be hinted at in the previous exercise with comments and observations like:

Hmm, you're working pretty hard to get rid of these feelings.

A lot of your day is spent working on this.

Do you have the energy to keep up with all of this each day?

Do you feel like you are getting the results you are looking for?

I'm starting to see a pattern here. These really help for a little while and seem to be causing problems in the long run.

It's almost like the issue is that these things won't change, even though you are trying really hard to make them.

A more explicit exercise can be used after the previous exercise is complete. An example of this is the Person in the Hole Metaphor. Although this metaphor is written out like a speech, do not implement it in that way. Walk the client through the metaphor being sure to allow him/her to interact with the metaphor and its content. This will ensure that the metaphor fits the client's experience and can clarify misunderstandings along the way:

Imagine that you're placed in a field, wearing a blindfold, and you're given a little bag of tools. You're told that your job is to run around this field, blindfolded, and live your life. So you start running around and sooner or later you fall into this big 
hole. Now one tendency you might have would be to try and figure out how you got in the hole--exactly what path you followed. You might tell yourself, "I went to the left, and over a little hill, and then I feel in," etc. In one sense, that may be true; you are in the hole because you walked exactly that way. However, knowing that is not the solution to knowing how to get out of the hole. Furthermore, even if you had not done exactly that, and you'd gone somewhere else instead, in this metaphor, you might have fallen into another hole anyway, because unbeknownst to you, in this field there are countless widely-spaced, fairly deep holes. Anyway, so now you're in this hole, blindfolded. Probably what you would do in such a predicament is take the bag of tools you were given and try to get out of the hole. Now just suppose that the tool you've been given is a shovel. So you dutifully start digging, but pretty soon you notice that you're not out of the hole. So you try digging faster, or with bigger shovelfuls, or with a different style. More, different, and better. More, different, and better. But all of that makes no difference, because digging is not the way out of the hole; it only makes the hole bigger. Pretty soon this hole is huge. It has multiple rooms, halls, and caverns. It is more and more elaborated. So maybe you stop for a while and try to put up with it. But it doesn't work -- you are still in the hole. This is like what has happened with your anxiety. It is bigger and bigger. It has become a central focus of your life. You know all this hasn't worked. But what I'm saying is that it can't work. You absolutely can't dig your way out of the hole. It's hopeless. That's not to say that there is no way out of the hole. But within the system in which you have been working--no matter how much motivation you have, or how hard you dig--there is no way out. This is not a trick. No fooling. You know that sense you have that you are stuck? And that you came here to get help to fix it? Well, you are stuck. And in the system in which you are working, there is no way out. The things you've been taught to do aren't working although they may work perfectly well somewhere else. The problem is not in the tools; it's in the situation in which you find yourself using them. So you come in here wanting a gold-plated steam shovel from me. Well, I can't give it to you and even if I could I wouldn't because that's not going to solve your problem. It'd only make it worse." If client asks for the way out of the hole, say something like "your job right now is not to figure out how to get out of the hole. That is what you have been doing right along. Your job is to accept that you are in one. In the position you are in right now, even if you were given other things to do, it wouldn't work. The problem is not the tool -- it is the agenda. It is digging. If you were given a ladder right now it wouldn't do any good. You'd only try to dig with it. And ladders make terrible shovels. If you need to dig, you've got a perfectly good tool already. You can't do anything else until you let go of the shovel and let go of digging as the agenda. You need to make room for something else in your hands. And that is a very difficult and bold thing to do. The shovel appears to be the only tool you have. Letting go of it looks as though it will doom you to stay in the hole forever. And I can't really reassure you on that. Nothing I can say right now would help ease the difficulty of what you have to do here. Your best ally is your own pain, and the knowledge that 
nothing has worked. Have you suffered enough? Are you ready to give up and do something else?

or

I want you to look around the room. Can you find anything in this room that was not created by the human mind? Our minds are wonderful tools when we need to fix things. If we need food, we go eat. If we have a flat tire, we figure out how to get a new one and put it on the car. If our hair is too long, we get it cut. This is how $95 \%$ of our world functions: if you have a problem, fix it. And that works for the most part. So let's talk about that other 5\%. That is the stuff that happens inside of us: thoughts, emotions, bodily sensations. Our minds attempt to use the same strategy of "fix it" that it uses for the $95 \%$ on the $5 \%$. However, let's see how well that works. I'm going to give you a scenario where I want you to imagine fixing, controlling, or stopping anxiety or nervousness. Let's imagine that you are asked to sing the national anthem at a professional baseball game that is being televised and will be broadcast all over the country. I'm going to hook you up to a machine that can detect any sort of distress. Now, I will give you $\$ 1000$ to sing the National Anthem, but you cannot feel any distress or really have any sort of thought about being distressed. Could you do that? Why (or why not)? It's a $\$ 1000$ ! If you really want that $\$ 1000$, why couldn't you control your feeling of being nervous? Yeah, so maybe the same control and "fix it" strategy our minds use for the $95 \%$ of our world that is external doesn't work for the $5 \%$ of the internal world. And oddly enough, it seems like your distress would actually go up when you tell it to not be there! Isn't that weird! The second you say "go away!" it actually shows up more than if you say "come on in."

The majority of the session focuses on the concepts of creative hopelessness and control as the problem. The therapist should not move on before the client sees and feels the uselessness and paradoxical effects of the control agenda. Often times the client will slip back into his or her control agenda throughout treatment and the therapist will need to help the client check out the function of his or her behavior.

Clinical judgment is necessary to determine when the focus of the session can turn to willingness (acceptance). It is recommended to avoid stating the word "acceptance" in session as clients tend to have a different meaning for acceptance than we do. Using the word "willingness" will save you time trying to disengage what the client's history has applied to the word "acceptance." The main concept you are working on in this section of session 2 is to help the client see that an open stance toward difficult internal experiences might be less exhausting and will allow for flexibility in their actions. An example of how to do this is:

Let's try an exercise where we can see the difference between saying "go away" 
to those thoughts versus saying "come on in." I have notecards here, one for you and one for me. We'll each write a thought on here that we usually like to push away. Mine is (the trainer should use an impulsive example as well). What is yours? Now I'm going to have you resist this thought as much as you can (Place your hand on one side of the card and the person's hand on the other side. Then begin pushing). Now don't let this thought touch your body. It is very important. Don't let it get near you! How are you feeling right now, pushing against this thought? What does your body feel like? Ok, now I want you to allow this card to sit on your lap (Set card on the person's lap). Just allow it to sit with you. No pushing, no fighting. Just welcome it to sit there and be with you. What is this like for you? How does your body feel right now? The thought is close and it is touching you. And oddly enough, when you were pushing against it and fighting it. The card was still touching your hand. So in both scenarios, the card/thought was touching you. What was different about these scenarios if the thought was touching you in both? How would you prefer to live your life? Fighting the thought of (insert internal experience from beginning) and having it touch you or welcoming it and still having it touch you? Can you imagine what that would look like in your life? Is there a way to compassionately welcome all the thoughts and feelings that show up for you throughout the day? One way that we can try this is to put this card in a pocket or a purse and carry it with us all day. I'm going to put mine in my pocket. If you're willing, you can do the same. We can choose to bring it along with us. Because, really, we both know that thought is going to be there whether we want it to or not. So how about we try another way of interacting with it. We can't get rid of it. Let's try bringing it in close and gently carrying it throughout the day. What do you think?

Imagine there are two scales, like the volume and balance knobs on a stereo. One is right out here in front of us and it is called "Anxiety" [Use labels that fit the client's situation, if anxiety does not, such as "Anger, guilt, disturbing thoughts, worry," etc. It may also help to move ones hand as if it is moving up and down a numerical scale]. It can go from 0 to 10 . In the posture you're in, what brought you in here, was this: "This anxiety is too high." It's way up here and I want it down here and I want you, the therapist, to help me do that, please. In other words you have been trying to pull the pointer down on this scale [the therapist can use the other hand to pull down unsuccessfully on the anxiety hand]. But now there's also another scale. It's been hidden. It is hard to see. This other scale can also go from 0 to 10. [move the other hand up and down behind your head so you can't see it] What we have been doing is gradually preparing the way so that we can see this other scale. We've been bringing it around to look at it. [move the other hand 
around in front] It is really the more important of the two, because it is this one that makes the difference and it is the only one that you can control. This second scale is called "Willingness." It refers to how open you are to experiencing your own experience when you experience it--without trying to manipulate it, avoid it, escape it, change it, and so on. When Anxiety [or discomfort, depression, unpleasant memories, etc.--use a name that fits the client's struggle] is up here at 10 , and you're trying hard to control this anxiety, make it go down, make it go away, then you're unwilling to feel this anxiety. In other words, the Willingness scale is down at 0 . But that is a terrible combination. It's like a ratchet or something. You know how a ratchet wrench works? When you have a ratchet set one way no matter how you turn the handle on the wrench it can only tighten the bolt. It's like that. When anxiety is high and willingness is low, the ratchet is in and anxiety can't go down. That's because if you are really, really unwilling to have anxiety then anxiety is something to be anxious about. It's as if when anxiety is high, and willingness drops down, the anxiety kind of locks into place. You turn the ratchet and no matter what you do with that tool, it drives it in tighter. So, what we need to do in this therapy is shift our focus from the anxiety scale to the willingness scale. You've been trying to control Mr. Anxiety for a long time, and it just doesn't work. It's not that you weren't clever enough; it simply doesn't work. Instead of doing that, we will turn our focus to the willingness scale. Unlike the anxiety scale, which you can't move around at will, the willingness scale is something you can set anywhere. It is not a reaction--not a feeling or a thought--it is a choice. You've had it set low. You came in here with it set low--in fact coming in here at all may initially have been a reflection of its low setting. What we need to do is get it set high. If you do this, if you set willingness high, I can guarantee you what will happen to anxiety. I'll tell you exactly what will happen and you can hold me to this as a solemn promise. If you stop trying to control anxiety, your anxiety will be low ....[pause] or ... it will be high. I promise you! Swear. Hold me to it. And when it is low, it will be low, until it's not low and then it will be high. And when it is high it will be high until it isn't high anymore. Then it will be low again. ... I'm not teasing you. There just aren't good words for what it is like to have the willingness scale set high--these strange words are as close as I can get. I can say one thing for sure, though, and your experience says the same thing--if you want to know for sure where the anxiety scale will be, then there is something you can do. Just set willingness very, very low and sooner or later when anxiety starts up the ratchet will lock in and you will have plenty of anxiety. It will be very predictable. All in the name of getting it low. If you move the willingness scale up, then anxiety is free to move. Sometimes it will be low, and sometimes it will be high, and in both cases you will keep out of a useless and traumatic struggle that can only lead in one direction.

Homework: At the end of session, the client may not be completely on board with using increasing willingness. This is okay. The homework is designed for the client to try it out and report back on what worked and what didn't. Set a specific behavioral commitment with the client (a specific measureable goal) that is related to the target behavior. Choose 
a small obtainable goal (e.g., smoke one less cigarette a day) that you and the client are confident that $\mathrm{s} /$ he can succeed and that it will bring up enough distress that the client can practice both avoidance/suppression and willingness. Have the client attend to the effects of both strategies and ask them to be prepared to discuss them the following session.

Session 3:

\begin{tabular}{|l|l|}
\hline Values & \begin{tabular}{l} 
Discuss what could be gained by letting go of the control agenda \\
\cline { 2 - 2 }
\end{tabular} \\
\cline { 2 - 2 } & $\begin{array}{l}\text { Define the concept of values } \\
\text { Clarify the client's values and assess the consistency of the his/her } \\
\text { behavior with those values }\end{array}$ \\
\hline
\end{tabular}

Recommended Readings: Chapter 11 (Hayes, Strosahl, \& Wilson, 2011)

Review Homework: Check in on the client's behavioral commitments and discuss the effectiveness of avoidance/suppression and willingness. Use this as an opportunity to refresh content from the previous session and to begin the discussion of values. A few examples of how to transition into talking about values are below:

So you mentioned that willingness was pretty difficult, we will keep practicing this and finding ways that might help with that. For now, I would like us to shift our focus to a discussion about why it might be worthwhile to go through all of this distress.

It sounds like willingness worked well for you. You felt a little like you were just gritting your teeth through it and were wondering why you are bothering to do this. Well let's talk about that today.

It definitely seems easier in the moment to just avoid or try to push away those feelings. From what I know about you, you didn't come to therapy looking for ways to make those brief moments better, you wanted a way to live your life better. I'm here to help you build a vital life that is not determined by those moments of distress.

\section{Defining and Clarifying Values}

The main goal of this session is to provide meaning and guidance for behaviors when the client has arrived at a point where internal experiences are no longer guiding those behaviors. Help the client understand the distinction between values and goals. Values are the motivation to accept internal experiences in the short term. It provides a context in which people are more likely to live in the way they want their life to be instead of making decisions based on immediate consequences. 
Let's talk a bit about how you would like to live your life. I'd like to go through some examples of the type of person you want to be. What is it about (use target behavior) that is important to you? Usually within our pain we find what is important to us and what is important to us, we find pain. You experience distress when deciding whether to (e.g., study, work, exercise, eat healthy). The fact that distress comes along with that decision means there's something important in there. Let's talk about what that is.

I like to call these "values." These are long term ways of being. It is like traveling west. You never reach west. You can always go more west from wherever you are. We can set "goals" each week that can help you go westward and you can stay on track with your values though.

The following are areas of life that are valued by some people. Not everyone has the same values and this worksheet is not a test to see if you have the "correct" values. Describe your values as if no one would ever read this worksheet. As you work, think about each area in terms of both concrete goals you might have, and also in terms of more general life directions. So, for instance, you might value getting married as a concrete goal and being a loving spouse as a valued direction. The first example, getting married is something that could be completed. The second example--being a loving spouse--does not have an end. You could always be more loving, no matter how loving you already were. Work through each of the life domains. Some of the domains overlap. You may have trouble keeping family separate from marriage/intimate relations. Do your best to keep them separate. I will provide assistance when you discuss this goals and values assessment. Clearly number each section, and keep them separate from one another. You may not have any valued goals in certain areas. You may skip those areas. It is also important that you write down what you would value if there were nothing in your way. We are not asking what you think you could realistically get, or what you or others think you deserve. We want to know what you care about, what you would want to work towards, in the best of all situations. While doing the worksheet, pretend that magic happened and that anything is possible.

1. Marriage/couples/intimate relations. In this section, write down a description of the person you would like to be in an intimate relationship. Write down the type of relationship you would want to have. Try to focus on your role in that relationship.

2. Family relations. In this section, describe the type of brother/sister, son/daughter, father/mother you want to be. Describe the qualities you would want to have in those relationships. Describe how you would treat these people if you were the ideal you in these various relationships.

3. Friendships/social relations. In this section, write down what it means to you to be a good friend. If you were able to be the best friend possible, how would you behave toward your friends? Try to describe an ideal friendship. 
4. Career/Employment. In this section, describe what type of work you would like to do. This can be very specific or very general. (Remember, this is in an ideal world.) After writing about the type of work you would like to do, write about why it appeals to you. Next, discuss what kind of worker you would like to be with respect to your employer and coworkers. What would you want your work relations to be like?

5. Education/Personal Growth \& Development. If you would like to pursue an education, formally or informally, or to pursue some specialized training, write about that. Write about why this sort of training or education appeals to you.

6. Recreation/Leisure. Discuss the type of recreational life you would like to have, including hobbies, sports and leisure activities.

7. Spirituality. We are not necessarily referring to organized religion in this section. What we mean by spirituality is whatever that means to you. This might be as simple as communing with nature, or as formal as participation in an organized religious group. Whatever spirituality means to you is fine. If this an important area of life, write about what you would want it to be. As with all of the other areas, if this is not an important part of your values, skip to the next section.

8. Citizenship. For some people, participating in community affairs is an important part of life. For instance, some people feel that it is important to volunteer with the homeless or elderly, lobby governmental policy makers at the federal, state, or local level, participate as a member of a group committed to conserving wildlife, or to participate in the service structure of a self-help group, such as Alcoholics Anonymous. If these sort of community oriented activities are important to you, write about what direction you would like to take in these areas. Write about what appeals to you about this area.

9. Health/Physical well-being. In this section, include your values related to maintaining your physical well-being. Write about health related issues such as sleep, diet, exercise, smoking, and so forth 


\begin{tabular}{|c|c|}
\hline \multicolumn{2}{|c|}{ Values Narrative Form } \\
\hline \multicolumn{2}{|c|}{$\begin{array}{l}\text { For Therapist: Generate a brief narrative for each row, based upon discussion of the } \\
\text { client's values assessment homework. If none is applicable, put "none." After generating } \\
\text { all narratives, read each to the client and refine. Continue this process, simultaneously } \\
\text { watching out for pliance-type answers, until you and the client arrive at a brief statement } \\
\text { that the client agrees is consistent with their values in a given domain. }\end{array}$} \\
\hline Domain & Valued Direction Narrative \\
\hline $\begin{array}{c}\text { Couples/Intimat } \\
\text { Relationships }\end{array}$ & \\
\hline Family Relations & \\
\hline Social Relations & \\
\hline Employment & \\
\hline $\begin{array}{c}\text { Education and } \\
\text { Training }\end{array}$ & \\
\hline Recreation & \\
\hline Spirituality & \\
\hline Citizenship & \\
\hline
\end{tabular}

\begin{tabular}{|c|c|c|c|c|}
\hline \multicolumn{5}{|c|}{$\begin{array}{l}\text { Read and then rate each of the values narratives generated by you and your therapist. } \\
\text { Rate how important this value is to you, on a scale of } 1 \text { (high importance) to } 10 \text { (low } \\
\text { importance). Rate how successfully you have lived this value during the past month on a } \\
\text { scale of } 1 \text { (very successfully) to } 10 \text { (not at all successfully). Finally rank these value } \\
\text { narratives in order of the importance you place on working on them right now, with } 1 \\
\text { being the highest rank, } 2 \text { the next highest, and so on. }\end{array}$} \\
\hline & & Rati & or & ank \\
\hline Domain & Valued Direction Narrative & 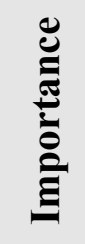 & 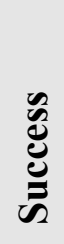 & 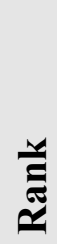 \\
\hline \multicolumn{5}{|c|}{$\begin{array}{c}\text { Couples/Intimate } \\
\text { Relationships }\end{array}$} \\
\hline \multicolumn{5}{|c|}{ Family Relations } \\
\hline \multicolumn{5}{|c|}{ Social Relations } \\
\hline \multicolumn{5}{|l|}{ Employment } \\
\hline \multicolumn{5}{|l|}{$\begin{array}{c}\text { Education and } \\
\text { Training }\end{array}$} \\
\hline \multicolumn{5}{|l|}{ Recreation } \\
\hline \multicolumn{5}{|l|}{ Spirituality } \\
\hline Citizenship & & & & \\
\hline
\end{tabular}


I imagine decision making like a fork in the road. In each decision we make, one of the forks takes us closer to the person we want to be and the other takes us further away from the person we want to be. Sometimes when we choose what feels best in the moment, it isn't what is best for us in the long run. Is your experience similar to this?

When we think about doing (insert goal), what comes up in your mind? Notice how there is a pull to do what is easier in the moment. There is this pull to do what will immediately feel better. What happens when we choose to get rid of that uncomfortable feeling? Right, it still comes back and sometimes gets bigger and stronger. Would it be worth bringing the thoughts of (insert internal experience) in order to have a life that is more about (insert value) than trying to remove that uncomfortable feeling? That uncomfortable feeling will be there no matter what. So do you choose to welcome it along, turn up that willingness dial, and live a life you care about or to spend your days fighting it and moving away from things that matter to you?

Homework: Continue with behavioral commitments that are related to the target behavior. Increase the difficulty of the behavior slightly. Remember to increase it enough that the client can still succeed and that there will be enough to distress to continue practicing willingness. This time, ask the client to visual the fork in the road when faced with the decision to meet the goal or not. Ask him/her to use the values as a compass/guide for that decision and to "carry" the internal experiences with him/her while walking down the chosen path. Remind the client to come prepared to discuss this at the following session.

\section{Session 4:}

Self as Context Increase distinction between the self and thoughts/emotions

Chessboard metaphor

Recommended Readings: Chapter 8 (Hayes, Strosahl, \& Wilson, 2011)

Review of Homework: Allow time to discuss behavioral commitment practice over the week and to discuss any barriers that arose to completion. Specifically look for processes that have already been covered: present moment, willingness, and values.

At this point in treatment the client will have had enough practice at attempts to change behavior that $\mathrm{s} /$ he will likely be able to articulate specific barriers. These barriers are likely to be that the client still views the internal experiences to be distressing and a part of him/her. This and the following session will address processes to help with that.

This session will focus on self as context. This process helps the client see internal experiences as events that are simply passing through. The client has a consistent part of him/herself called the "observing self" that is separate from the content of thoughts, emotions, and sensations. This part simply watches these events as they occur. The goal 
of this session is to increase the client's awareness of the observing self. This will help decrease attachment to the content of internal events and thus make it more likely for clients to follow their values.

\section{Chessboard Metaphor}

The Chessboard metaphor is a central ACT intervention and another way to connect the client to the distinction between content and the observing self.

It's as if there is a chess board that goes out infinitely in all directions. It's covered with different colored pieces, black pieces and white pieces. They work together in teams, like in chess--the white pieces fight against the black pieces. You can think of your thoughts and feelings and beliefs as these pieces; they sort of hang out together in teams, too. For example, "bad" feelings (like anxiety, depression, resentment) hang out with "bad" thoughts and "bad" memories. Same thing with the "good" ones. So it seems that the way the game is played is that we select which side we want to win. We put the "good" pieces (like thoughts that are selfconfident, feelings of being in control, etc.) on one side, and the "bad" pieces on the other. Then we get up on the back of the white queen and ride to battle, fighting to win the war against anxiety, depression, thoughts about using drugs, whatever. It's a war game. But there's a logical problem here, and that is that from this posture, huge portions of yourself are your own enemy. In other words, if you need to be in this war, there is something wrong with you. And since it appears that you're on the same level as these pieces, they can be as big or even bigger than you are, even though these pieces are in you. So somehow, even though it is not logical, the more you fight the bigger they get. If it is true that "if you are not willing to have it, you've got it," then as you fight them they get more central to your life, more habitual, more dominating, and more linked to every area of living. The logical idea is that you will knock enough of them off the board so that you eventually dominate them--except your experience tells you that the exact opposite happens. Apparently, the black pieces can't be deliberately knocked off the board. So the battle goes on. You feel hopeless, you have a sense that you can't win, and yet you can't stop fighting. If you're on the back of that white horse, fighting is the only choice you have because the black pieces seem life threatening. Yet living in a war zone is a miserable way to live.

As the client connects to this metaphor, it can be turned to the issue of the self.

Therapist: Now, let me ask you to think about this carefully. In this metaphor, suppose you aren't the chess pieces. Who are you?

Client: Am I the player?

Therapist: That's exactly what you've been trying to be, so that is an old idea. The player has a big investment in how this war turns out. Besides, who are you playing 
against? Some other player? So suppose you're not that either.

Client: .... Am I the board?

Therapist: It's useful to look at it that way. Without a board, these pieces have no place to be. The board holds them. Like what would happen to your thoughts if you weren't there to be aware that you thought them? The pieces need you. They cannot exist without you, but you contain them, they don't contain you. Notice that if you're the pieces, the game is very important; you've got to win, your life depends on it. But if you're the board, it doesn't matter if the war stops or not. The game may go on, but it doesn't make any difference to the board. As the board, you can see all the pieces, you can hold them, you are in intimate contact with them and you can watch the war being played out on your consciousness, but it doesn't matter. It takes no effort.

The chessboard metaphor is often physically acted out in therapy. For example, a piece of cardboard is placed on the floor and various attractive and ugly things are put on top (e.g., cigarette butts, pictures). The client may be asked to notice that the board exerts no effort to hold the pieces (a metaphor for the lack of effort that is needed in willingness, with the physical act of the board holding things as a metaphor for willingness). The client may be asked to notice that at board level only two things can be done: hold the pieces and move them all in a direction. We cannot move specific pieces without abandoning board-level. Notice also that the board is in more direct contact with the pieces than the pieces are to each other--so willingness is not about detachment or dissociation. Rather, when we "buy" a thought or struggle with an emotion we go up to piece level and at that level, other pieces, while scary, are not genuinely being touched at all.

Once the client has been introduced to the metaphor, it is useful to reinvigorate it periodically by simply asking the client, "are you at the piece level or at the board level right now"? All the arguments, reasons, and so on that the client brings in are all examples of "pieces" and thus this metaphor can help defuse the client from such reactions. The concept of "board level" can be used frequently to connote a stance in which the client is looking at psychological content, rather than looking from psychological content. The point is that thoughts, feelings, sensations, emotions, memories and so on are pieces: they are not you. This is immediately experientially available, but the fusion with psychological content can overwhelm this awareness. Metaphors such as the chessboard metaphor help make the issue concrete.

\section{Observer Exercise}

Before this exercise the client should be told to not converse with the therapist during the exercise. The client should give the most brief answer possible to any questions and save conversation until the exercise is finished. We need to provide the client with an experience of themselves as context rather than as themselves as content. 
The Observer Exercise (a variant of the "self-identification exercise" developed by Assagioli, 1971, pp. 211-217) is designed to begin to establish a sense of self that exists in the present and provides a context for cognitive defusion.

We are going to do an exercise now that is a way to begin to try to experience that place where you are not your programming. There is no way anyone can fail at the exercise; we're just going to be looking at whatever you are feeling or thinking so whatever comes up is just right. Close your eyes, get settled into your chair and follow my voice. If you find yourself wandering, just gently come back to the sound of my voice. For a moment now, turn your attention to yourself in this room. Picture the room. Picture yourself in this room and exactly where you are. Now begin to go inside your skin, and get in touch with your body. Notice how you are sitting in the chair. See if you can notice exactly the shape that is made by the parts of your skin that touch the chair. Notice any bodily sensations that are there. As you see each one, just sort of acknowledge that feeling and allow your conscious to move on. [pause] Now notice any emotions you are having and if you have any just acknowledge them [pause]. Now get in touch with your thoughts and just quietly watch them for a few moments [pause]. Now I want you to notice that as you noticed these things a part of you noticed them. You noticed those sensations ... those emotions ... those thoughts. and that part of you we will call the "observer you." There is a person in here, behind those eyes, that is aware of what I am saying right now. And it is the same person you've been your whole life. In some deep sense this observer you is the you that you call you.

I want you to remember something that happened last summer. Raise your finger when you have an image in mind. Good. Now just look around. Remember all the things that were happening then. Remember the sights ... The sounds ... Your feelings ... and as you do that see if you can notice that you were there then noticing what you were noticing. See if you can catch the person behind your eyes who saw, and heard, and felt. You were there then, and you are here now. I'm not asking you to believe this. I'm not making a logical point. I am just asking you to note the experience of being aware and check and see if it isn't so that in some deep sense the you that is here now was there then. The person aware of what you are aware of is here now and was there then. See if you can notice the essential continuity--in some deep sense, at the level of experience, not of belief, you have been you your whole life.

I want you to remember something that happened when you were a teenager. Raise your finger when you have an image in mind. Good. Now just look around. Remember all the things that were happening then. Remember the sights ... The sounds ... Your feelings ... Take your time. And when you are clear about what was there see if you just for a second catch that there was a person behind your eyes then who saw, and heard, and felt all of this. You were there then, too, and see if it isn't true, as an experienced fact, not a belief, that there is an essential continuity between the person aware of what you are aware of now 
and the person who was aware of what you were aware of as a teenager in that specific situation. You have been you your whole life.

Finally, remember something that happened when you were a fairly young child, say around age six or seven. Raise your finger when you have an image in mind. Good. Now just look around again. See what was happening. See the sights ... hear the sounds ... feel your feelings ... and then catch the fact that you were there seeing, hearing, and feeling. Notice that you were there behind your eyes. You were there then, and you are here now. Check and see if in some deep sense the "you" that is here now was there then. The person aware of what you are aware of is here now and was there then.

You have been you your whole life. Everywhere you've been, you've been there noticing. This is what I mean by the "observer you." And from that perspective or point of view I want you to look at some areas of living. Let's start with your body. Notice how your body is constantly changing. Sometimes it is sick and sometimes it is well. It may be rested or tired. It may be strong or weak. You were once a tiny baby, but your body grew. You may have even have had parts of your body removed, like in an operation. Your cells have died and literally almost every cell in your body was not there as a teenager, or even last summer. Your bodily sensations come and go. Even as we have spoken they have changed. So if all this is changing and yet the you that you call you has been there your whole life that must mean that while you have a body, as a matter of experience and not of belief, you do not experience yourself to be just your body. So just notice your body now for a few moments, and as you do this, every so often notice you are the one noticing. [give the client time to do this]

Now let's go to another area: your roles. Notice how many roles you have or have had. Sometimes you're in the role of a [fit these to client, e.g., "mother... or a friend... or a daughter... or a wife... sometimes you're a respected worker... other times you're a leader... or a follower"... etc.]. In the outside world, you're in some role all the time. If you were to try not to be, then you'd be playing the role of not playing a role. Even now, part of you is playing a role... the client role. Yet all the while notice that you are also present. The part of you that is "you"... is watching and aware of what you are aware of. And in some deep sense that "you" does not change. So if your roles are constantly changing, and yet the you that you are has been there your whole life, it must be that while you have roles, you do not experience yourself to be your roles. Do not believe this. This is not a matter of belief. Just look and notice the distinction between what you are looking at, and the you that is looking.

Now let's go to another area: emotions. Notice how your emotions are constantly changing. Sometimes you feel love and sometimes hatred, calm and then tense, joy-sorrowful, happy-sad. Even now you may be experiencing emotions. . .interest, boredom, relaxation. Think of things you have liked, and 
don't like any longer; of fears that you once had that now are resolved. The only thing you can count on with emotions is that they will change. Though a wave of emotion comes, it will pass in time. And yet while these emotions come and go, notice that in some deep sense that "you" does not change. That must be that while you have emotions, you do not experience yourself to be just your emotions. Allow yourself to realize this as an experienced event, not as a belief. In some very important and deep way you experience yourself as a constant. You are you through it all. So just notice your emotions for a moment and as you do notice also that you are noticing them [Leave a brief period of silence].

Now let's turn to a very difficult area. Your own thoughts. Thoughts are difficult because they tend to hook us and pull us up to piece level. If that happens, just come back to the sound of my voice. Notice how your thoughts are constantly changing. You used to be ignorant--then you went to school and learned new thoughts. You have gained new ideas, and new knowledge.

Sometimes you think about things one way and sometimes another. Sometimes your thoughts may make little sense. Sometimes they seem to come up automatically, from out of nowhere. They are constantly changing. Look at your thoughts even since you came in today and notice how many different thoughts you have had. And yet in some deep way the you that knows what you think is not changing. So that must mean that while you have thoughts, you do not experience yourself to be just your thoughts. Do not believe this. Just notice it. And notice even as you realize this, that your stream of thoughts will continue. And you may get caught up with them. And yet in the instant that you realize that, you also realize that a part of you is standing back, watching it all. So now watch your thoughts for a few moments, and as you do, notice also that you are noticing them [Leave a brief period of silence].

So as a matter of experience and not of belief you are not just your body... your roles ... your emotions ... your thoughts. These things are the content of your life, while you are the arena...the context...the space in which they unfold. As you see that, notice that the things you've been struggling with, and trying to change are not you anyway. No matter how this war goes, you will be there, unchanged. See if you can take advantage of this connection to let go just a little bit, secure in the knowledge that you have been you through it all, and that you need not have such an investment in all this psychological content as a measure of your life. Just notice the experiences in all the domains that show up and as you do notice that you are still here, being aware of what you are aware of [Leave a brief period of silence].

Now again picture yourself in this room. And now picture the room. Picture [describe the room]. Take a few more deep breaths. And when you are ready to come back into the room, open your eyes.

After this exercise, process the client's experience with the exercise. Be careful to 
avoid analysis of the experience, but focus on the experience itself. It is useful to see if there were any particular qualities of the experience of connecting with the "you". It is not unusual for clients to report a sense of tranquility or peace. Life experiences invoked in this exercise, many of which are threatening and anxiety promoting, can be received peacefully and tranquilly (i.e. accepted with a willingness posture) when they are viewed as bits and pieces of self-content, not as defining the self per se. It is usually worth leaving the client with the active implications of this experience. The therapist can link the client back to experiences with the chessboard metaphor: For example, "there is one other thing which the board, as a board can do, other than hold the pieces. It can take a direction, regardless of what the pieces are doing at the time. It can see what is there, feel what is there, and still say, 'Here we go'!

Homework: The client can be assigned this exercise as homework. The client should find a place in his or her home where s/he will not be interrupted, get centered, and observe what occurs. Continue to set increasingly difficult behavioral commitments and invite the client to incorporate the aspects of the session into decision making in his/her life.

\section{Session 5:}

\begin{tabular}{|l|l|}
\hline Defusion & Undermine cognitive fusion using the Passengers on the Bus
\end{tabular}
metaphor

Recommended Readings: Chapter 9 (Hayes, Strosahl, \& Wilson, 2011)

Review of Homework: Review the client's practice with the observer exercise and success and/or barriers to behavioral commitments. Allow time to discuss any reactions to treatment and home practice.

This session focuses on the process of defusion, the acts of reducing the literal meaning of internal experiences and realization that internal experiences do not need to guide behaviors. There are several ways to reach this point with a client. Some examples are shown below:

\section{Passengers on the Bus Metaphor}

The Passengers on the Bus metaphor is a core ACT intervention aimed at deliteralizing provocative psychological content through objectification. This can be particularly effective because it assists clients in looking at internal experiences in a way that is less threatening and easier and more rewarding to accept. This metaphor can also be adjusted to fit the client. An example of an adjustment would be to use the fork in the road metaphor used earlier in session. The "bus" could be a backpack the client carries with some objects that represent internal experiences inside the backpack. The client can walk, bike, drive, etc. down the chosen road. 
It's as if there is a bus and you're the driver. On this bus we've got a bunch of passengers. The passengers are thoughts, feelings, bodily states, memories, and other aspects of experience. Some of them are scary, and they're dressed up in black leather jackets and they've got switchblade knives. What happens is, you're driving along and the passengers start threatening you, telling you what you have to do, where you have to go. "You've got to turn left," "you've got to go right," etc. The threat that they have over you is that, if you don't do what they say, they're going to come up from the back of the bus.

It's as if you've made deals with these passengers, and the deal is, "You sit in the back of the bus and scrunch down so that I can't see you very often, and I'll do what you say, pretty much." Now what if one day you get tired of that and say, "I don't like this! I'm going to throw those people off the bus!" You stop the bus, and you go back to deal with the mean-looking passengers. Except you notice that the very first thing you had to do was stop. Notice now, you're not driving anywhere, you're just dealing with these passengers. And plus, they're real strong. They don't intend to leave, and you wrestle with them, but it just doesn't turn out very successfully.

Eventually you go back to placating the passengers, to try to get them to sit way in the back again where you can't see them. The problem with that deal is that, in exchange, you do what they ask in exchange for getting them out of your life. Pretty soon, they don't even have to tell you, "Turn left"--you know as soon as you get near a left-turn that the passengers are going to crawl all over you. Eventually you may get good enough that you can almost pretend that they're not on the bus at all, you just tell yourself that left is the only direction you want to turn. However, when they eventually do show up, it's with the added power of the deals that you've made with them in the past.

Now the trick about the whole thing is this: The power that the passengers have over you is $100 \%$ based on this: "If you don't do what we say, we're coming up and we're making you look at us." That's it. It's true that when they come up they look like they could do a whole lot more. They've got knives, chains, etc. It looks like you could be destroyed. The deal you make is to do what they say so they won't come up and stand next to you and make you look at them. The driver (you) has control of the bus, but you trade off the control in these secret deals with the passengers. In other words, by trying to get control, you've actually given up control! Now notice that, even though your passengers claim they can destroy you if you don't turn left, it has never actually happened. These passengers can't make you do something against your will.

The therapist can continue to allude to the bus metaphor throughout deliteralization work. Questions such as, "Which passenger is threatening you now?" can help re-orient the client who is practicing emotional avoidance in session. 


\section{Reformulating Language Conventions}

There a specific language conventions that seem to maintain the power that the internal experiences have over clients. Tell the client that if $\mathrm{s} / \mathrm{he}$ is willing to experiment with a couple of little verbal conventions, we are going to try some new things to undermine the tendency for words to pull us into a struggle. Say:

There are things built into our language that help pull us up into the war zone, things that lead us to take our thoughts to literally be what they say they are. So in here, for a while, maybe we can adopt a couple of verbal conventions just to call our attention to what we're saying and what we really mean when we say these things. The conventions I'm going to propose may be a little awkward, but they're not something that we'll need to adopt forever. The first convention is this: Name the type of language being used by saying, "I'm having the (thought/feeling/evaluation/bodily sensation) that..." If you name the process, it's easier to see what it really is, rather than what it just says it is.

The key components of the reformulation are:

1. "I" statements. The particular behavioral events must be phrased in the first person.

2. A clear label of the behavioral process. The main ones in most clinical work are thoughts, feelings, evaluations, bodily sensations, and memories.

3. Doing or having, not being. There is a subtlety in here that we do not deliberately teach to clients, but that nevertheless is usually learned. Respondent behavior is usefully viewed as something you have. Operant behavior is usefully viewed as an action you chose. In both cases, however, these actions or reactions are not who you are. Thus, the construction "I am angry" is almost always harmful. It places an emotion as a quality of being. "I feel angry" or "I have a feeling of anger" are much safer because they distinguish between the person and the event.

Typical client verbalization: "This whole relationship stinks. It's sad really. There is just no way to pull it back together."

Reformulated client verbalization: "I'm having the evaluation that this relationship stinks. I have sad feelings associated with that thought, and then I have the thought that there is no way to pull it back together."

Typical client verbalization: "No one could live like I do. I am too anxious. It is miserable."

Reformulated client verbalization: "I'm having the thought that no one could live like I do. I have feelings of anxiety and I have the thought that they are too much. I evaluate it as miserable." 
The artificiality of these verbal constructions is a problem initially. If the therapist is persistent, however, most clients can -- within just a half an hour or so -- get the hang of it. Typically, there is no need to be watchful about the conventions after a short while. Just an hour or two of consistent application will get them firmly established and available for use as needed. Then they can be called upon whenever the client is getting all tangled up in the content of private events. The conventions help create enough distance between the person and their own reactions so that these reactions can be seen as reactions, rather than the world being seen through these reactions.

The second convention has to do with our use of the words 'but' and 'and.' What 'but' literally means is that what follows the word, 'but', contradicts what went before the word. It's literally a rebuttal. So, 'this, but that' means that there are two things that are inconsistent, that are literally at war with each other. However, what really is the case is that you've got both of them, 'this, and that.' So the little convention we might adopt is to say 'and' instead of 'but' when we talk. If you try it, you'll see that almost always 'and' is more true to your experience. For example, if I want to go to work and yet I feel resistant, instead of 'I want to go, but I feel so resistant,' try 'I want to go and I feel so resistant.' Both things are true, the wanting to go to work, and the feeling of resistance. By calling attention to what we're saying with the use of this little convention, it will help make you more sensitive to one of the ways that people get pulled into the piece-level struggle with their own history.

Homework: Continue setting behavioral commitments and ask the client to use skills and concepts learned in the session (dependent upon the work done in session). Remember to be increasing the difficulty of the commitments based on the client's progress.

\section{Session 6:}

Committed

Action

Increased behavioral commitments to engage in valued living based on recent values work

Recommended Readings: Chapter 12 (Hayes, Strosahl, \& Wilson, 2011)

Review of Homework: Allow time to check on the success and barriers to the behavioral commitments from the previous session. Be sure to inquire enough to determine the client's progress on each process that has been reviewed.

This session focuses entirely on increasing actions that are deliberately linked to values. The following exercises will assist the client in engaging in valued activities over slipping back into an avoidance strategy.

\section{Unwanted Party Guest}

Imagine that you got a new house and you invited all the neighbors over to a party, a housewarming. Everyone's invited in the whole neighborhood--you even put up a sign at the supermarket. So all the neighbors show up, the party's 
going great, and here comes neighbor Joe, who lives behind the supermarket in the trash dumpster. He's stinky and smelly and you think, "Ugh, why did he show up?" However, you did say on the sign, "Everyone's welcome." Can you see that it's possible for you to welcome him, and really, fully, do that without liking that he's there? You can welcome him even though you don't think well of him. You don't have to like him. You don't have to like the way he smells, or his life style, or his clothing. You may be embarrassed about the way he's dipping into the punch or the finger sandwiches. Your opinion of him, your evaluation of him is absolutely distinct from your willingness to have him as a guest in your home. Now you can decide that even though you said everyone was welcome, in reality he's not welcome. As soon as you do that, the party changes. Now you have to be at the front of the house, guarding the door so he can't come back in. Or if you say, okay, you're welcome, but you don't really mean it, you only mean that he's welcome as long as he stays in the kitchen and doesn't mingle with the other guests, then you're going to have to be constantly making him do that, and your whole party will be about that. Meanwhile, life's going on, the party's going on, and you're off guarding neighbor Joe. It's just not life-enhancing. It's not much like a party. It's a lot of work. What the metaphor is about, of course, is all the feelings and memories and thoughts that show up that you don't like; they're just more unwanted guests at the door. The issue is the posture you take with regards to your own stuff. Are they welcome? Can you choose to welcome them in, even though you don't like the fact they came? If not, what's the party going to be like?

The fantasy is that withholding willingness will promote peace of mind. The reality is the opposite. In fact, most clients have noticed that when we try hard to stop one reaction from joining the party, other undesirable reactions follow along right behind.

\section{Moving Through a Swamp}

At this point in therapy, it is useful to explain to the client that the need for willingness emerges in the context of commitment. Without a goal and a commitment to values and goals, there is no need for willingness.

It is as if there is a swamp in front of you. Willingness is what happens when you are willing to go into that swamp. But notice also that there is a purpose to it. It is not that we need to wallow in swamps. It is that when we are going somewhere, sometimes there is a swamp there, and we have the choice either to change directions or to open up. It is as if you could cast a string across the swamp to reach a particular point on the other side. Then, when you are up to your stomach in goop, you can always refer back to the string and see if you are headed in the direction you set for yourself. Only you can cast that string, and without it willingness loses its direction.

Homework: Set behavioral commitments for the week. After this session, the client will likely have a renewed sense (if it was low) of meaning to do the homework. This is a 
good time to increase the difficulty of commitments, especially because only 2 sessions remain to practice any processes that are lacking. Help the client see this without judgment or being pushy.

Session 7 \& 8:

\begin{tabular}{|l|l} 
Review & Review any processes that still need attention
\end{tabular} Discuss future behavior and addressing relapse

Recommended Readings: Review Chapter 4 (Hayes, Strosahl, \& Wilson, 2011) and use of the tools in it

These final two sessions are difficult to describe in a manual. The purpose of these sessions is to address any processes where the client still needs training/practice. The skills used throughout all of the sessions and assessment skills used at the beginning of treatment and at the beginning of each session will be the content for these sessions. Each session will begin with assessment (using tools described in Chapter 4 or a mental check list) to determine where the client is at on each process. After determining the areas that need the most work. Additional exercises, metaphors, and in session practice (e.g., holding a cigarette in hand to bring up urges) can be done. What is chosen is determined by the client's progress. Homework for session 7 will continue the pattern used throughout treatment (setting new goals and working on the specific process of interest).

\section{Future Behavior and Relapse}

The end of session 8 is devoted to discussing any future barriers to success. Within this discussion, let the client know that it is expected that s/he will fall back into old ways and begin to use the control agenda again. Based on the specific concerns of the client, you can recommend continued behavior tracking, daily mindfulness practice, weekly values clarification, and checking on the consistency of values-driven behaviors. Help the client find ways to catch when s/he begins to fall into old patterns and help $\mathrm{him} / \mathrm{her}$ get back to where s/he wants to be instead of relapsing completely. You can make recommendations for self-help books such as Get Out of Your Mind and Into Your Life. This can be used as a reference to refresh the client on therapy practices. 


\section{WEEKLY BEHAVIOR TRACKING FORM}

Instructions: Place a tally in the box next to the day each time you do the behavior listed below. Please keep this form with you at all times and mark the tally as soon as possible after the behavior.

\begin{tabular}{|c|c|}
\hline & Behavior: \\
\hline Monday & \\
\hline Tuesday & \\
\hline Wednesday & \\
\hline Thursday & \\
\hline Friday & \\
\hline Saturday & \\
\hline Sunday & \\
\hline
\end{tabular}


Appendix D

Individual Data 
Control
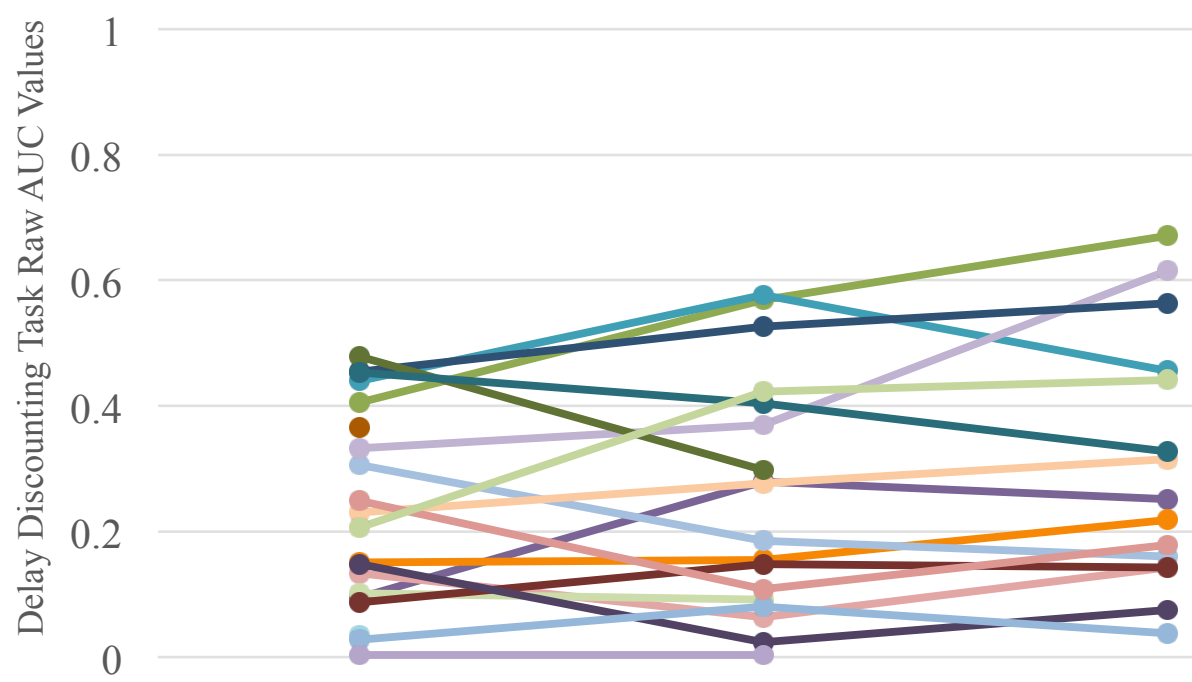

Time 1

Time 2

Time 3

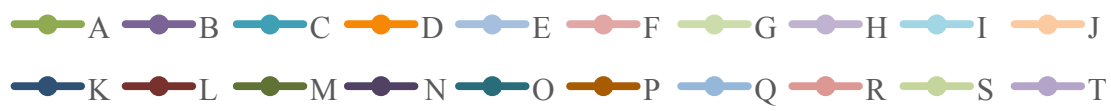

\section{ACT}
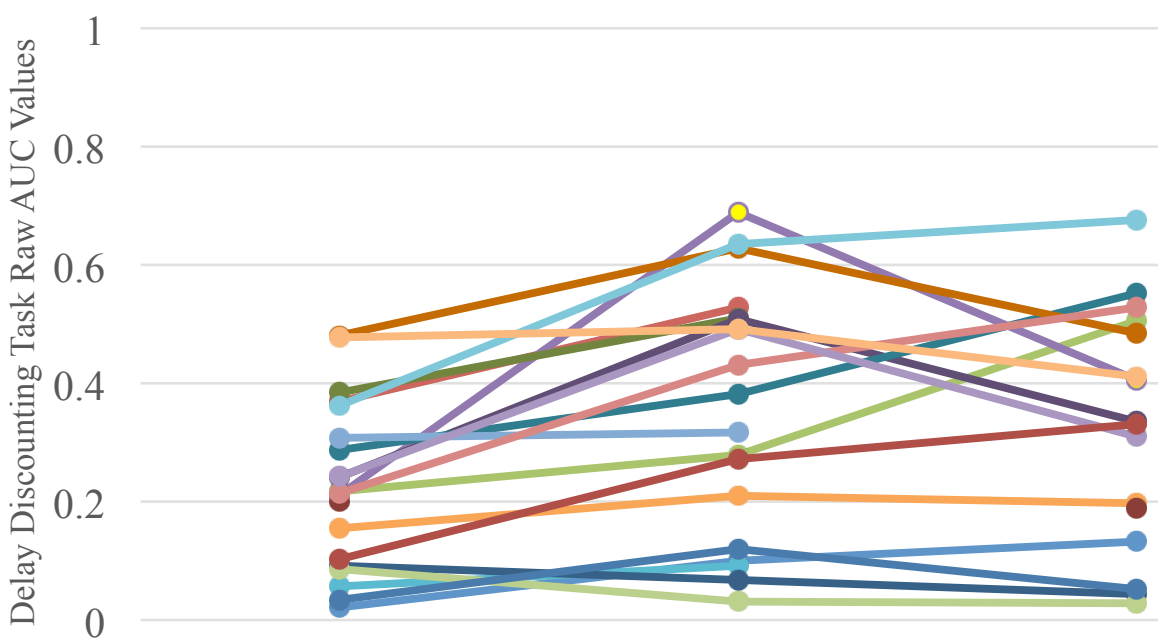

Time 1

Time 2

Time 3

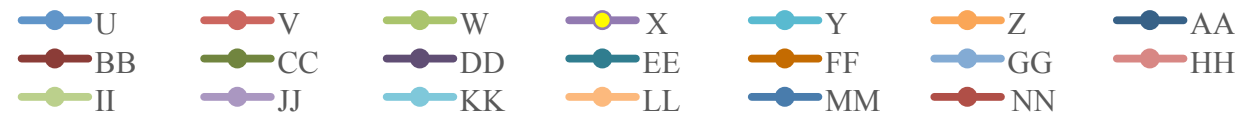

Figure D. 1. Delay Discounting Task individual data. 
Control
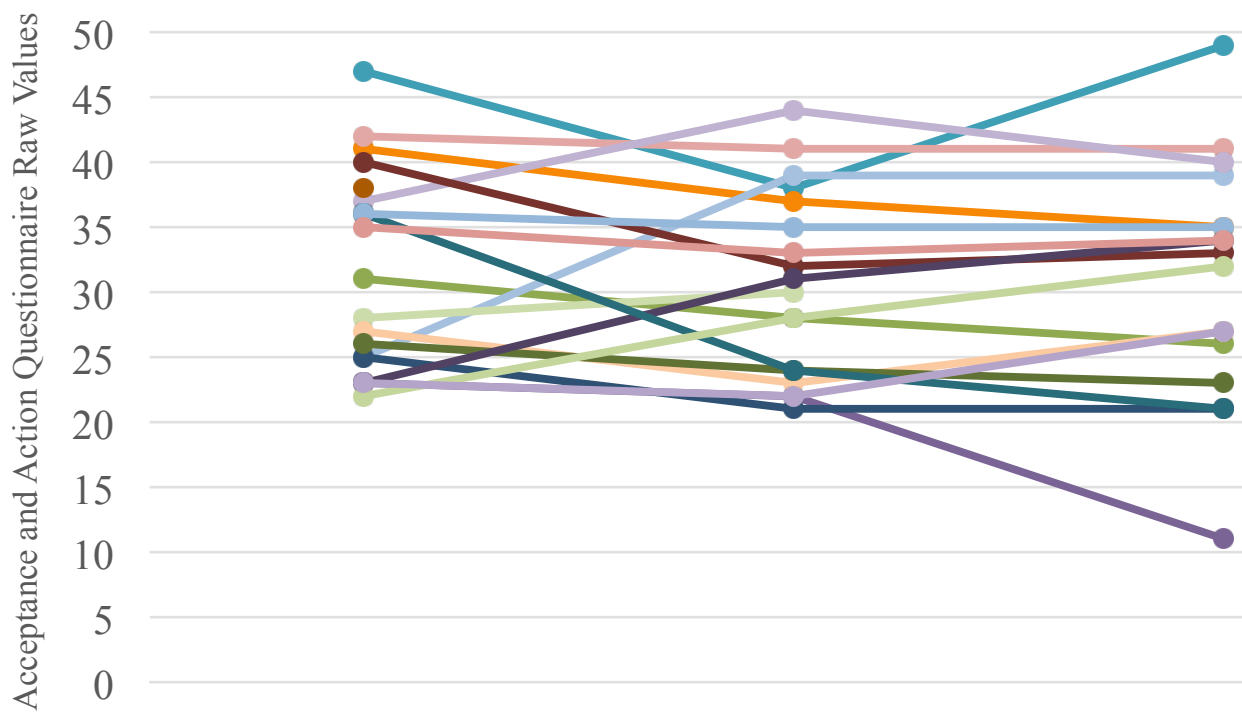

Time 1

Time 2

Time 3

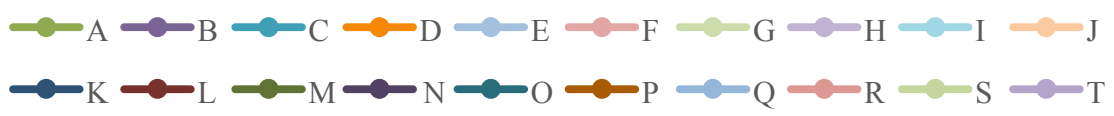

ACT

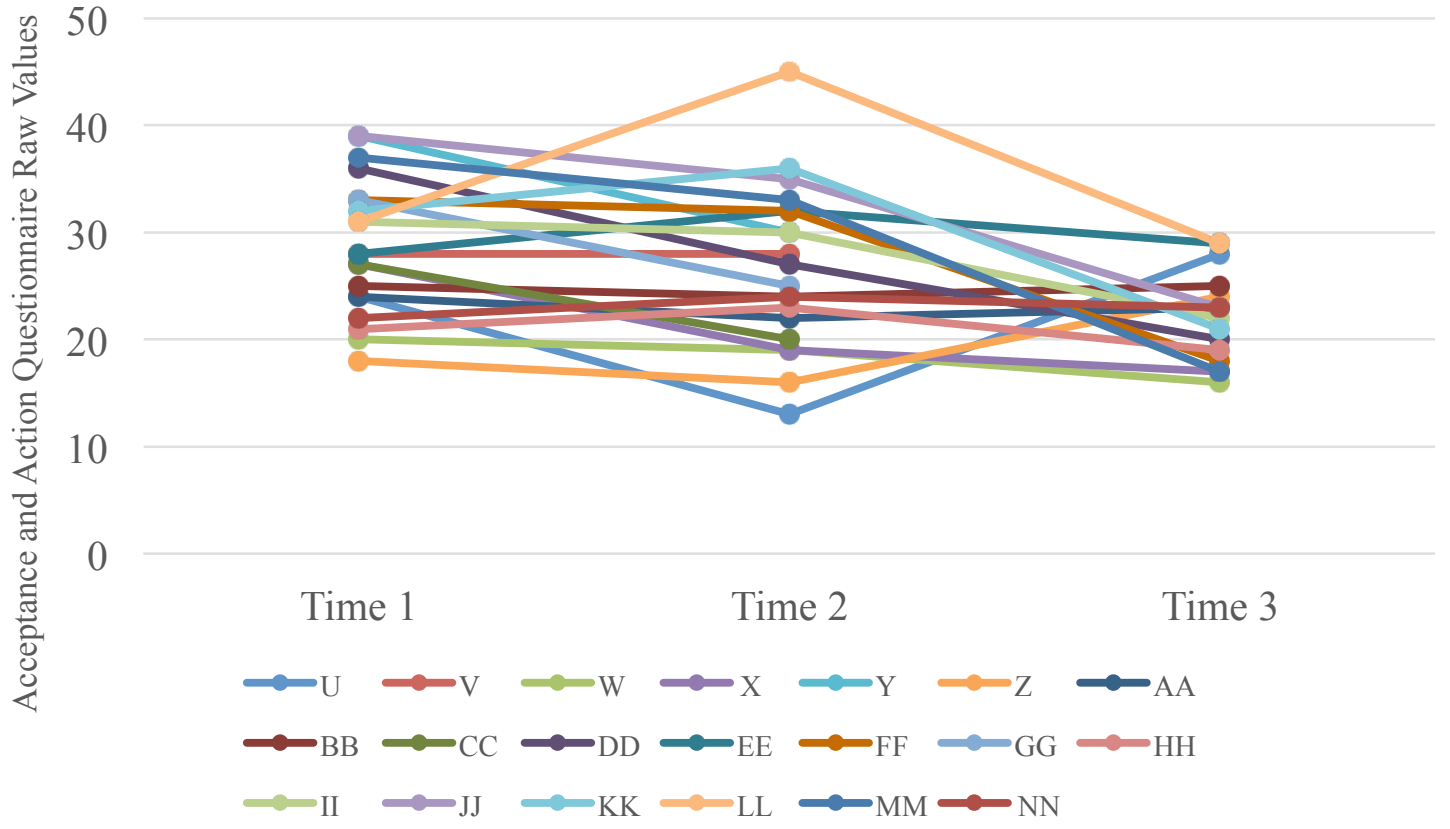

Figure D.2. Acceptance and Action Questionnaire individual results. 
Control

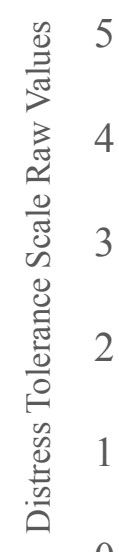

0
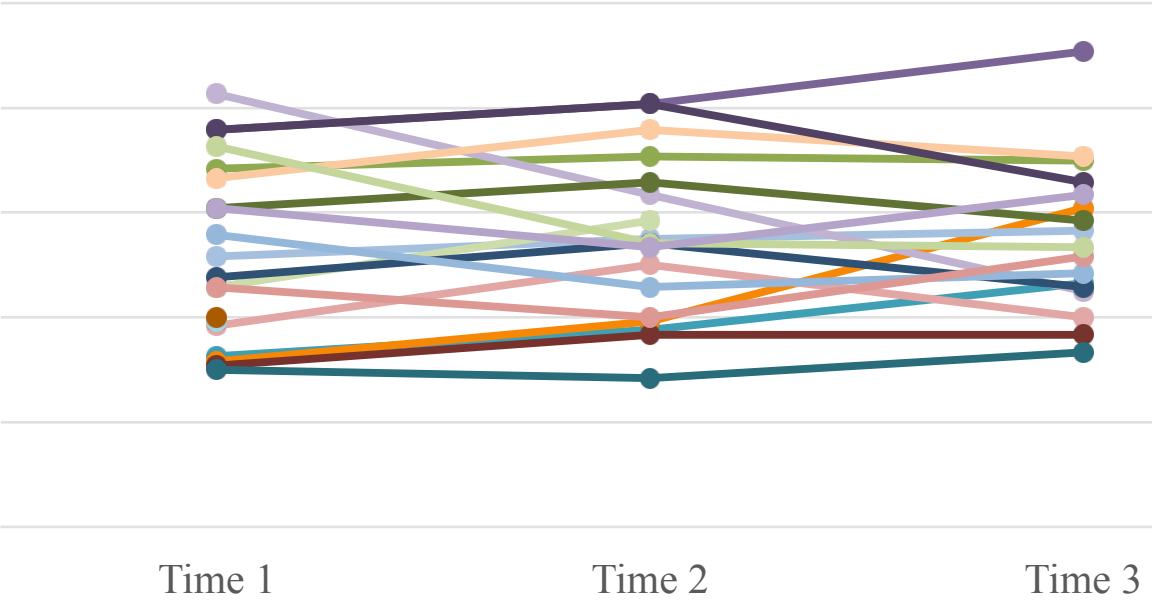

$$
\begin{aligned}
& \rightarrow \mathrm{A} \rightarrow \mathrm{B} \rightarrow \mathrm{C} \rightarrow \mathrm{D} \rightarrow \mathrm{E} \rightarrow \mathrm{F} \rightarrow \mathrm{G} \rightarrow \mathrm{H} \rightarrow \mathrm{I} \rightarrow \mathrm{J} \\
& \rightarrow \mathrm{K} \rightarrow \mathrm{L} \rightarrow \mathrm{M} \rightarrow \mathrm{N} \rightarrow \mathrm{O} \rightarrow \mathrm{P} \rightarrow \mathrm{Q} \rightarrow \mathrm{R} \rightarrow \mathrm{S} \rightarrow \mathrm{T}
\end{aligned}
$$

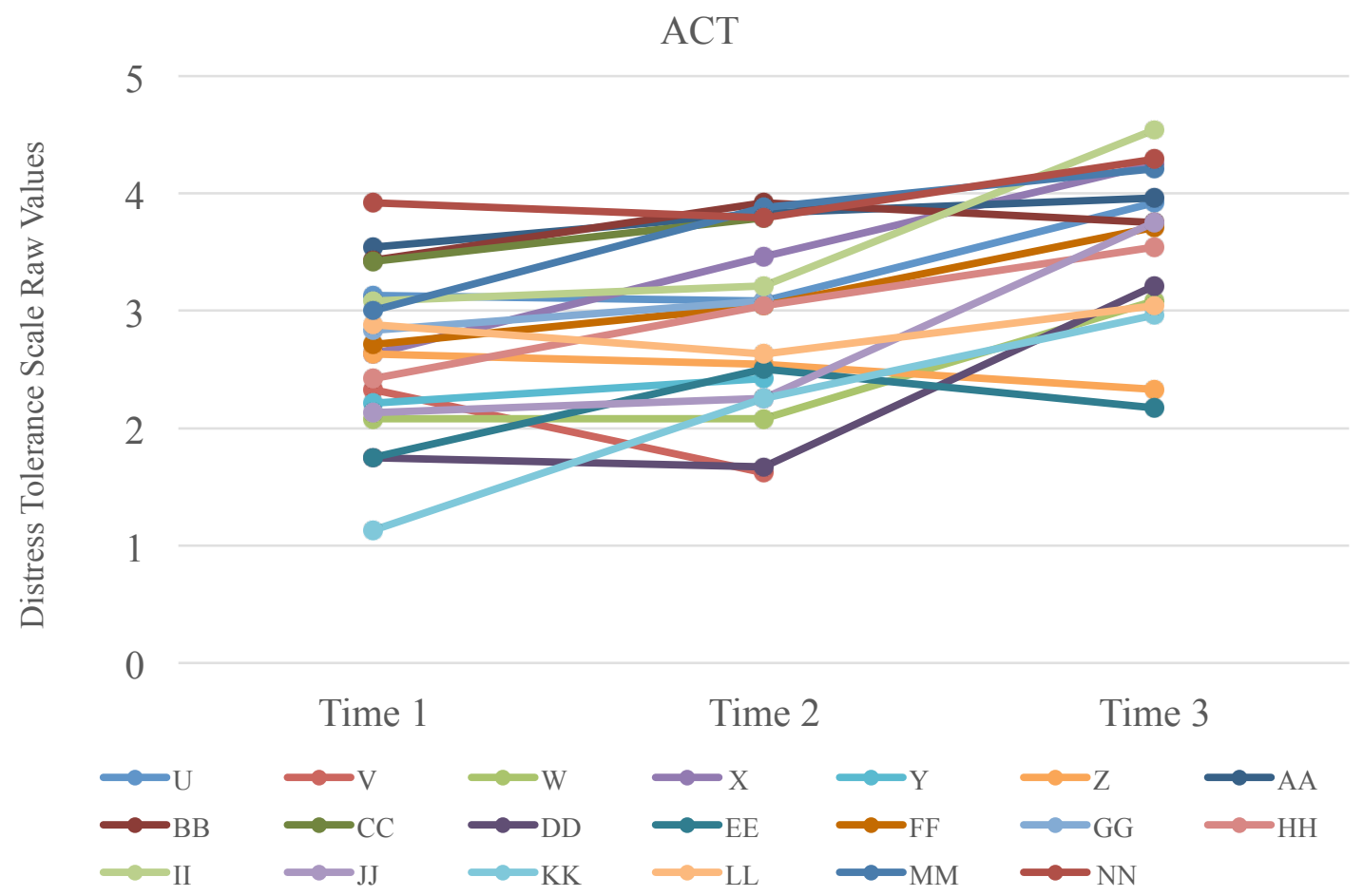

Figure D.3. Distress Tolerance Scale individual results. 
Control

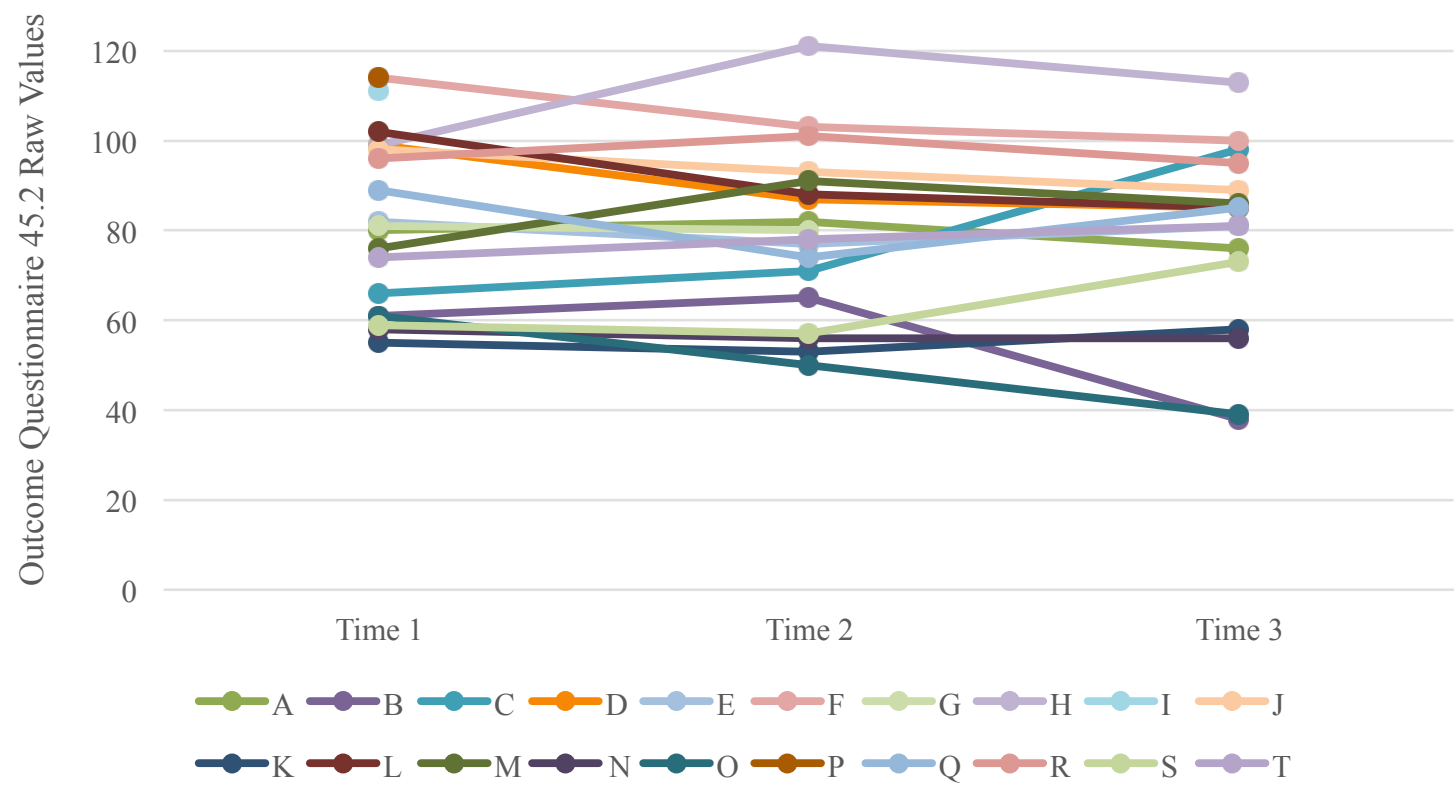

ACT

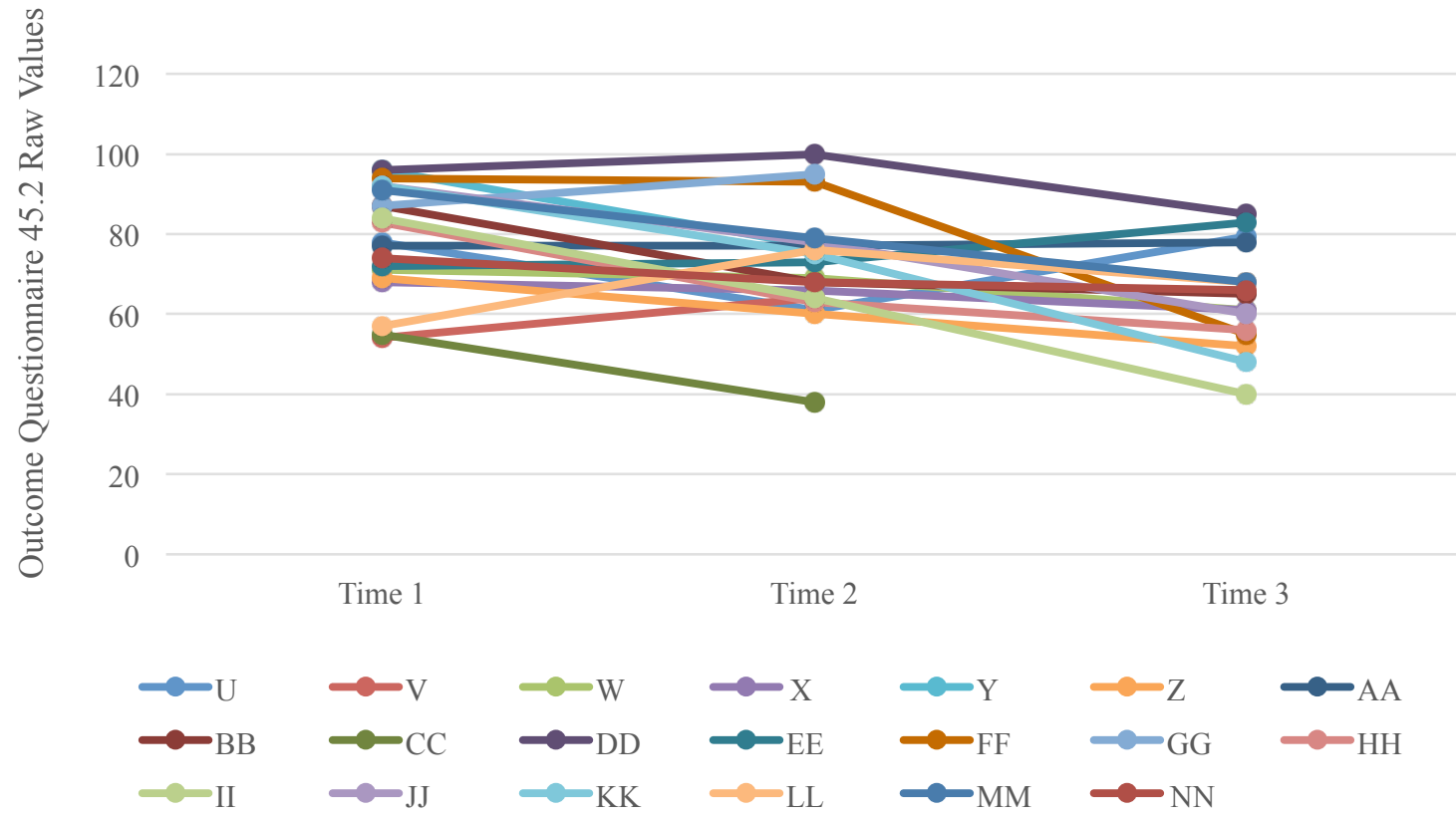

Figure D.4. Outcome Questionnaire-45.2 individual results. 

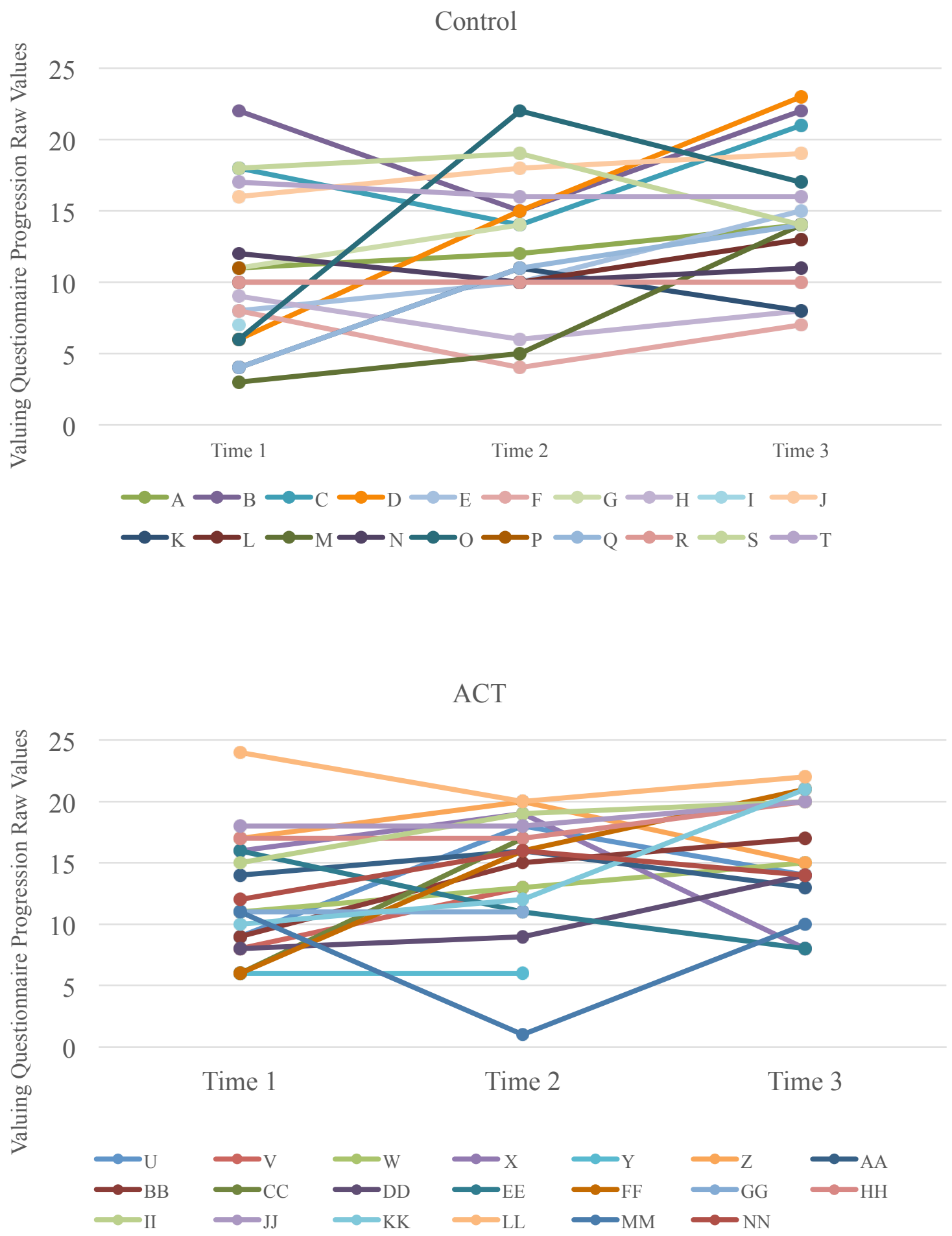

Figure D.5. Valuing Questionnaire-Progression individual results. 
Control

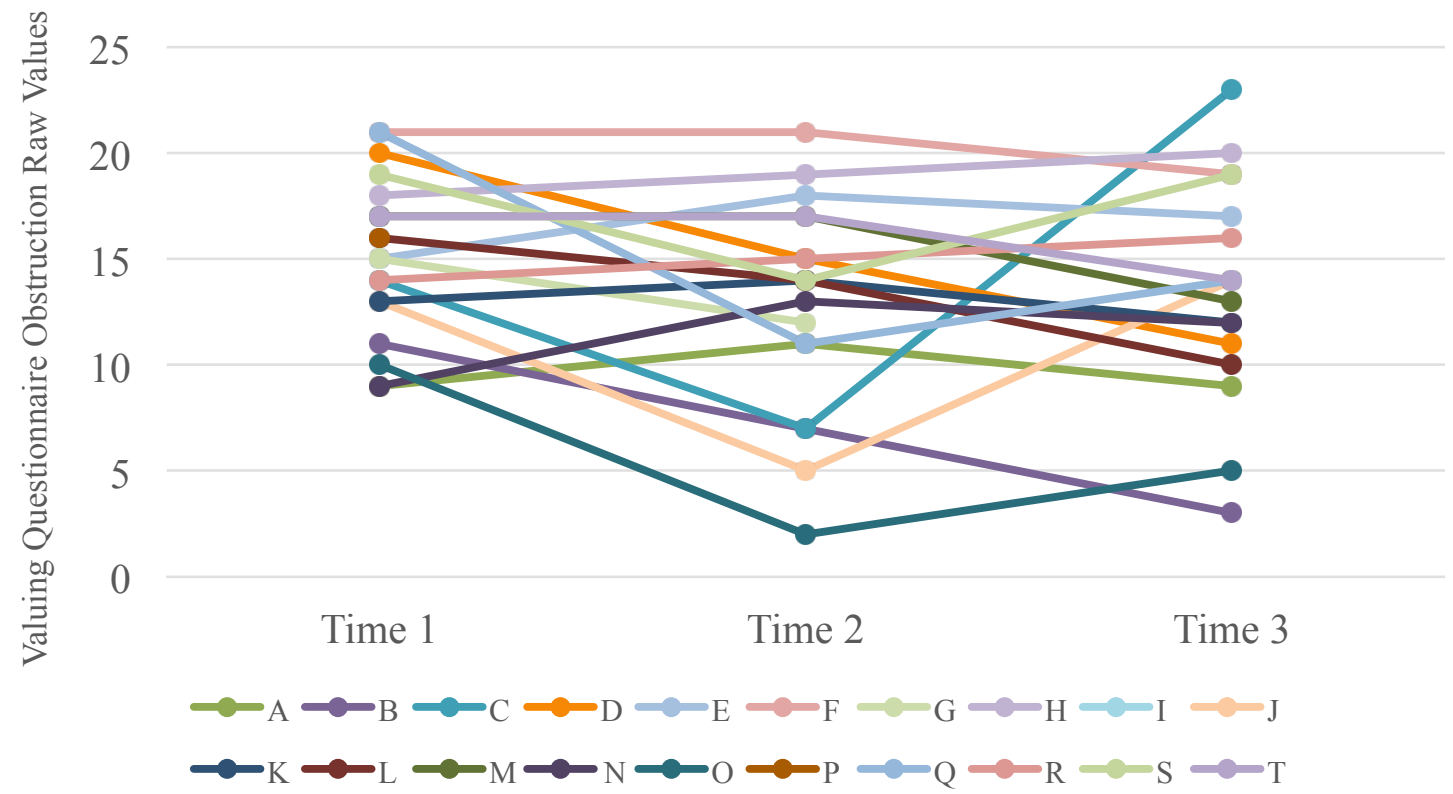

ACT

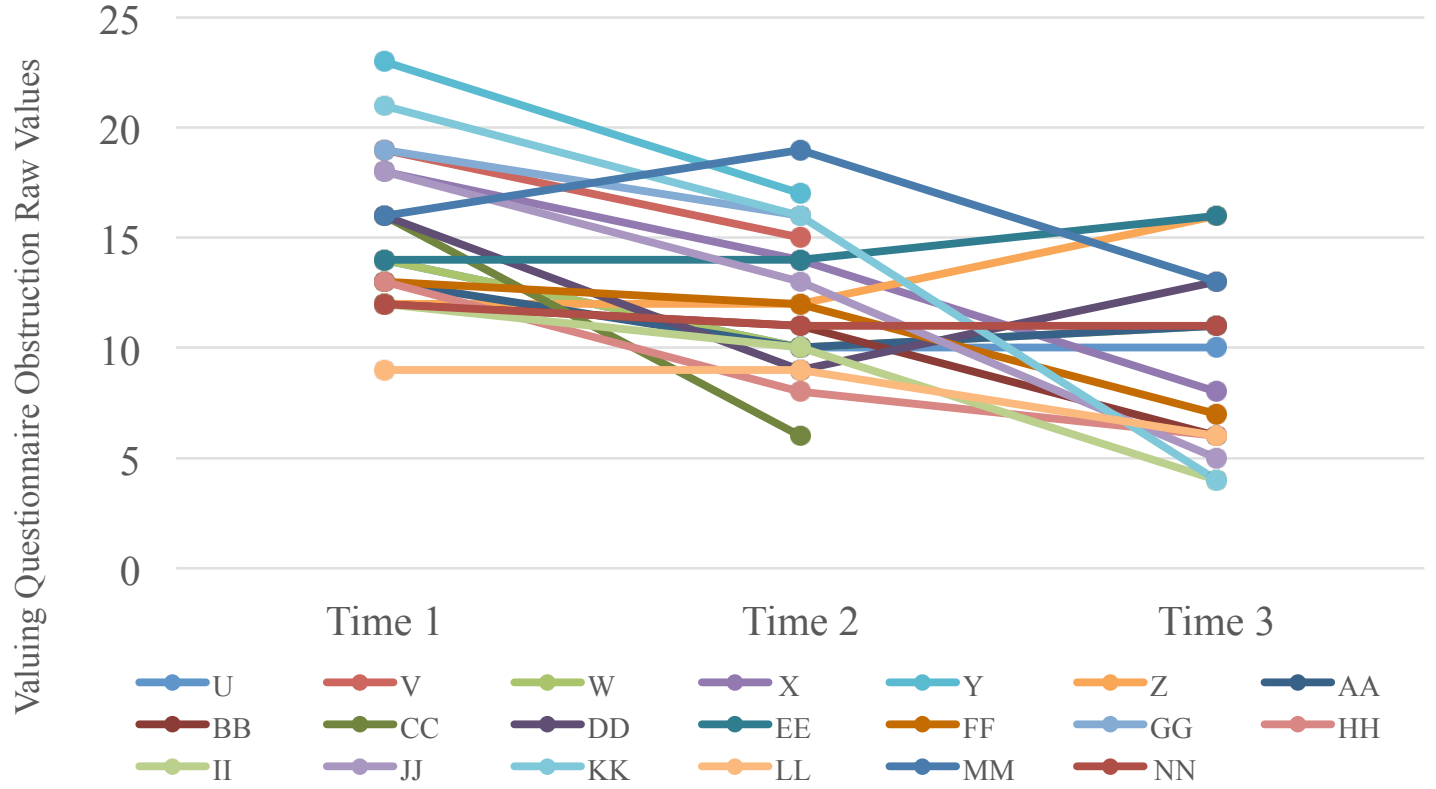

Figure D.6. Valuing Questionnaire-Obstruction individual results. 

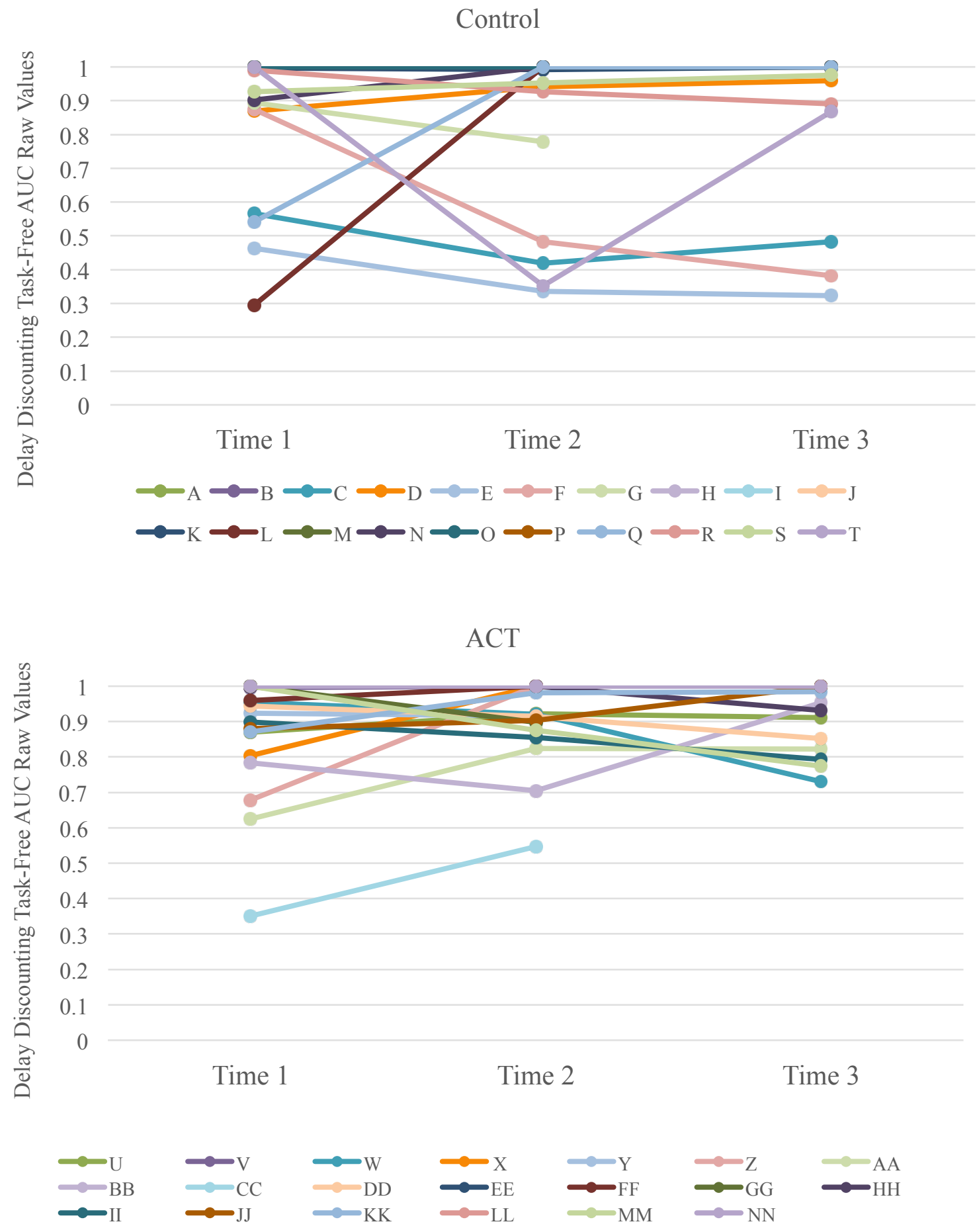

Figure D.7. Delay Discounting Task-Free individual results. 
Control
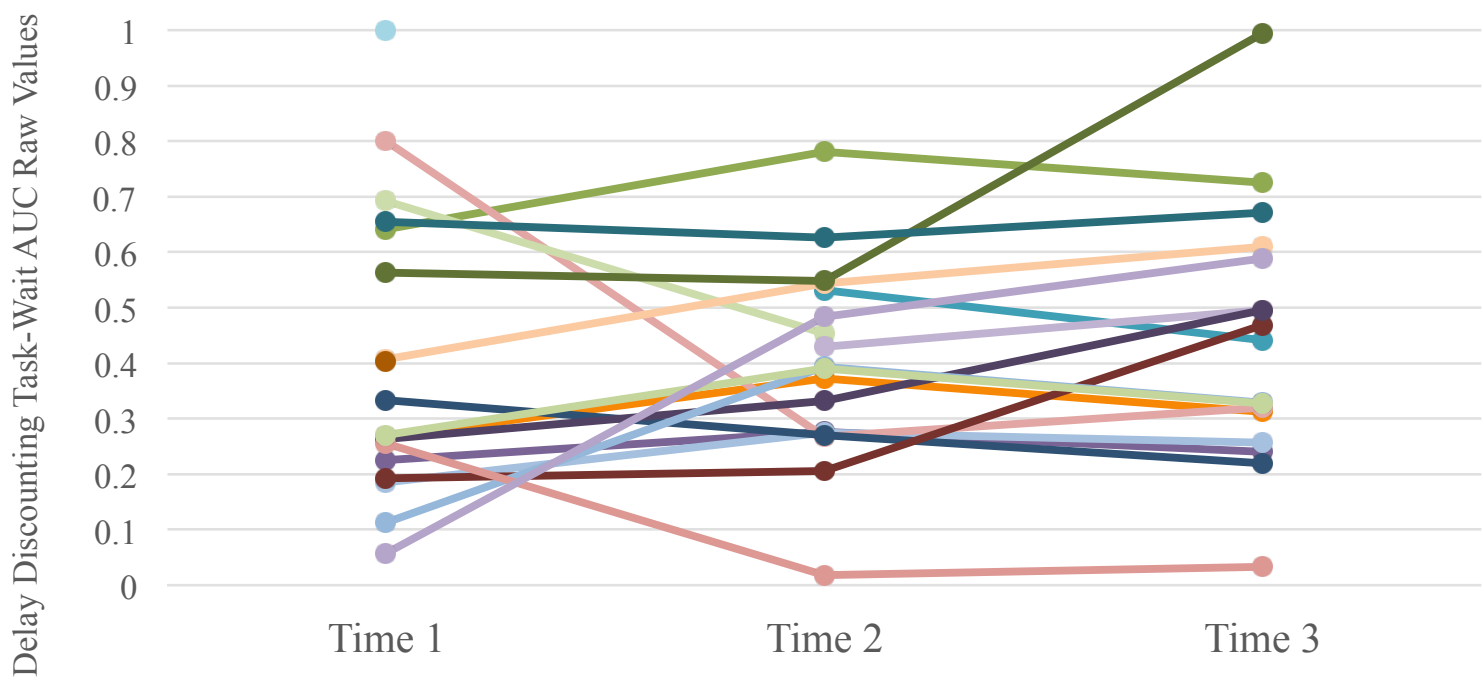

$$
\begin{aligned}
& \rightarrow \mathrm{A} \rightarrow \mathrm{B} \rightarrow \mathrm{C} \rightarrow \mathrm{D} \rightarrow \mathrm{E} \rightarrow \mathrm{F} \rightarrow \mathrm{G} \rightarrow \mathrm{H} \rightarrow \mathrm{I} \rightarrow \mathrm{J} \\
& \rightarrow \mathrm{K} \rightarrow \mathrm{L} \rightarrow \mathrm{M} \rightarrow \mathrm{N} \rightarrow \mathrm{O} \rightarrow \mathrm{P} \rightarrow \mathrm{Q} \rightarrow \mathrm{R} \rightarrow \mathrm{S} \rightarrow \mathrm{T}
\end{aligned}
$$

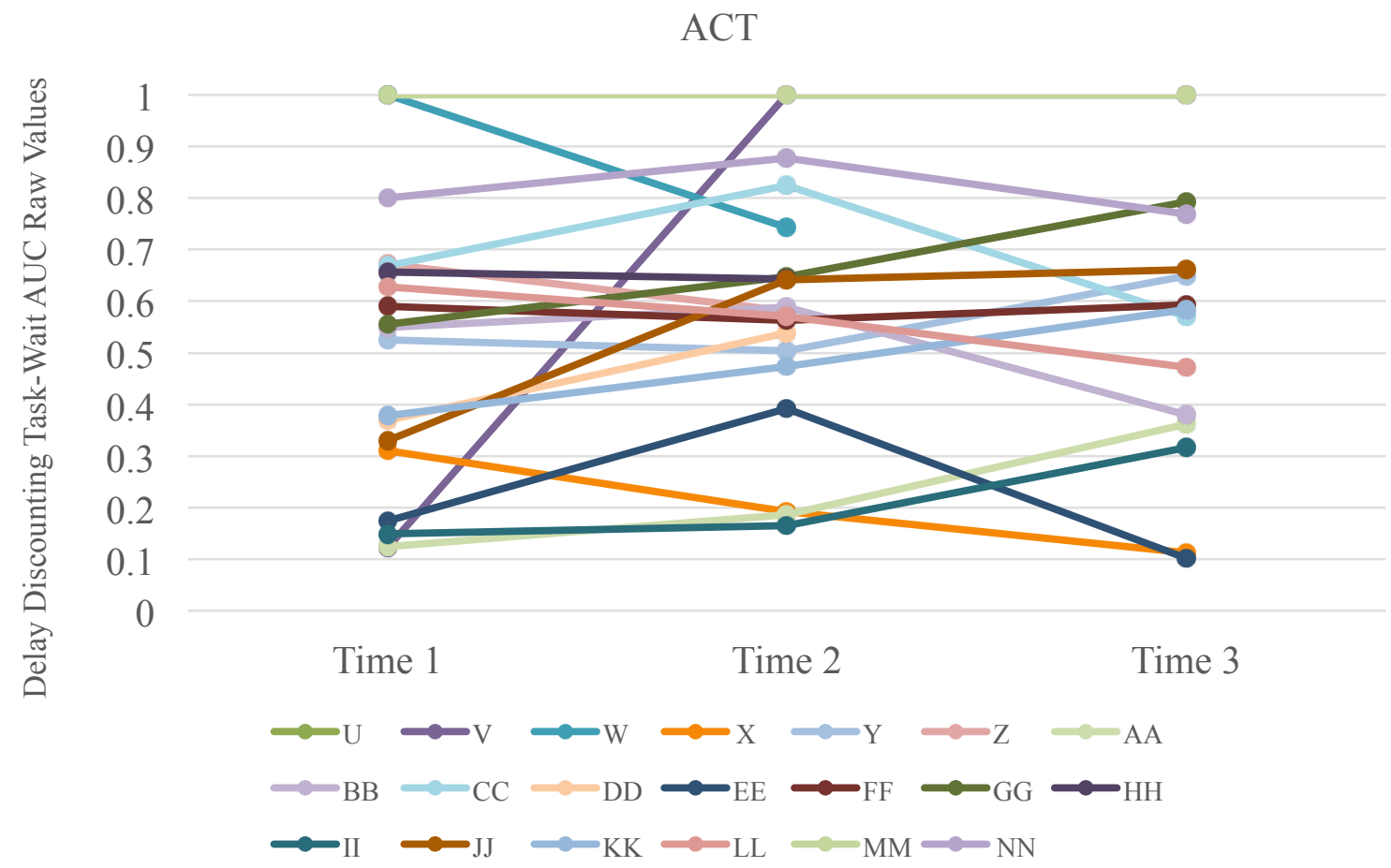

Figure D.8. Delay Discounting Task-Wait individual results. 
CURRICULUM VITAE

\author{
KATE L. MORRISON
}

\title{
Contact Information
}

Office Address: 2810 Old Main Hill

Department of Psychology

Utah State University

Logan, UT 84322-2810

Email: kate.morrison@aggiemail.usu.edu

\section{Education}

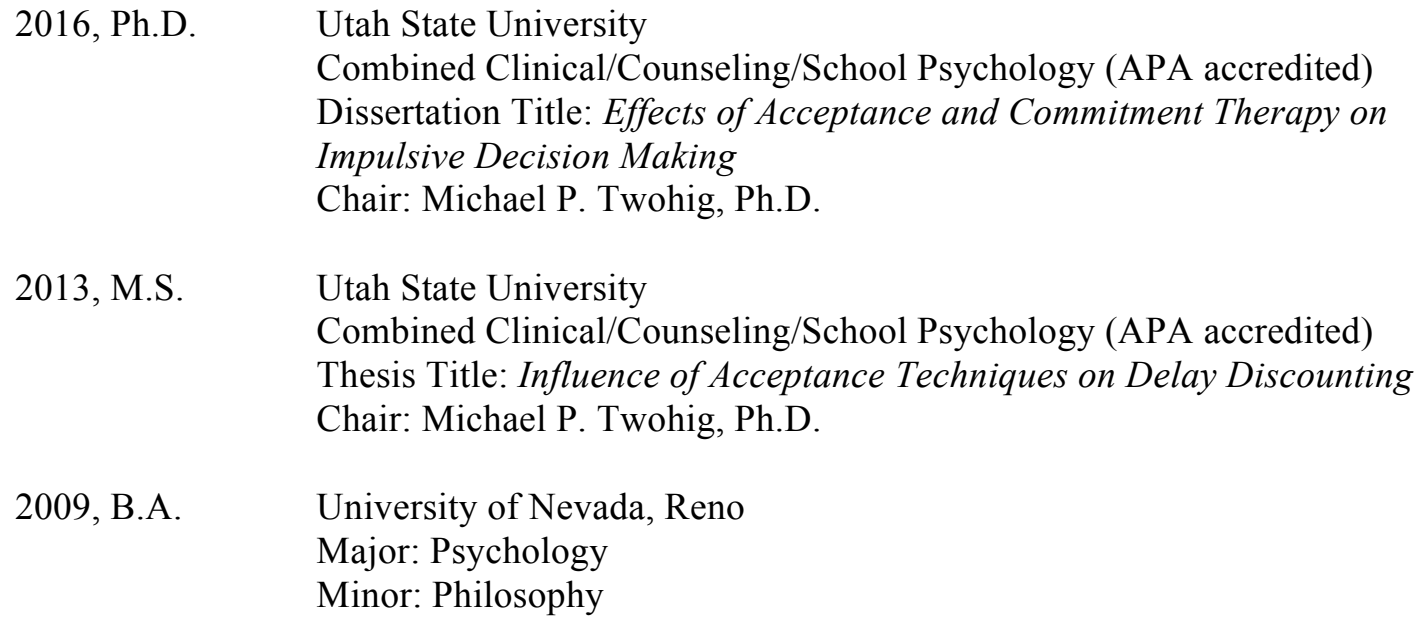

\section{Clinical Experience}

\section{2/2015 - 6/2016 ACT Research Therapist \& Assessor}

Effects of Acceptance and Commitment Therapy on Impulsive Decision Making

Center for Clinical Research - Logan, UT

Supervisor: Michael P. Twohig, Ph.D.

- Adult community population with impulsive decision making and problematic behaviors

- Administer individual acceptance and commitment therapy sessions

- Assess delay discounting

$11 / 2014-$ $7 / 2016$

\section{ACT Consultant \& Trainer}

Temporary Assistance for Needy Families Grant: Individualized Financial Education and Values Achievement Program Housing and Financial Counseling Center - Logan, UT 
Supervisor: Michael P. Twohig, Ph.D.

- Adults in Drug Court

- Developed acceptance and commitment therapy enhanced financial planning treatment manual

- Training and consultation with financial counselors

8/2013 - 5/2014 Mental Health Manager

Bear River Head Start - Northern Utah \& Southern Idaho

Supervisor: Melanie M. Domenech Rodríguez, Ph.D.

- Urban and rural child, adolescent, and adult low-income population

- Individual, family, couple, and school assessment and intervention

- Behavioral parent/school training, family systems therapy, and cognitive behavioral therapy

- Community outreach and staff training

- In-vivo, telepsychotherapy, and in-home assessment and intervention

8/2013-5/2014 Student Therapist

Center for Persons with Disabilities, BioMedical Division - Logan, UT

Supervisor: Clint Field, Ph.D.

- Children, adolescent, and parent community population

- Individual therapy and parent training

- Behavioral parent training and acceptance and mindfulness interventions

$10 / 2012-$

$2 / 2013$

\section{Research Therapist \& Assessor}

Altering Impulsive Decision Making With An Acceptance-Based Procedure Center for Clinical Research - Logan, UT

Supervisor: Michael P. Twohig, Ph.D.

- Adult university students with impulsive decision making

- Administered 90-minute individual acceptance and mindfulness training

- Assessed delay discounting

\section{5/2012 - 5/2013 Student Therapist}

Anxiety and Related Disorders Clinic - Logan, UT

Supervisor: Michael P. Twohig, Ph.D.

- Child, adolescent, and adult community population with anxiety and related disorders

- Structured clinical interviews and individual therapy

- Acceptance and commitment therapy, habit reversal training, and exposure and response prevention 
$9 / 2011-$

$11 / 2014$

8/2011 - Present

(assessor

International OCD Foundation Grant: Combining Acceptance and Commitment Therapy with Exposure and Response Prevention to Enhance

Treatment Engagement

Center for Clinical Research - Logan, UT

Supervisors: Michael P. Twohig, Ph.D. \& Jonathan S. Abramowitz, Ph.D.

- Adults with obsessive-compulsive disorder

- Implement intensive outpatient intervention: acceptance and commitment therapy + exposure and response prevention and exposure and response prevention alone

- Conduct pretreatment structured interviews

8/2011-5/2013 Student Therapist

Utah State University Psychology Community Clinic - Logan, UT

Supervisors: Susan Crowley, Ph.D. \& Kyle Hancock, Ph.D.

- Child, adolescent, and adult community population

- Individual assessment, diagnosis, and interventions

- Cognitive behavioral therapy and behavior modification

\section{8/2009-8/2010 Intervention Specialist}

Advanced Child Behavior Solutions, LLC - Reno, NV

Supervisor: Kenneth R. MacAleese, Ph.D., BCBA-D

- Children and adolescents with autism and related disorders

- One to one in-home treatment (applied behavior analysis)

- Implemented and designed behavioral protocols

- Children with autism

- One to one in-home treatment (applied behavior analysis) 
- Implemented and assessed effectiveness of behavior protocols

- Supervised and trained team of tutors

3/2008-8/2008 Inclusion Technician

City of Reno, Parks and Recreation - Reno, NV

Supervisor: Patrick M. Ghezzi, Ph.D., BCBA-D

- Children with intellectual and/or physical disabilities in before and after school and summer programs

- Assessed, designed, implemented, and trained staff and parents in behavior protocols to increase inclusion of children with disabilities in city programs

8/2005 - 1/2007 Trainer, Case Manager, \& Floor Supervisor

Person-Centered Assessment Training and Habilitation - Reno, NV

Supervisor: W. Lawrence Williams, Ph.D., BCBA

- Adults with intellectual disabilities and severe aggression

- Implemented, designed, assessed, and trained staff in behavior protocols to teach language, social, daily living, and academic skills while addressing problem behavior

\section{Research Experience}

9/2015-Present Clinical Interviewer

Understanding Conditioned Aversive Reflexes in Misophonia

Misophonia Treatment Institute

Collaborator: Thomas H. Dozier, M.S., BCBA

- Interviewing participants with misophonia about their physiological responses to aversive sounds

1/2015-Present Data Collection Assistant

Prevalence and Characteristics of Misophonia

Multiple Sites

Collaborators: James Claiborn, Ph.D., ABPP, Stephanie L. Hart, Ed.D., BCBA-D, \& Thomas H. Dozier, M.S., BCBA

- Manage IRB status and survey data collection at Utah State University

11/2014-Present Graduate Research Assistant

Temporary Assistance for Needy Families Grant: Individualized Financial

Education and Values Achievement Program

Housing and Financial Counseling Center - Logan, UT

Supervisors: Amy L. Odum, Ph.D. \& Michael P. Twohig, Ph.D.

- Large randomized controlled trial comparing ACT enhanced financial education to financial education alone for adults in Drug Court

Manage data collection and participant tracking (Other roles in "Clinical

Experience")

$9 / 2014-$

Treatment Adherence Coder 
$10 / 2014$

Training Therapists in Brief Acceptance and Commitment Therapy in a Primary Care Setting

East Tennessee State University

PI: Jodi Polaha, Ph.D.

- Acceptance and commitment therapy treatment adherence coding

\section{2/2013-Present Research Consultant}

ACT as a Treatment for Misophonia

Cognitive-Behavioral Therapy Center of WNC

Collaborators: Trent R. Codd, III, Ed.S., LPC, BCBA \& Michael P. Twohig, Ph.D.

- Assisted with study design and treatment manual creation for a case series on ACT for adults with misophonia

- Ongoing case and data collection consultation

\section{8/2010 - Present Graduate Research Assistant}

Multiple Research Projects

Center for Clinical Research - Logan, UT

Supervisor: Michael P. Twohig, Ph.D.

- Acceptance and commitment therapy treatment adherence coding

- Design, manage, administer, analyze, and disseminate clinical research trials on the treatment of anxiety and related disorders and problematic decision making (Other information in "Clinical Experience" and "Publications")

\section{0/2009 -2/2010 Research Assistant}

Relaxation Training and Developmental Disabilities: A Review and Practical Solutions

Advanced Child Behavior Solutions, LLC - Reno, NV

PI: Kenneth R. MacAleese, Ph.D., BCBA-D

- Conducted literature searches, reviews, and discussions

1/2007 - 8/2010 Undergraduate Research Assistant

Multiple Research Projects

Department of Psychology, University of Nevada-Reno

Supervisor: Steven C. Hayes, Ph.D.

- Acceptance and commitment therapy treatment adherence coding

- Conducted data entry, recruitment, and research design

Administered computerized assessments and interventions

8/2005 - 5/2006 Undergraduate Research Assistant

Parent-Child Interaction in Childhood Asthma: The Roles of Parental Negative Affectivity, Emotion Regulation, and Anxiety Sensitivity Department of Psychology, University of Nevada-Reno Supervisor: Holly Hazlett-Stevens, Ph.D.

- Data entry and literature searches 
Teaching Experience

\author{
1/2015 - 4/2015 Instructor, Utah State University \\ Psychology 5200 - Introduction to Counseling and Interviewing (online) \\ 12 mixed undergraduate and graduate students \\ 1/2015 - 4/2015 Instructor, Utah State University \\ Psychology 3210 - Abnormal Psychology \\ 150 undergraduate students \\ 9/2014 - Instructor, Utah State University \\ 12/2014 Psychology 3500 - Scientific Thinking and Methods in Psychology \\ 40 undergraduate students \\ 5/2014 - 8/2014 Graduate Teaching Assistant, Utah State University \\ Supervisor: Jennifer Grewe, Ph.D. \\ Psychology 1010 - Introduction to Psychology (online) \\ 20 undergraduate students \\ 8/2010 - 8/2011 Graduate Teaching Assistant, Utah State University \\ Supervisor: Scott C. Bates, Ph.D. \\ Psychology 1010 - Introduction to Psychology (online and on-campus) \\ 700 undergraduate students (3 courses)
}

\title{
Workshop Experience
}

Twohig, M. P., \& Morrison, K. L. (Anticipated December 2015). Introduction to acceptance and commitment therapy. One-day workshop conducted at Uinta Academy in Logan, UT.

Twohig, M. P., \& Morrison, K. L. (September 2015). Introduction to acceptance and commitment therapy and ACT experiential workshop. Two-day workshop conducted at the annual Introduction to Acceptance and Commitment Therapy Workshop Series in Logan, UT.

Morrison, K. L. (April 2015). Why am I so impulsive? Invited workshop at the annual Mental Health Is No Joke event in Logan, UT.

Twohig, M. P., Homan, K. J., \& Morrison, K. L. (September 2013). Introduction to acceptance and commitment therapy. Workshop conducted at the annual Introduction to Acceptance and Commitment Therapy Workshop Series in Logan, UT.

Twohig, M. P., \& Morrison, K. L. (September 2012). Introduction to acceptance and commitment therapy. Workshop conducted at the annual Introduction to Acceptance and Commitment Therapy Workshop Series in Logan, UT.

Morrison, K. L. (December 2012). An introduction to ACT for supervisors. Invited workshop at Utah State University Counseling and Psychological Services in Logan, UT. 
Professional Experience

$8 / 2011-$

$10 / 2015$

$5 / 2014-$

$12 / 2014$

$8 / 2012-5 / 2013$

$5 / 2011-8 / 2013$

\section{Assor}

Research Laboratory Manager

Center for Clinical Research - Logan, UT

Supervisor: Michael P. Twohig

- Maintained research laboratory operations

- Organized undergraduate research assistant applications, trainings, and seminars

- Lead organizer for annual fundraising workshop

\section{Professional Officer}

Journal of Contextual Behavioral Science

Supervisor: Joseph Ciarrochi, Ph.D.

- Monitored journal progress

- Supported journal promotion and administrative functions

Graduate Student Representative

Utah State University Clinical Faculty Search Committee

- Reviewed applications

- Collaborated with committee on selection process

- Summarized student feedback and presented to committee

\section{Content Management \& Administrative Assistant}

Supervisors: Emily N. Rodriguez, M.A., Jason Luoma, Ph.D., \& David

Gillanders, Ph.D.

- Supported administrative functions of the organization

- Monitored public listservs

- Supported administrative functions for the endorsement of peerreviewed ACT trainers

- Created, updated, and organized website content (www.contextualscience.org)

3/2011 - Present Psychology Outreach Organizer

Department of Psychology, Utah State University

Supervisor: Scott C. Bates, Ph.D. \& Gretchen Gimpel Peacock, Ph.D.

- Organize and manage a high school psychology class visit of the psychology department each school year 


\section{Grant Activity}

Title: The Role of Impulsivity in Tic Expression and Tic Suppression

Date submitted: November 2010 (Not Funded)

Amount: \$57,606

Funding source: Tourette's Syndrome Association

Role: Research assistant, co-author of application, assist with submission (PI: Twohig)

Title: The Role of Impulsivity in OCD and Its Treatment

Date submitted: February 2011 (Not Funded)

Amount: \$32,906

Funding source: International OCD Foundation

Role: Research assistant, co-author of application, assist with submission (PI: Twohig)

\section{Publications}

\section{Peer Reviewed Journal Articles}

Morrison, K. L., \& Twohig, M. P. (in press). A functional and cohesive treatment of Tourette's disorder and chewing tobacco use. Clinical Case Studies. doi: $10.1177 / 1534650115599442$

Barney, J., Field, C. E., Morrison, K. L., \& Twohig, M. P. (in press). Treatment of pediatric obsessive-compulsive disorder utilizing parent-facilitated acceptance and commitment therapy (ACT). Psychology in the Schools.

Twohig, M. P., Abramowitz, J. S., Bluett, E. J., Fabricant, L. E., Jacoby, R. J., Morrison, K. L., . . . Smith, B. M. (2015). Exposure therapy for OCD from an acceptance and commitment therapy (ACT) framework. Journal of Obsessive-Compulsive and Related Disorders, 6, $167-$ 173. doi: 10.1016/j.jocrd.2014.12.007

Twohig, M. P, Morrison, K. L., \& Bluett, E. J. (2014). Acceptance and commitment therapy for obsessive-compulsive disorder and obsessive-compulsive spectrum disorders: A review. Current Psychiatry Review, 10(4), 296-307. doi: 10.2174/1573400510666140714172145

Bluett, E. J., Homan, K. J., Morrison, K. L., Levin, M. E., \& Twohig, M. P. (2014). Acceptance and commitment therapy for anxiety and OCD spectrum disorders: An empirical review. Journal of Anxiety Disorders, 28(6), 612-624. doi: 10.1016/j.janxdis.2014.06.008

Woidneck, M. R., Morrison, K. L., \& Twohig, M. P. (2014). Acceptance and commitment therapy for the treatment of posttraumatic stress among adolescents. Behavior Modification, 38(4), 451-476. doi: 10.1177/0145445513510527

Morrison, K. L., Madden, G. J., Odum, A. L., Friedel, J. E. \& Twohig, M. P. (2014). Altering impulsive decision making with an acceptance-based procedure. Behavior Therapy, 45(5), 630-639. doi:10.1016/j.beth.2014.01.001

Armstrong, A. B., Morrison, K. L., \& Twohig, M. P. (2013). A preliminary investigation of acceptance and commitment therapy for adolescent obsessive-compulsive disorder. 
Journal of Cognitive Psychotherapy, 27(2), 175-190. doi: 10.1891/0889-8391.27.2.175

Dehlin, J. P., Morrison, K. L., \& Twohig, M. P. (2013). Acceptance and commitment therapy as a treatment for scrupulosity in obsessive-compulsive disorder. Behavior Modification, 37(3), 409-430. doi: 10.1177/0145445512475134

\section{Book Chapters}

Morrison, K. L., Smith, B. M., Lee, E. B., \& Twohig, M. P. (in press). Acceptance and commitment therapy for OC-spectrum disorders. In J. S. Abramowitz, D. McKay, \& E. Storch (Eds.) Handbook of obsessive compulsive disorders across the lifespan. Hoboken, NJ: Wiley.

Twohig, M. P., Bluett, E. J., Morrison, K. L., \& Woidneck, M. R. (2014). Habit reversal. In S. Hofmann (Ed.). Cognitive behavioral therapy: A complete reference guide. (pp. 203222). Wiley-Blackwell: West Sussex, UK. doi: 10.1002/9781118528563.wbcbt10

\section{Manuscripts in Progress}

Morrison, K. L., Smith, B. M., \& Twohig, M. P. (in review). Mindfulness and acceptance therapies for obsessive-compulsive and related disorders. In C. Pittenger (Ed.) Obsessive-compulsive disorder: Phenomenology, pathophysiology, and treatment. Oxford University Press: New York.

\section{Conference Presentations}

*denotes presenter

*Morrison, K. L. (Chair), *Coyne, L. W., *Forsyth, J. P., *Hayes, S. C., *Herbert, J. D., \& *Twohig, M. P. (anticipated November 2015). Addressing common clinical issues using acceptance and commitment therapy. Panel discussion at the annual meeting of the Association for Behavioral and Cognitive Therapies in Chicago, IL.

*Morrison, K. L., Madden, G. J., Odum, A. L., Friedel, J. E., \& Twohig, M. P. (June 2014). Altering impulsive decision making with an acceptance-based procedure. Symposium presented at the annual meeting of the Association for Contextual Behavioral Science in Minneapolis, MN.

Codd, III, R. T., *Morrison, K. L., \& Twohig, M.P. (June 2014). ACT as a treatment for misophonia in an adult female. Symposium presented at the annual meeting of the Association for Contextual Behavioral Science in Minneapolis, MN.

*Abramowitz, J. S., Berry, B. M., Bluett, E. J., Fabricant, L., Jacoby, R. J., Morrison, K. L., \& Twohig, M. P. (November 2013). Predictors of OCD symptom dimensions: Obsessional beliefs and experiential avoidance. Paper presented at the annual meeting of the Association for Behavioral and Cognitive Therapies in Nashville, TN.

*Morrison, K. L., Madden, G. J., Odum, A. L., Friedel, J. E., \& Twohig, M. P. (November 2013). Influence of acceptance techniques on impulsive decision making. Poster presented at the annual meeting of the Association for Behavioral and Cognitive 
Therapies in Nashville, TN.

Armstrong, A., Morrison, K., \& *Twohig, M. P. (November, 2012). ACT for adolescent OCD. Paper presented at the annual meeting of the Association for Behavioral and Cognitive Therapies in National Harbor, MD.

*Twohig, M., Abramowitz, J., Fabricant, L., Morrison, K., \& Bluett, E. (July 2012). Combining acceptance and commitment therapy with exposure and response prevention to enhance the treatment of $O C D$. Poster presented at the annual conference of the International OCD Foundation in Chicago, IL.

*Armstrong, A., Morrison, K., \& Twohig, M. (November 2011). Acceptance and commitment therapy for adolescent $O C D$. Poster presented at the annual meeting of the Association for Behavioral and Cognitive Therapies in Toronto, ON.

*Morrison, K. L. (Chair), *Lawyer, S. R., *Madden, G. J., *Mitchell, S. H., \& *Twohig, M. P. (May 2011). Delay discounting as a diagnostic criteria for acceptance-based therapies. Panel discussion at the Annual Association for Behavior Analysis International Conference in Denver, CO.

*MacAleese, K. R., Dubuque, M. L., Morrison, K. L., Maillard, G., Scheinle, R., \& MacAleese, A. N. (February 2010). Relaxation training and developmental disabilities: A review and practical solutions. Paper presented at the annual meeting of the California Association of Behavior Analysis in Irvine, CA.

*Plumb, J. C., Levin, M. E., Hayes, S. C., Morrison, K. L., DeFreitas, J., \& Bowes, E. (July 2009). Using a brief values intervention to increase studying behavior in college students. Paper presented at annual meeting of the Association for Contextual Behavioral Science in Enschede, Netherlands.

*Castellanos, J. A., Bishop, M. R., Morrison, K. L., Sigler, K. A., \& Ghezzi, P. M. (May 2007). A case study examining a self-management procedure with a child diagnosed with autism. Poster presented at the annual meeting of the Association for Behavior Analysis International in San Diego, CA.

\section{Specialty Trainings}

11/2014 Allies Seminar

Allies on Campus

Utah State University, Logan, UT

11/2014 Racial Privilege Workshop

Sheree Haggan \& Lacey Haggan

Access \& Diversity Center, Utah State University, Logan, UT

ACT Boot Camp

2/2014 Steven C. Hayes, Ph.D, Kelly G. Wilson, Ph.D., \& Kirk D. Strosahl, Ph.D.

Reno, NV 
2/2013 Cultural Competence Training

Melanie M. Domenech Rodríguez, Ph.D. \& Michael P. Twohig, Ph.D.

Utah State University, Logan, UT

7/2012 The Compassionate Use of Exposure Strategies in ACT

John P. Forsyth, Ph.D.

ACBS World Conference, Bethesda, MD

4/2012 Getting Started as a Successful Proposal Writer and Academician Workshop Stephen W. Russell, D.V.M, Ph.D.

Utah State University, Logan, UT

8/2011 Yoga and Meditation: The Art and Science of a Compassionate Path to Well Being

Susan Schrott, LCSW

Utah State University, Logan, UT

\section{Awards \& Honors}

$2015 \quad$ Lawson Family Fellowship $(\$ 3,000)$

2014 Graduate Research Assistant of the Year Award, College of Education and Human Services

2013 Walter R. Borg Applied Practice and Research Award $(\$ 2,500)$

$2013 \quad$ Michael Bertoch Scholarship $(\$ 1,000)$

\section{Professional Organization Membership}

2010 - Present Association for Behavioral and Cognitive Therapies

- Addictive Behaviors SIG

- Behavior Analysis SIG

- Mindfulness \& Acceptance SIG

2008 - Present Association for Contextual Behavioral Science

- Rocky Mountain ACBS Chapter

- Prevention SIG \& Environmental Sub-Group

- $\quad$ Student SIG

2007 - $2011 \quad$ Association for Behavior Analysis International 